\title{
Beiträge zur Lehre von der syphilitischen Epilepsie.
}

\author{
Von \\ Dr. R. Hahn (Hohenweitzschen, Sa.). \\ (Eingegangen am 20. Mai 1913.)
}

Daß die Sy philis epileptische Zustandsbilder hervorzurufen vermag, haben schon ältere Autoren, wie Ulrich von Hutten, Thierry de Héry, Paracelsus, Nicol. Massa, Morgagni, Ambr. Paré, Fr. Hoffmann, Sauvages, Boerhave, van Swieten, Astruc, Sanchez, Tissot, J. Franck u. a. behauptet; Plenck, B. Bell, Bravais u.a. publizierten bereits einschlägige Fälle; Broadbent, Buzzard, Jackson, Schuster, Charcot, Fournier, Lancerea ux, Troussea u und zahlreiche andere Beobachter der neueren Zeit wiesen auf eine große Reihe bemerkenswerter anatomischer und klinischer Tatsachen hin und auch sonst wird der Frage nach dem ursächlichen Zusammenhange zwischen der Syphilis und der Epilepsie, wie die zusammenfassenden Ausführungen Gowers, Férés, Binswangers, Nonnes u. a. erkennen lassen, noch fortgesetzt die eingehendste Beachtung zu teil.

Wenn aber die Existenz einer ,s y philitische n Epilepsie" gegenwärtig wohl auch fast allgemein zugegeben wird, so unterliegt der Begriff selbst doch noch vielfachen Schwankungen und können die im $\mathrm{Zu}$ sammenhang damit stehenden Lehren als abgeschlossen und in allen Einzelheiten geklärt bis jetzt nicht betrachtet werden. Die in der Literatur vorhandene Kasuistik bietet eine große Reihe widerspruchsvoller Krankheitstypen dar und macht es erklärlich, daß über die Pathogenese und Eigenart der syphilitischen Epilepsie die verschiedensten Anschauungen geäußert worden sind. Binswanger hat die schwebenden Fragen in seiner monographischen Bearbeitung der Epilepsie eingehend besprochen und eine lichtvolle kritische Sichtung der Literatur vorgenommen. Trotzdem dürften weitere kasuistische Beiträge zur Lehre von der syphilitischen Epilepsie nicht ganz überflüssig erscheinen; denn so eng sich die aufgestellten pathogenetischen Theorien auch an sonstige Erfahrungen und Lehren der Pathologie anlehnen mögen, ihr Wert, ihre Zuverlässigkeit, ihre Allgemeingültigkeit wird sich doch nur an der Hand einer entsprechenden Kasuistik nachprüfen lassen; an einer solchen ist aber, soweit es sich speziell um Krankheitsfälle vom Typus 
der gewöhnlichen genuinen Epilepsie handelt, noch immer eher Mangel als Uberfluß vorhanden. Um die mitgeteilten Krankheitsfälle jedoch ohne Schwierigkeit zu den über die syphilitische Epilepsie aufgestellten Lehren in Beziehung setzen zu können, erschien es geboten, eine zusammenfassende kritische Übersicht der bis jetzt gewonnenen Ergebnisse der klinisch-ätiologischen Forschung voranzuschicken.

Aus dem Studium der einschlägigen Literatur, insbesondere auch der grundlegenden Arbeiten Fourniers ergibt sich zunächst das eine, daß unter dem Begriffe der syphilitischen Epilepsie die vers chied en sten konvulsionären Zustände zusammengefaßt worden sind. Nur zu einem kleinen Teile handelt es sich dabei um echte epileptische Insulte, in der überwiegenden Mehrzahl der Fälle dagegen unterscheidet sich das Krankheitsbild deutlich von dem der gewöhnlichen genuinen Epilepsie. Während man früher fast ausschließlich die akquirierte Syphilis als ätiologischen Faktor geltend machte, wurde in neuerer Zeit in steigendem Maße auch der hereditären Syphilis Beachtung zu teil; es fand sich, daß die akquirierte nicht minder wie die hereditäre Syphilis Krankheitsfälle der verschiedensten Art hervorzurufen vermag.

Soweit die erworbene Syphilis in Frage kommt, lassen sich nach Binswanger im wesentlichen zwei Gruppen von Epilepsie unterscheiden: 1. die parasyphilitische Form im Sinne Fourniers, 2. die tertiäre gummöse und postsyphilitische Form.

Die überwiegende Mehrzahl der in der Literatur mitgeteilten Fälle hat materielle Gehirnprozesse zur Grundlage und gehört dementsprechend der zweiten Gruppe Binswangers zu; ja die meisten Autoren betrachten allein die Existenz dieser Form als einwandfrei sichergestellt.

Was zunächst die tertiäre gummöse Form der Epilepsie anbetrifft, so umfaßt sie nach Binswangers Darlegungen die verschiedensten Krampfformen; als ihr pathologisch-anatomisches Substrat müssen spezifische Veränderungen am Zentralnervensystem angesehen werden. Todd, Echeverria, Lancereaux, Charcot, Fournier u. a. fanden meist eine circumscripte gummöse Pachymeningitis mit Beteiligung der weichen Häute; die neuerdings beigebrachte Kasuistik aber läßt erkennen, daß es sich auch um anders lokalisierte umschriebene oder um mehr diffuse gummöse Prozesse an den Hüllen des Gehirns, an den Gefäßen oder im Innern des Gehirns handeln kann. Kommt es in Fällen dieser Art zu Konvulsionen - und das scheint namentlich bei hereditär belasteten Individuen der Fall zu sein - so werden sich daneben in der Regel noch mehr oder minder scharf ausgeprägt die Erscheinungen der Gehirnsyphilis im Krankheitsbilde bemerkbar machen, neben allerhand sonstigen kortikalen Reiz- und Lähmungserscheinungen insbesondere allerhand basale meningitische und arteriitische Gehirn- 
symptome. Fast stets aber wird auch der Krampfanfall selbst eine Reihe charakteristischer Eigentümlichkeiten zeigen, insofern sich ihm meist die Attribute der kortikalen Jacksonschen Epilepsie hinzugesellen, sowohl in der Form umschriebenster klonischer Zuckungen ohne Bewußtseinsverlust, als auch in Form hemilateraler oder generalisierter Rindenkrämpfe klonischen Gepräges mit oder ohne Trübung des Sensoriums. Sorgfältigste Beobachtung der Krampfanfälle selbst und genaueste Beachtung aller sonst etwa noch hervortretenden cerebralen Begleiterscheinungen wird also hier für gewöhnlich eine echte Epilepsie a uszuschließen erlauben und die Zugehörigkeit des Krankheitsbildes zur Gehirnsyphilis mit mehr oder minder großer Bestimmtheit erweisen.

Dieser Gruppe ist nach Binswanger auch die sogenannte postsyphilitische Form der Epilepsie zuzurechnen. Sie weist bemerkenswerte Beziehungen zur progressiven Paralyse und zur Tabes dorsalis auf, d. h. zu denjenigen Erkrankungen des Zentralnervensystems, für die Möbius den Begriff der Metasyphilis aufgestellt hat. Binswanger hebt nachdrücklichst hervor, daß vielfach wohl die im Verlaufe der progressiven Paralyse auftretenden epileptiformen Konvulsionen mit wahren epileptischen Anfällen verwechselt worden sein mögen, namentlich in früherer Zeit, als die Erkenntnis der progressiven Paralyse in klinischer und pathologisch-anatomischer Hinsicht noch nicht zu der heutigen Sicherheit fortgeschritten war. Auch eröffnen, wie wir jetzt mit Bestimmtheit wissen, gelegentlich epileptische Insulte das Auftreten diffuser degenerativer Gehirnerkrankungen; sie stellen dann eben nur den ersten ernsten Ausdruck einer progressiven Paralyse dar. Jahrelang können lediglich typische epileptische Anfälle in Form großer wie kleiner Attacken zur Wahrnehmung gelangen, bis endlich - in einem von Binswanger erwähnten Falle z. B. erst 10 Jahre darnach - der zunehmende Verfall der Intelligenz, das deutlichere Hervortreten der somatischen Reiz- und Lähmungserscheinungen und schließlich der Befund charakteristischer diffuser Hirnrindenveränderungen die $\mathrm{Zu}$ gehörigkeit des Krankheitsbildes zur progressiven Paralyse erweist. Erst jüngt publizierte Näcke einen solchen atypisch verlaufenen Fall. Fast nichts wies zunächst auf Paralyse hin; typische epileptische Krampfanfälle beherrschten lange Zeit das Krankheitsbild, selbst die Entwicklung einer eigentlichen Demenz ließ lange auf sich warten; erst später änderte sich das Krankheitsbild, das sich noch durch 6-8 Wochen dauernden rudimentären Korsak off schen Symptomenkomplex kompliziert zeigte, allmählich mehr und mehr und die schließlich erhobenen makro- und mikroskopischen Befunde bestätigten das Vorhandensein einer Paralyse. Analoge Beobachtungen - nur weniger ausgeprägt - bringen auch $\mathrm{HaBmann}$ und Zingerle in ihrer kürz- 
lich erschienenen Arbeit bei. Die Autopsie ergab in einem solchen ursprünglich als Epilepsie aufgefaßten Fall von Paralyse, wie Binswanger mitteilt, ausgebreiteten hochgradigen Gewebsschwund in der Hirnrinde; daneben aber fanden sich auch Gebiete mit noch völlig intakter Nervensubstanz oder Bezirke, in denen kleinste nekrotische Herde mit Zell- und Nervenfaserschwund, sowie Gefäßdegeneration bestanden. Er glaubt, daß solche miliaren nekrotischen Herde gelegentlich vielleicht schon lange vor dem Auftreten der eigentlichen progressiven Paralyse pathologische Reizzustände setzen, d. h. eben Anlaß zur Entwicklung eines epilepsieähnlichen Vorstadiums geben können. Unter Umständen aber kann auch die von Nissl und Alzheimer beschriebene Endarteriitis syphilitica differentialdiagnostisch konkurrieren. Alzheimer selbst erwähnt einen Fall, der klinisch ausschließlich epileptische Symptome darbot und unter den Erscheinungen eines schweren Status epilepticus schon im Verlaufe der ersten Anfälle erlag, während die anatomische Untersuchung syphilitische Endarteriitis der kleinsten Rindengefäße nachwies.

Charcot, Fournier, Jackson u. a. waren bemüht, differentialdiagnostische Merkmale für solche der zweiten Gruppe Binswangers zuzuweisenden Krankheitsfälle aufzufinden. Wie jedoch die Durchsicht der Literatur ergibt und alle neueren Autoren bestätigen, kann die differentielle Abgrenzung gelegentlich auch heute noch unïberwindliche Schwierigkeiten bereiten. Es gibt eben Fälle, in denen auf organische Gehirnprozesse hindeutende Krankheitserscheinungen für mehr oder minder lange Zeit völlig fehlen; monosymptomatisch bleibende Krampfanfälle, die sich äußerlich in nichts von denen der genuinen Epilepsie unterscheiden, stellen dann das einzige Merkmal einer im Anschluß an die akquirierte Syphilis zustande gekommenen Erkrankung des Zentralnervensystems dar. Die genaue Beobachtung des weiteren Krankheitsverlaufes mag freilich in einem Teil der Fälle schließlich noch zur Diagnose einer spezifischen, grob anatomischen Veränderung führen, namentlich dann, wenn cerebrale und sonstige charakteristische Begleiterscheinungen in den intraparoxysmellen Intervallen sich hinzugesellen und die Anfälle selbst mehr und mehr den Typus organisch bedingter Konvulsionen annehmen. Andere Male fällt vielleicht der Erfolg oder Mißerfolg einer antiluetischen Kur für oder gegen die Annahme einer tertiären luetischen Epilepsie entscheidend ins Gewicht oder ein ganz circumscripter prodromaler Kopfschmerz erlaubt, wie Charcot betont hat, den richtigen Schluß zu ziehen; manche Fälle wieder lassen sich in Zukunft vielleicht leichter als bisher, wie wenigstens No n ne mit A pelt nachgewiesen $\mathbf{z u}$ haben glaubt, durch den Globulinbefund $\left(`\right.$, Phase $\left.I^{\prime \prime}\right)$ gegeneinander abgrenzen. In einigen wenigen Fällen aber versagen alle differentialdiagnostischen Merkmale, namentlich dann, 
wenn sogenannte stumme Hirnregionen von einer Läsion betroffen wurden; da auf spezifische oder postsyphilitische Gehirnrückenmarksveränderungen hindeutende klinische Krankheitszeichen dann völlig fehlen oder wenigstens während eines längeren Zeitraumes ganz zurücktreten, so wird eventuell durchaus nur das Bild einer gewöhnlichen genuinen Epilepsie vorgetäuscht. Fälle dieser Art sind es denn auch, die als syphilitische Epilepsie im eigentlichen Sinne in Anspruch genommen worden sind. Fournier hat für sie zum Teil wenigstens eine besondere Genese angenommen und sie in seinen späteren Arbeiten unter dem Begriff der paras y philitischen Form der Epilepsie zusammengefaßt; er betrachtet sie mit seinem Schüler Féré als eine rein dynamische und funktionelle Gehirnstörung und ordnet sie direkt der gewöhnlichen genuinen Epilepsie unter. Noch genauer definiert sie Pellizzari als ,Epilepsia sine materia“" und nimmt für sie toxische Einwirkungen des Syphilisgiftes auf das Zentralnervensystem an. Unter den neueren Autoren begegnet die Beweiskraft des beigebrachten Beobachtungsmaterials zwar noch mannigfachen Zweifeln; dennoch glauben die meisten die ,pparasyphilitische" Genese der Epilepsie für einige wenige Fälle wenigstens anerkennen zu dürfen.

Am entschiedensten spricht, wie Binswanger, Nonne u. a. ausführen, der Erfolg der antisyphilitischen Behandlung gegen die Annahme einer durch die vorausgegangene syphilitische Infektion herbeigeführten rein funktionellen Störung der cerebralen Vorgänge; solche Erfolge haben aber die meisten Autoren in den von ihnen beigebrachten einschlägigen Fällen aufzuweisen gehabt; ja in einem Teil der Fälle soll ein solcher Erfolg selbst dann noch erzielt worden sein, wenn die Krampfanfälle schon seit einer Reihe von Jahren bestanden hatten. In den von Gros und Lancereaux aus der Literatur zusammengestellten Fällen z. B. wurde nach Anwendung antiluetischer Verfahren stets definitive Heilung erzielt. Es handelte sich in diesen Fällen klinisch im übrigen stets nur um typische Epilepsie, die ausnahmslos erst in einem für die echte genuine Epilepsie ungewöhnlich späten Alter, in der Regel erst mehrere Jahre ( $1-8 \mathrm{~J}$.$) nach der syphilitischen Infektion$ aufgetreten war; in keinem der 14 Fälle war der Kranke von Jugend auf epileptisch; Symptome einer anatomischen Gehirnläsion waren selbst nach längerer Krankheitsdauer nicht zur Wahrnehmung gelangt; nur 3 Fälle boten noch manifeste Erscheinungen von Syphilis am Körper dar, in allen anderen Fällen waren sie bereits seit längerer Zeit verschwunden. Besonders überzeugend erscheint u. a. ein Fall von Trous sea $\mathbf{u}$ und Pid o $\mathrm{x}$ : Ein junger, früher syphilitischer Diplomat erkrankte an schwerer Epilepsie; mehrere Jahre ohne Erfolg behandelt, unterzog er sich schließlich einer Quecksilberkur; die Epilepsie verschwand und noch nach 12 Jahren konnte dauernde Heilung festgestellt werden. 
In einem ähnlichen Falle Gowers handelte es sich um einen neuropathisch nicht belasteten 37 jährigen Mann, der 1 Jahr nach der spezifischen Infektion den ersten epileptischen Anfall bekam. Zeichen eines organischen Gehirnleidens fehlten. 4 Monate nach Einleitung einer Jodkalikur blieben die Anfälle ganz weg.

Angesichts der in diesen und anderen Fällen erzielten therapeutischen Erfolge erinnert Binswanger an die Tatsache, daß der methodischen Quecksilber- und Jodbehandlung immer nur spezifisch neoplastische Krankheitsprozesse weichen. Er neigt daher zu der Annahme, daß es sich in Fällen der erwähnten Art um die ersten Anfänge oder um räumlich nur wenig ausgedehnte spezifisch neoplastische Prozesse, um einer Rückbildung durch antisyphilitische Kuren noch zugängliche Meningealoder Gefäßerkrankungen gehandelt hat. Ja er sowohl als auch Nonne raten selbst noch solchen Fällen gegenüber zu größter Vorsicht, in denen die antisyphilitische Behandlung dauernde Erfolge nicht gebracht hat; es gäbe genug Fälle von gummöser Gehirnsyphilis, bei denen dem Leiden trotz zahlreicher antisyphilitischer Kuren nicht Einhalt zu tun war; gesichert wäre die Annahme einer rein funktionellen Natur der syphilitischen Epilepsie streng genommen nur da, wo die Autopsie den Mangel jeder anatomischen Erkrankung im Bereiche des Zentralnervensystems bestätige, wo auch die genaueste mikroskopische Durchforschung des Gehirns das Vorhandensein eines „postsyphilitischen“ Leidens, speziell einer progressiven Paralyse nicht aufzudecken vermöchte.

Auch die Meinung Fourniers, daß die parasyphilitische Form der Epilepsie stets nur in der Sekundär periode der Syphilis auftrete und mit ihr zugleich wieder verschwinde, ob nun eine antisyphilitische Behandlung stattfand oder nicht, hält Binswanger nicht für einwandfrei und glaubt, daß sie gelegentlich irreführen könne. Wie er ausführt und durch zwei charakteristische Beobachtungen illustriert, ist eine strikte Trennung der sogenannten Sekundär- und Tertiärerscheinungen in der Praxis durchaus nicht immer durchzuführen; gar nicht so selten träten insbesondere die luetischen Erkrankungen der Hirngefäße schon zu einer Zeit auf, zu welcher noch deutliche Haut- und Schleimhautaffektionen der sekundären Periode bestünden, und zuweilen könnten sich dann zugleich gummös-meningitische Krankheitsprozesse hinzugesellen. In Fällen dieser Art könnten sich für die scharfe Trennung der sekundären und tertiären Form der syphilitischen Epilepsie im Sinne Fourniers gelegentlich unüberwindliche praktische Schwierigkeiten ergeben.

Trotz solcher Skepsis gelangt aber Binswanger schließlich doch noch zur Anerkennung einer syphilitisch-epileptischen Neurose im Sinne Fourniers und Férés. Die Grundlage dafür bilden Fälle, in denen die Syphilis stimulierend auf die Auslösung von Anfällen wirkt, 
resp. eine bestehende Epilepsie durch die luetische Infektion gesteigert oder neu hervorgerufen wird; eine Beeinflussung durch antiluetische Kuren ist in solchen Fällen nicht immer in zweifelloser Weise zu konstatieren. Fournier selbst zitiert den Fall einer 26 jährigen Frau, die, seit der Kindheit epileptisch, in 10 Jahren nur 6 Anfälle gehabt hatte; in der sekundären Periode einer Syphilis bekam sie in 4 Monaten 11 Anfälle; unter dem Einfluß einer spezifischen Behandlung nahm die Epilepsie jedoch ihre alte Form wieder an. Féré beobachtete einen ihm 1882 von Charcot zugeschickten Kranken, der, seit 14 Jahren epileptisch, bis zum 28. Jahre nie mehr als einen Anfall im Monat gehabt hatte. Zu dieser Zeit akquirierte er eine Lues, und sofort nach dem Auftreten der ersten Plaques muqueuses traten die Anfälle in gehäufter Form hervor. Verschiedene antisyphilitische Kuren brachten wohl spezifische luetische Prozesse an den Augen und Knochen, nicht aber die Epilepsie zur Heilung; vielmehr gelangten nach der luetischen Infektion andauernd häufiger als früher Krampfanfälle zur Auslösung. Binswanger, der aus seiner reichen Erfahrung nur diesen einen „,reinen“ Fall mitzuteilen vermochte, berichtet von einem 37 Jahre alten, neuropathisch belasteten Kranken, der bis zum 6. Lebensjahre an epileptischen Krampfanfällen gelitten hatte; im 27. Lebensjahre zog er sich eine luetische Infektion zu; zwei bis drei Jahre danach traten von neuem typische epileptische Insulte auf, die unter dem Einfluß einer kombinierten Jod- und Bromnatriumbehandlung zwar wieder seltener wurden, aber nie ganz zum Verschwinden gebracht werden konnten. In einem analogen Falle Nonnes handelte es sich um einen 27 jährigen Kaufmann, der vom 14. - 18. Jahre an Epilepsie gelitten hatte und mit 25 Jahren eine Syphilis akquirierte; $3 / 4$ Jahre später stellten sich wieder epileptische Anfälle ein, die jedoch wiederholten antiluetischen Kuren und einem sofort eingetretenen antiepileptischen Régime wichen. - Die Krampfanfälle entsprachen in allen diesen Fällen nach Form, Verlauf und Begleiterscheinungen durchaus denen der gewöhnlichen genuinen Epilepsie; corticale und andere cerebrale, auf materielle Läsionen hindeutende Krankheitszeichen fehlten; der Charakter des Krankheitsbildes blieb während der Dauer der Beobachtung im wesentlichen immer der gleiche. Vogt hat diese Fälle in Übereinstimmung mit Binswanger aufgefaßt als ,Verstärkung einer hereditärepileptischen Anlage durch Lues“ und glaubt, daß es sich hier ,um das Wachrufen der latenten epileptischen Disposition durch die erworbene Syphilis" handelte; daraus erkläre sich auch die häufige zeitliche Anlehnung an die Sekundärperiode der Syphilis.

Dem gegenüber berichtet Nonne von Fällen, in denen eine hereditäre Belastung nicht vorlag und als einziges ursächliches Moment für die erst in späteren Lebensjahren hervorgetretene Epilepsie eine er- 
worbene Syphilis in Frage kam. Von 14 bis 1908 beobachteten Fällen dieser Art hebt er sieben besonders hervor, weil bei ihnen die Beobachtungszeit eine genügend lange war. Der jüngste dieser 7 Patienten war 36 , der älteste 52 Jahre alt, als der erste epileptische Anfall auftrat. Die Infektion lag einmal nur 6 Monate, zweimal $1 \mathrm{Jahr}$, einmal 2 Jahre, je einmal 5, 7 und 12 Jahre zurück. Die Anfälle entsprachen durchaus denen der genuinen Epilepsie und traten ohne nachweisbare äußere Veranlassung alle 2-6 Monate auf, waren also in keinem Falle häufig. Nie wurden prä- oder postepileptische Dämmerzustände festgestellt, interkurrente psychische Anomalien fehlten, eine Demenz oder Charakterveränderung gelangte nicht zur Ausbildung. Die mehrfach wiederholten antiluetischen Behandlungen, speziell auch intensive Jodmedikationen blieben ohne Einfluß auf die Anfälle.

Nonne glaubt für diese Fälle, auch ohne die anatomische Bestätigung dafür zu haben, spezifische Veränderungen am Gehirn ausschließen zu dürfen und betrachtet sie als luetisch bedingte einfache Epilepsien, bzw. als epileptische Neurosen. Die Beweise findet er in folgendem: Klinisch lag nur gewöhnliche Epilepsie vor; corticale Symptome und andere cerebrale Begleiterscheinungen fehlten; der Charakter der Anfälle blieb während einer längeren Beobachtungszeit stets der gleiche. Eine hereditäre neuropathische Belastung lag nicht vor; andere ätiologische Momente waren auszuschließen; das Alter war ein für den Beginn der Epilepsie ungewöhnlich spätes und lag stets jenseits des 35. Lebensjahres, $d . h$. jenseits derjenigen Altersgrenze, in der eine etwa noch auftretende Epilepsie nach Fournier und Féré wohl stets als luetisch bedingt zu betrachten sei; andererseits lag Senium nicht vor. Eine gewisse differentialdiagnostische Bedeutung glaubt Nonne in seinen Fällen im übrigen noch dem seltenen Auftreten der Krampfanfälle, dem Ausbleiben prä- oder postepileptischer Dämmerzustände und interkurrenter psychischer Störungen, sowie dem Nichteintreten einer Demenz oder Charakterveränderung beimessen zu dürfen.

Wenn man indessen alle einschlägigen Mitteilungen der Literatur Revue passieren läßt, wird man demgegenüber wohl sagen müssen, absolut sichere Einzelkriterien gibt es für diese Form der syphilitischen Epilepsie nicht. Weder das Fehlen eines initialen Schreies, das Fournier als bemerkenswert hervorgehoben hat, noch das Fehlen eines Dämmerzustandes oder das Erhaltenbleiben der Intelligenz kann, wie entgegenstehende Beobachtungen von Dornblüth z. B. erkennen lassen, im Einzelfalle als charakteristisches differentialdiagnostisches Merkmal in Anspruch genommen werden; auch der Erfolg oder Mißerfolg der antiluetischen Therapie beweist an sich noch nichts, ebensowenig das Alter, in dem der erste Anfall zur Auslösung gelangte, das seltenere oder häufigere Auftreten der Anfälle, das Beschränktbleiben 
derselben auf die Tages- oder Nachtzeit $\boldsymbol{u}$. dgl. m. Ohne die Kenntnis der Ätiologie würde die Annahme einer durch Lues bedingten einfachen epileptischen Neurose gewiß oft ganz unsicher bleiben, da die Epilepsie selbst sich in nichts von einer gewöhnlichen genuinen Epilepsie zu unterscheiden braucht. Bezüglich der Beschaffenheit der Intelligenz und des Charakters z. B. ist hervorzuheben, daß es genug Epileptiker ohne Syphilis gibt, welche bemerkenswerte geistige Defekte trotz jahrelangen Bestehens der Krankheit nicht aufweisen; bezüglich der in manchèn Fällen erzielten therapeutischen Erfolge ist zu berücksichtigen, daß auch bei gewöhnlicher genuiner Epilepsie s pontan langdauernde Remissionen eintreten können; bezüglich des Alters kann es nach statistischen und sonstigen Ermittelungen als festgestellt betrachtet werden, daß die gewöhnliche Epilepsie zwar in der überwiegenden Mehrzahl aller Fälle im jugendlichen Alter zum Ausbruch gelangt, in nicht allzu seltenen Fällen aber gelangt sie eben auch erst nach dem 25. -35. Lebensjahre, ja selbst im Senium noch als sogenannte Epilepsia tarda zur Entwicklung, ohne daß Syphilis in der Anamnese nachzuweisen wäre; bezüglich des zeitlichen Auftretens und der Häufigkeit der einzelnen aufeinander folgenden Anfälle aber bestehen auch bei der gewöhnlichen genuinen Epilepsie die weitgehendsten Differenzen. Zur Feststellung der Diagnose bedarf es eben der genauesten Berücksichtigung aller das Krankheitsbild konstituierenden Faktoren; werden materielle Gehirnveränderungen vermißt, fehlen andere ätiologische Momente, läßt sich in der Anamnese eine akquirierte Syphilis nachweisen und spricht sonst nichts dagegen, so wird die Annahme einer einfachen epileptischen Neurose auf syphilitischer Grundlage im Einzelfalle gerechtfertigt erscheinen können, obwohl die anatomische Bestätigung dafür vielleicht nicht zu erbringen ist. Immerhin darf selbst dann noch die Frage aufgeworfen werden, ob nicht etwa bei der großen Verbreitung der Syphilis einerseits und der Epilepsie andererseits nur eine zufällige Koinzidenz vorliegt, ob es sich nicht etwa nur um eine gewöhnliche genuine Epilepsie bei syphilitisch infizierten Individuen handelt. Jedenfalls erscheint nach alledem der Rat Binswangers durchaus beachtlich, die Diagnose „epileptische Neurose auf syphilitischer Basis“ immer nur unter größtem Vorbehalt zu stellen.

Die Entwicklung einer solchen „,parasyphilitischen“ Epilepsie kann nach Binswangers Darlegungen in dreifacher Weise erfolgen. Einmal können durch das syphilitische Allgemeinleiden, durch die sogenannte syphilitische Dyskrasie allgemeine oder lokalisierte Ernährungsstörungen speziell im Nervensystem zustande kommen, durch die das Individuum für die epileptische Erkrankung geeigneter gemacht würde; es bestehe dann derselbe ursächliche Zusammenhang wie zwischen der Syphilis und anderen funktionellen Nerven- und Geisteskrankheiten, 
etwa Neurasthenie, Hypochondrie, Hysterie usw. Zweitens könne man rekurrieren auf die Stoffwechselprodukte des organisierten syphilitischen Virus, die sogenannten Syphilistoxine; diese führten degenerative Veränderungen der Nervenfasern oder Nervenzellen, zuweilen auch der Gefäße herbei. Wo ausgedehntere degenerative Prozesse von progressivem Charakter zustande kämen, gelange als solche postsyphilitische Erkrankung klinisch Tabes dorsalis bzw. progressive Paralyse zur Entwicklung; wo die Veränderungen der Nervenzellen resp. Nervenfasern dagegen nur geringfügiger Natur seien, wo sie nicht völligen Untergang derselben, sondern lediglich eine Schädigung der Leistung herbeiführten, würde vielleicht nur die Basis für Entwicklung der epileptischen Veränderung geschaffen. Drittens müsse nach dem heutigen Stande der Syphilisforschung die Möglichkeit zugegeben werden, daß einfache „,irritative", d. h. entzündliche Vorgänge, wie sie in relativ frühen Stadien der konstitutionellen Syphilis auf der Haut und den Schleimhäuten zur Ausbildung kämen, sich auch am Centralnervensystem abspielen könnten. Es würde sich hier um direkt durch das syphilitische Virus erzeugte, einer antisyphilitischen Behandlung zugängliche Krankheitsbilder handeln. Binswanger hält eine toxische Schädigung der Centralnervensubstanz im Sinne molekularer Gewebsläsionen für am meisten wahrscheinlich.

Gegen die erste Möglichkeit führt Nonne die Tatsache an, daß oft - und so auch in der Mehrzahl seiner Fälle - durchaus nicht ,dyskrasische" Individuen von der „parasyphilitischen" Form der Epilepsie be. fallen wurden; die dritte Annahme aber könnte, wie er meint, nur für die Fälle zutreffen, in denen die Epilepsie in einem noch dem Sekundärstadium der Syphilis zuzurechnenden Zeitraume aufträte; das sei aber bekanntlich nicht immer der Fall. Er neigt daher gleichfalls der Annahme einer mehr toxischen Pathogenese dieser Form der syphilitischen Epilepsie zu und macht darauf aufmerksam, daß sie Rückhalt in dem refraktären Verhalten einer solchen Epilepsie gegen eine antisyphilitische Therapie und noch mehr in den Fällen gewinne, in denen sich eben eine typische ,,postsyphilitische" Erkrankung, nämlich die Tabes dorsalis, an die Epilepsie anschließt. Er führt zwei solche selbstbeobachtete Fälle an. In dem einen handelte es sich um einen 53 jährigen Herrn, der sich im 50. Lebensjahre syphilitisch infiziert hatte und $2^{1} / 2$ Jahre später von allgemeinen epileptischen Krämpfen mit Zungenbiß und Enuresis befallen wurde, in dem andern Falle um einen 40 jährigen Kaufmann, bei dem sich die Epilepsie 4 Jahre nach der spezifischen Ansteckung einstellte. Erscheinungen einer tabischen Hinterstrangserkrankung gesellten sich im ersten Falle 1 Jahr später, im zweiten Falle 3 Jahre später hinzu. Zeichen von Nervensyphilis waren vorher nicht hervorgetreten. Auf wiederholte antiluetische Kuren reagierte 
in beiden Fällen weder die Epilepsie noch die Tabes. Auch Binsw anger hat in jüngster Zeit einen „reinen" Fall dieser Fortentwicklung zur Tabes gesehen, ihn aber nicht näher beschrieben. Ein von Gajkiewicz mitgeteilter Fall unterscheidet sich von diesen beiden Fällen dadurch, daß der 13 Jahre nach der Infektion aufgetretenen Epilepsie wahrscheinlich eine spezifisch gummöse Veränderung am Gehirn zugrunde lag; darauf schien wenigstens die Tatsache hinzuweisen, daß die antiluetische Behandlung, für welche ja die durch spezifisch anatomische Veränderungen erzeugte Gehirnsyphilis ein im allgemeinen immer noch dankbares Objekt darstellt, die Epilepsie zur Ausheilung brachte; die Tabes trat 6 Jahre später auf.

$\mathrm{Daß}$ auch die hereditäre $\mathrm{S} y$ philis nicht selten die verschiedenartigsten Epilepsieformen hervorzurufen vermag, kann nach den Mitteilungen und Feststellungen von Althaus, Jackson, Gowers, Fournier, Féré, Erlenmeyer, Fischl, Kowalewsky, Heubner, Binswanger, Nonne, Bratz und Lüth u. a. als erwiesen betrachtet werden. Sind doch Kinder, wie die Darlegungen $R \mathbf{u} \mathbf{m p f s}$, Hochsingers u. a. erkennen lassen, in ganz besonderem Maße der Gefahr ausgesetzt, infolge hereditärer Syphilis von Nervenkrankheiten befallen zu werden, und aus der sogenannten ,,spasmophilen "Eigenschaft des kindlichen Gehirns erklärt es sich vielleicht, daß konvulsionäre Attacken hier mit einer gewissen Vorliebe sich einzustellen scheinen. Speziell allgemeine Krampfanfälle von typisch epileptischem Gepräge treten bei kongenitaler Lues nach der Mehrzahl der neueren Autoren sogar häufiger auf als bei erworbener Syphilis. Größere statistische Erhebungen über die Häufigkeit der Epilepsie auf der Basis einer angeborenen Lues fehlen freilich noch; doch schwanken die bisherigen Angaben zwischen $5-12 \%$. Jedenfalls betrachtet Binswanger die hereditäre Syphilis wohl mit Recht als ein prädisponierendes Element von weittragendster Bedeutung nicht nur für die Entwicklung der Neurosen überhaupt, sondern ganz besonders auch für die Entwicklung einer Epilepsie. Daß sie nur verhältnismäßig selten als ursächliches Moment dafür in Anspruch genommen zu werden pflegt, hängt nach ihm in der Hauptsache gewiß damit zusammen, daß die Feststellung des syphilitischen Ursprungs der ererbten krankhaften Anlage oft die erheblichsten Schwierigkeiten bereitet. Wohl ruft die kongenitale Lues nicht allzuselten spezifische Prozesse am kindlichen Körper hervor; aber etwa zurückgebliebene Residuen sind später nicht mehr sicher als durch spezifische Veränderungen bedingt zu erkennen. In anderen Fällen mögen wohl schwerwiegende Verdachtsmomente auf angeborene Syphilis vorliegen, weil etwa allgemeine Ernährungs-, Wachstums- und Entwicklungsstörungen bestehen oder Rhachitis, Skrophulose, Hydrocephalus, Idiotie, Zeichen organischer Gehirnläsionen u. dgl. m. im Krankheits- 
bilde nebenher laufen; aber der exakte Nachweis eines Zsammenhangs dieser Erscheinungen mit einer kongenitalen Lues ist mangels spezifischer Merkmale nicht $\mathrm{zu}$ erbringen. Läßt sich doch selbst bei erwiesener Syphilis der Erzeuger nicht immer die Möglichkeit von der Hand weisen, daß Herd- und andere cerebrale Begleiterscheinungen vielleicht auch durch Gehimläsionen anderen, nicht spezifisehen Ursprungs zur Auslösung gelangt sind. Andere Male stehen für die Annahme einer hereditär-syphilitischen Ätiologie der Epilepsie nur die zufällige Beobachtung luetischer Erscheinungen, resp. hereditär-syphilitischer Stigmata bei Geschwistern, wie in Fällen von Jackson und Soltmann, oder, wie in einem Falle von Althaus, der Erfolg einer spezifischen Kur und. ähnliche konkomittierende Nebenumstände mehr zu Gebote. So bleibt man schon in solchen Fällen, noch mehr aber in Fällen, in denen körperliche Störungen nahezu völlig vermißt werden und klinisch mehr oder minder ausschließlich die Epilepsie das Krankheitsbild beherrscht, zunächst fast allein auf die Anamnese angewiesen. Diese aber versagt bezüglich des Nachweises der Syphilis der Erzeuger nicht selten völlig. In neuester Zeit freilich haben wir in der Wassermannschen Reaktion eine wertvolle Bereicherung unseres diagnostischen Rüstzeuges erhalten. Denn wenn man bedenkt, daß die Wassermannsche Reaktion nach E. Forster ${ }^{1}$ ) in 14529 Fällèn von Syphilis positiv ausfiel, während unter 5028 Kontrolluntersuchungen bei Leuten ohne alle anamnestischen und klinischen Anhaltspunkte für Lues nur 59 mal Komplementablenkung im Blute gefunden wurde, so wird man wohl sagen dürfen, daß der positive Ausfall der Wassermannschen Reaktion beweisend für Syphilis ist. Daran dürfte auch die Tatsache nichts ändern, daß ein der Syphilisreaktion analoges Phänomen mit einer gewissen Konstanz auch bei Frambösie, Trypanosomenerkrankung und Lepra, sowie - und das kommt praktisch wohl allein in Frage - vorübergehend auch bei Scharlach zu beobachten ist. $O b$ freilich die positive Reaktion auf virulentes Virus hinweist, erscheint unsicher; da sie bekanntlich auch bei gewöhnlicher und hereditärer Paralyse trotz Fehlens der Spirochäten in der Regel eintritt, nicht minder oft auch bei Tabes dorsalis, so darf diese Frage als gelöst bis jetzt wohl nicht betrachtet werden²).

1) E. Forster, Die Syphilis des Nervensystems. Lewandowskys Handb. d. Neurol. Bd. 3. Berlin 1912. S. 354.

2) Ganz neuerdings freilich wollen Noguchi, der bekannte Spirillenforscher am Rockefellerinstitut in New York, und sein Mitarbeiter Moore bei 14 unter 71, nach einer noch neueren Mitteilung sogar bei 48 unter 200 Paralytikergehirnen Spirochäten in der Hirnrinde gefunden haben. Sollten sich diese Befunde bestätigen, und sollten sie in gleicher Weise auch bei Tabes dorsalis erhoben werden - nur bei einem von 12 untersuchten Tabesfällen ist bis jetzt die Auffindung der Spirochaeta pallida im Hinterstrange des Dorsalmarks angeblich gelungen -, 
Wie bei den auf akquirierter Lues beruhenden Epilepsieformen kann man auch bei der auf hereditärsyphilitischer Grundlage entstehenden Epilepsie mit Gowers, Kowalewsky, Binswanger u.a. im wesentlichen zwei Gruppen annehmen: 1. die parasyphilitische Form, 2. die durch grob anatomische Veränderungen am Gehirn bedingte Form der Epilepsie.

Auch hier gilt das gleiche, was oben bereits für die akquirierte Syphilis betont wurde: in der überwiegenden Mehrzahl der Fälle entwickelt sich, wie auch 0 ppenheim bestätigt, die Epilepsie auf der Basis materieller Gehirnprozesse. Entweder handelt es sich dabei um Prozesse spezifischer oder um solche nicht spezifischer Art. Die spezifischen Veränderungen stellen bald gummöse Tumoren, bald gummöse Infiltrate dar und treten uns teils circumscript, teils diffus ausgebreitet als meningitische, meningoencephalitische und encephalitische Prozesse bzw. als Endarteriitis syphilitica oder als luetische Affektionen der knöchernen und häutigen Hüllen des Gehirns entgegen. Nach Kaha nes Darstellung ruft aber die ererbte Syphilis nicht selten auch grob anatomische Veränderungen nicht spezifischer Natur im Bereiche des Centralnervensystems hervor, und zwar soll für viele Fälle von Ernährungs-, Entwicklungs- und Wachstumsstörungen des Gehirns, für viele Fälle von Atrophie Hypoplasie, Sklerosierung, hydrocephalischem Erguß und manche anderen Hemmungsbildungen und Gewebsentartungen mehr oder minder ausschließlich die kongenitale Lues das schädigende Moment abgeben. Endlich würden dieser Gruppe noch „,postsyphilitische“ Erkrankungen von progressivem degenerativem Charakter zuzuweisen sein, wie sie wohl den im jugendlichen Alter auftretenden Fällen von. progressiver Paralyse und Tabes dorsalis zugrunde liegen ${ }^{1}$ ). Gerade bei der kindlichen Paralyse sind ja epileptiforme ,paralytische“ Anfälle ein recht häufiges Vorkommnis.

Klinisch werden sich freilich auch in Fällen dieser Art in der Regel noch mehr oder minder deutlich Symptome der grob anatomischen Gehirnläsion im Krankheitsbilde bemerkbar machen; die Verknüpfung typischer allgemeiner Krampfanfälle mit corticalen Konvulsionen, mit

so müßte der Möbiussche Begriff der Metalues natürlich aufgegeben werden, da es sich dann eben bei Paralyse und Tabes nicht um meta-, post- oder parasyphilitische, sondern um echte syphilitische Prozesse handeln würde. Doch darf bis auf weiteres wohl noch am Begriffe der Metalues, der sich 2 Jahrzehntë hindurch vorzüglich bewährt hat,- festgehalten werden. Ihre Befunde haben Noguchi und Moore mit den Krankengeschichten zugleich im Journ. of experim. Med., Bd. 17 No. 2 vom Februar 1913 veröffentlicht. Vgl. auch Noguehi, Studien über den Nachweis derSpirochaeta pallida im Zentralnervensystem bei der progressiven Paralyse und bei Tabes dorsalis. Münch. med. Wochenschr. 1913. No. 14.

1) Vgl. die zusammenfassenden Übersichten und Berichte darüber bei Alzheimer, Nonner.a. 
Reiz- und Lähmungserscheinungen in einem oder mehreren Gehirnnerven, mit mehr oder minder schnell fortschreitendem geistigem Verfall, mit Idiotie, Aphasie, Hemi- oder Paraplegie u. dgl.m., wird die organische Grundlage dann unter Umständen klarlegen helfen. Wie aber Fournier, He ubner u. a. betonen, bleiben die allgemeinen epileptischen Krampfanfälle gerade bei Kindern oft lange Zeit isoliert und gesellen sich vielfach erst ganz allmählich Zeichen fortschreitender Demenz und schwerer organischer Gehirnläsionen hinzu, und Cramer bemerkt mit Recht, daß in der Literatur nicht selten geradezu paralytische Formen von Epilepsie auf hereditärer syphilitischer Basis sich beschrieben finden. Wie erheblich aber die differentialdiagnostischen Schwierigkeiten sich im Einzelfalle gestalten können, zeigt beispielsweise der letzterwähnte Fall in der Arbeit von Bratz und Lüth, in dem klinisch durchaus nur das Gesamtbild einer gewöhnlichen genuinen Epilepsie ohne alle lokalen Reizerscheinungen vorlag, während die Sektion das Vorhandensein einer spezifischen Erkrankung der häutigen und knöchernen Hüllen an zwei Stellen der Gehirnkonvexität ergab. In anderen Fällen mögen zwar auch in der Hauptsache nur allgemeine Krampfanfälle vom Charakter der genuinen Epilepsie bestehen; immerhin lassen wenigstens einige akzidentelle Symptome oder etwa vorhandene "Stigmata der Lues des Nervensystems" u. dgl. m., eventuell in Verbindung mit antiluetischen Kurerfolgen Zweifel an der Zugehörigkeit zur nicht grob anatomisch bedingten Epilepsie aufkommen. Das dürfte z. B. für manche anderen Fälle in der Bratz-Lüthschen Arbeit zutreffen, vielleicht auch für den von Nonne angeführten Fall, der ein im 7. Lebensjahre epileptisch gewordenes Kind betraf, bei welchem Zeichen hereditärer Syphilis an Haut, Schleimhäuten und Knochen fehlten, aber als ,Stigma der Lues des Nervensystems" doppelseitige Mydriasis und Lichtstarre bestand; unter kombinierter QuecksilberJodbehandlung wurden die Anfälle seltener und die geistige Entwicklung ging weiter vor sich. Streng genommen wird sich freilich auch für eine klinisch in der gewöhnlichen Weise verlaufende kongenital-luetische Epilepsie die Zugehörigkeit zur sogenannten ,parasyphilitischen“" Form erst durch die Autopsie, durch die Ausschließung materieller Gehirnveränderungen mit Sicherheit erweisen lassen. Denn nach den neueren anatomischen Untersuchungen von Alzheimer, Ranke, Rondoni u. a. liegen solchen syphilitischen Epilepsien (und Idiotien) gewiß nicht selten fibrös indurative Erscheinungen in der Pia und gliöse Prozesse im Gehirn mit Untergang der spezifischen Elemente der Rinde, Gefäßvermehrung und lymphocytärer Gefäßscheideninfiltration zugrunde, während in anderen Fällen überwiegend die Gefäße mit Schwellung und Desquamation der Endothelien betroffen sind. Gleichwohl wird man für einige wenige Fälle wenigstens unter ähnlichen Vor- 
behalten wie bei der akquirierten Syphilis eine auf dem Boden der kongenitalen Lues entstandene einfache epileptische Neurose anerkennen dürfen. Darunter würden trotz fehlender anatomischer Bestätigung etwa Fälle wie der von Kowalewsk y mitgeteilte Fall eines 11 jährigen schwachen, skrofulösen Mädchens zu rechnen sein, bei dem die Epilepsie im 10. Lebensjahre auftrat, eine antisyphilitische und antiepileptische Behandlung aber freilich ,recht guten" Erfolg gehabt haben soll, oder der von Binswanger beschriebene Fall eines $16^{1} / 2$ jährigen schwäch. lichen, skrofulösen Knaben, bei welchem die Epilepsie erst im 13. Lebensjahre - angeblich imAnschluß an einen Schreck - zur Auslösung gelangte, die Krampfanfälle aber durch entsprechende Kuren nicht zu beeinflussen waren. Auch Bratz und Lüth glauben die Mehrzahl ihrer Fälle der „,parasyphilitischen“ Form der Epilepsie zuweisen zu dürfen.

Schon Reynold und Kowalewsky behaupteten, daß die Kinder luetischer Eltern oft nicht die Syphilis direkt, sondern nur ein weniger resistentes Nervensystem erbten, das leicht zur Epilepsie hinneige. Kowalews k y hat sich besonders bemüht, über die Art dieser Schädigung der Nervensubstanz eine klare Vorstellung zu gewinnen. Neben Ubertragung des spezifischen syphilitischen Virus von den Eltern auf die Nachkommen hält er einen allgemeinen schädigenden Einfluß für möglich, und zwar nimmt er für letzteren Fall Veränderungen der Blutmischung durch Toxine der Syphilis an. Das syphilitische Gift gehe als chemische Substanz auf die embryonale Zelle über und konzentriere sich bei weiterem Wachstum des Embryos besonders stark im Zentralnervensystem. Bald rufe es, von allgemeiner Schwäche und Kraftlosigkeit abgesehen, grobe makroskopische Deformation, etwa große Defekte der Entwioklung der Hirnteile hervor, bald nur chemischmolekulare Veränderungen der nervösen Gebilde. Je nach der Intensität und Ausdehnung der Schädigung wechselten auch die klinischen Erscheinungen der hereditären Syphilis des Nervensystems, vom Idiotismus angefangen bis auf die leichtesten Formen der Neurasthenie; die Hysterie, Chorea und Epilepsie stellten Zwischenformen dieser Reihe dar. Nicht eine spezielle Neurose erwachse auf dem Boden einer hereditären Syphilis des Gehirns, sondern nur die Neigung zu irgendeiner nervösen oder psychischen Erkrankung. Wenn er aber weiter meint, die parasyphilitische Form der Epilepsie finde ihre Erklärung in einer erblichen Úbertragung der Erkrankung des Vaters, die durch spezifische oder Gefäßveränderungen bedingte hereditär syphilitische Epilepsie dagegen in einer solchen der Mutter, so stellt er sich die Genese der verschiedenen Epilepsieformen wohl zu einfach vor. Binswanger adoptiert die Annahme eines doppelten Einflusses und meint, daß entweder eine syphilitische Keimesinfektion oder lediglich 
eine Keimschädig u ng eintreten könne. Im ersteren Falle entwickelten sich im kindlichen Organismus früher oder später spezifische Erscheinungen der Lues hereditaria, im letzteren Falle käme, von Rhachitis, Skrofulose, Anämie, Debilität und anderen Erscheinungen der „Dyskrasie" abgesehen, teils mit, teils ohne erbliche Belastung eventuell auch jene anatomisch noch nicht definierbare ,epileptische Veränderung der Hirnrinde" zustande, die weiterhin unter dem Einflusse irgendeiner Gelegenheitsursache zu Krampfanfällen führe. Als eine Zwischenform bezeichnet er solche Fälle, in denen früher oder später Zeichen der ererbten Syphilis auftreten, daneben aber die Epilepsie gewissermaßen als selbständiger Krankheitsvorgang sich entwickelt, ohne daß irgendwelche Symptome einer organischen spezifischen Erkrankung des Gehirns oder seiner Hüllen vorhanden sind; die Ansiedelung der hereditären Syphilis in anderen Organen als dem Gehirne des Kindes schädige dann eventuell erst später von dieser Lokalisation aus durch Toxine das Gehirn und rufe auf diese Weise eine funktionelle Epilepsie hervor. Zur Illustrierung dieser Entstehungsmöglichkeit führt Binswanger einen höchst instruktiven Fall an:

Ein 16 Jahre alter, kräftig gebauter Knabe hatte sich bis zum 14. Jahre körperlich und geistig völlig normal entwickelt. Der Vater war zur Zeit der Zeugung des Sohnes vom Nachschub einer Syphilis betroffen gewesen; die Mutter ist nervös, ihre Schwester psychisch krank. Die später nach einer erneuten antisyphilitischen Behandlung des Vaters geborene Tochter ist körperlich und geistig ganz gesund. Der Verdacht auf die hereditäre Lues wurde durch adenoide Wucherungen im Nasenrachenraume hervorgerufen, welche auf Jodkur zurückgingen und in Verbindung mit örtlicher Behandlung zur Heilung gelangten. Zwischen dem 14. und 15. Lebensjahre stellten sich eigentümlich lokalisierte und zweifellos reflektorisch bedingte Schlundkrämpfe bei völlig erhaltenem Bewußtsein ein, die sich in der Folgezeit wiederholten; ein halbes Jahr später traten voll entwickelte Krampfanfälle von typisch epileptischem Gepräge hinzu. Wesentliche Intelligenzstörungenbestanden nicht, doch fiel seit dem Auftreten der Schlundkrämpfe eine gewisse Abnahme des Gedächtnisses, verbunden mit Euphorie, auf. Methodische Brom- und Jodkuren brachten nur geringe Besserung. Binswanger nimmt an, $\mathrm{da} B$ in diesem Falle die Epilepsie dem Zusammenwirken mehrerer Umstände entsprungen sei: der hereditären Belastung, der Lues und den Schlundkrämpfen, die den eigentlichen epileptischen Krampfanfällen vorausgingen. Die letzteren könnten die epileptischen Krampfanfälle rein reflektorisch oder dadurch herbeigeführt haben, daß sie sekundär venöse Stasen und damit zugleich Störungen der Gehirnernährung und pathologische Abänderungen der zentralen Erregbarkeit bewirkten. Nicht auszuschließen aber sei die Möglichkeit, daß „bei dem späten Aufleben der seit der Zeugung latent gebliebenen syphilitischen Invasion neben den irritativen und neoplastischen lokalen Prozessen auch die anderen toxischen Folgeerscheinungen der syphilitischen Durchseuchung" aufgetaucht wären und in Form feinster partieller (,,molekularer") Gewebsschädigungen Anlaß zur Entwicklung der epileptischen Veränderung gegeben hätten.

Auch Bratz und Lüth glauben für einige ihrer Fälle die Annahme nicht von der Hand weisen zu dürfen, „daß die als Dermatitis, Coryza 
usw. lokalisierte Erbsyphilis durch ihre Toxine erst in späteren Lebensjahren das Zentralnervensystem geschädigt hat". Andererseits aber geben sie ihrer Meinung auch dahin Ausdruck, daß sich ,,bei der großen Verbreitung der Syphilis wie der Epilepsie eine zufällige Koinzidenz nicht für jeden Fall werde abweisen lassen". Zu beachten ist schließlich noch, daß, wie Cramer bemerkt, die hereditäre Syphilis in der Regel wohl nicht allein die Epilepsie hervorruft, daß hier vielmehr noch andere Momente mitsprechen dürften; sonste müßte uns bei der Deszendenz von syphilitischen Eltern doch wohl häufiger die Epilepsie entgegentreten. Cramer beobachtete z. B. bei 5 Kindern einer Familie durchweg Zeichen der hereditären Lues, aber nur eines davon hatte Epilepsie. In anderen Fällen wieder können eine Reihe von Kindern bei anamnestisch erwiesener Lues der Erzeuger dauernd ganz gesund bleiben, während das eine oder andere als einziges Stigma eine in der gewöhnlichen Weise verlaufende Epilepsie darbietet. Welcher Art die hier etwa noch mitsprechenden Momente sein müssen, ist uns bis jetzt freilich nur wenig bekannt.

Bevor wir nun die eigenen einschlägigen Beobachtungen folgen lassen, sei kurz bemerkt, daß sich wohl leicht eine Vermehrung der Kasuistik hätte herbeiführen lassen, wenn das Gesamtmaterial der hiesigen Anstalt einer systematischen Untersuchung nach ätiologisch-klinischen Gesichtspunkten unterworfen worden wäre und alle Fälle mit positiver Wassermannscher Reaktion Berücksichtigung gefunden hätten. So beschränkt sich das beigebrachte Material im wesentlichen auf Fälle, in denen die Lues anamnestisch sichergestellt war, oder nach der Art der klinisch hervorgetretenen Krankheitserscheinungen einem Zweifel kaum begegnen konnte. Aus äußeren Gründen fanden von den lebenden Kranken ferner mit einer Ausnahme (Fall V) lediglich selbstbeobachtete weibliche Patienten Verwendung, während von hier Verstorbenen nur besonders typische Fälle herausgegriffen wurden. Daß in letzterer Beziehung die Ausbeute keine große sein konnte, geht schon daraus hervor, daß sich unter den seit 1891 in der hiesigen Anstalt Verstorbenen nach dem Ergebnisse einer früheren Ermittlung1), von 6 Paralytikern abgesehen, nur 4 Epileptiker befanden, bei denen die Syphilis anamnestisch erwiesen war und als Krankheit auslösendes Moment betrachtet werden konnte. Von vornherein auszuschließen waren natürlich solche Fälle, die aus irgendeinem Grunde in anamnestischer, ätiologischer und klinischer Hinsicht nur wenig beweiskräftig erschienen, unter den verstorbenen Paralytikern, insbesondere also diejenigen, welche im Leben zu Verwechselungen mit genuiner Epilepsie Anlaß überhaupt nicht oder etwa nur für ganz kurze Zeit geboten hatten, unter dem lebenden Krankenmaterial alle diejenigen, welche auffälligere

1) Vgl. Allg. Ztschr. f. Psych. 69, 821 u. 824.

z. f. d. g. Neur. u. Psych. O. XvII. 
Abweichungen vom Typus der gewöhnlichen genuinen Epilepsie darboten und durch etwa im Krankheitsbilde hervortretende Reiz- und Lähmungserscheinungen, schnell fortschreitende Demenz und sonstige cerebrale und allgemein somatische Begleiterscheinungen ohne weiteres auf progressive Paralyse oder andersartige organische Gehirnläsionen verdächtig erschienen. Die Krankengeschichten selbst wurden zum Teil nicht unerheblich gekürzt und alles für Beurteilung der Sachlage unerhebliche Detail weggelassen; im übrigen stützen sich die beigebrachten Einzelheiten durchgehends auf das Ergebnis der fortlaufenden Beobachtung und wiederholter eingehender Untersuchungen.

Fall I. Elsa Schr., geb. 24. IV. 1879 nach normal verlaufener Schwangerschaft; auch die Geburt verlief ungestört. Großvater mütterlicherseits Tabiker. Der Vater der Kranken litt vor der Eheschließung (1876) an Lues und bekam noch später mehrfach Rezidive; er starb 1910 an Herzfehler. Die Mutter und 4 Geschwister -- davon 1 älter, 3 jünger als die Kranke - sind, wie es heißt, gesund; über Fehlgeburten ist nichts bekannt; doch sollen die Kinder, auch die Kranke, in der Jugend zum Teil an skrofulösen Hautausschlägen gelitten haben.

Die Kranke war und blieb trotz aller Pflege und Abwartung zart von Konstitution; sie wuchs in einfachen, aber geordneten häuslichen Verhältnissen auf, überstand Masern und Röteln gut ohne nervöse Begleiterscheinungen, besuchte bis zum 12. Jahre die Schule, wurde dann noch etwas durch Privatunterricht gefördert und im 15. Lebensjahre konfirmiert. Anfangs soll sie geweckt gewesen sein und in der Schule Eifer gezeigt haben, später störte sie den Unterricht und blieb geistig sichtlich immer mehr zurück. Während der Zahnungsperiode trat ein Anfall nicht näher beschriebener Art auf, seit dem 12. Lebensjahre kamen zuweilen plötzliche Ohnmachtsanwandlungen vor, erst mit Eintritt der Menses im 15. Lebensjahre setzten typische epileptische Insulte in voll ausgeprägter Form ein. Quecksilberoder Jodkalikuren wurden früher nicht vorgenommen, die Behandlung mit Brompräparaten, Arsen usw. erwies sich als erfolglos. Allmählich steigerten sich die Anfälle nach Zahl und Heftigkeit. Bis zur Unterbringung in der hiesigen Anstalt - am 8. II. 1911 - befand sich die Kranke zu Hause, nur mit leichtesten Arbeiten beschäftigt, die sie pünktlich, aber ganz mechanisch, ohne alle Selbständigkeit und Überlegung ausführte.

Die Kranke, $157 \mathrm{~cm}$ lang, ist regelmäßig, aber wenig kräftig entwickelt; das Körpergewicht schwankte in der hiesigen Anstalt zwischen 41 bis $48 \mathrm{~kg}$. Sie sieht blaß und anämisch aus. Krankhafte Störungen im Bereiche der Sinnesorgane bestehen ebensowenig wie Lähmungen, Ankylosen, Paresen, Störungen der Motilität, Sensibilität und Reflextätigkeit usw. Der Schädel ist symmetrisch entwickelt, normal groß; sein größter Horizontalumfang beträgt $52 \mathrm{~cm}$, sein Längendurchmesser 16, sein größter Querdurchmesser $15 \mathrm{~cm}$. Die Stirn erscheint leicht vorgewölbt, ebenso die Scheitelbeine, dazwischen findet sich in der Mittellinie eine leichte Einkerbung, also Caput natiforme mäßigen Grades. Die Schneidezähne sind schlecht gestellt, an der unteren Kante halbmondförmig ausgebuchtet, zum Teil gerifft, die Nacken- und Halsdrüsen etwas geschwollen. Im übrigen fehlen auf hereditäre Lues hindeutende Stigmata, auch die Pupillen reagieren durchaus normal; doch ergab die Wassermannsche Reaktion bei jeder bisher ausgeführten Untersuchung ein positives Resultat. Vorn am Zungenrande bemerkt man beiderseits einige Narben. Innere Organe o. B., Urin frei von Zucker und Eiweiß.

Abgesehen davon, daß die seit dem 15. Lebensjahre aufgetretenen Krampfanfälle allmählich an Zahl und Heftigkeit zugenommen haben sollen, blieben sie 
sich nach Typus und Verlauf im übrigen stets gleich. Die Insulte beginnen ohne ausgesprochene Aura, bald mit, bald ohne Schrei. Meist treten vollentwickelte Krampfanfälle von 1-11/2 Minuten Dauer auf, gelegentlich aber auch Anfälle von petit mal. Die tonisch-klonischen Muskelkrämpfe sind allgemein, beiderseits gleich stark ausgeprägt, stets begleitet von völligem Bewußtseinsverlust und nachfolgender Amnesie, oft verbunden mit Zungenbiß, sonstigen kleinen Verletzungen und Enuresis. Die Paroxysmen treten bald vereinzelt, bald in Gruppen von 2-5 Anfällen auf, in der Regel alle 14 Tage, nur selten nachts. Insgesamt gelangten in der hiesigen Anstalt bis Ende April 1913160 teils voll ausgeprägte, teils rudimentäre epileptische Insulte zur Auslösung, 129 bei Tage, 31 nachts. Die Zahl der in einem Monat wahrgenommenen Anfälle schwankte zwischen 3-11; die längste anfallsfreie Zwischenzeit betrug gegen 3 Wochen. Nach Ablauf der Paroxysmen erscheint die Kranke apathisch, matt, angegriffen, schläfrig, durchaus unbesinnlich, nach besonders schweren Anfällen oft einige Tage lang teilnahmlos, benommen und in jeder Hinsicht noch stumpfer als sonst; meist freilich erholt sich die Kranke schnell wieder. In der Intervallärzeit machen sich auf organische Gehirnaffektionen hindeutende Symptome in keiner Weise geltend; nie bestanden Erbrechen, Klagen über Kopfweh, isolierte klonische Zuckungen u. dgl. $\mathrm{m}$.

Psychisch erscheint die Kranke in der Zwischenzeit ruhig, geordnet, lenksam, gutmütig, harmlos, klar, zeitlich und örtlich orientiert, aber intellektuell wenig rege, ziemlich stumpf, interesselos, kurz geistig in mittlerem Grade abgeschwächt. Nur unmittelbar nach Anfällen zeigt sie sich mitunter etwas gereizt, überempfindlich, starrköpfig und ruhelos.

Kombinierte Brom-Jodkuren waren bis jetzt von bemerkenswertem Erfolge nicht begleitet. Auch die Anämie blieb allen therapeutischen Maßnahmen gegenüber bestehen. Auf spezifische luetische Prozesse hindeutende Krankheitserscheinungen kamen hier nicht zur Wahrnehmung.

Fall II. Id a F., geb. 9. XI. 1883. Der Vater starb 1900 an Lungentuberkulose; sonst ist Näheres über ihn nicht bekannt geworden. Die Mutter wurde seinerzeit wegen sekundärer Syphilis behandelt und starb bald nach der Geburt des Kindes; sie litt an epileptischen Krämpfen, als deren anatomische Grundlage ein syphilitischer Gehirntumor angenommen wurde. Die vor der Kranken geborenen 3 Kinder starben bald nach der Geburt; über Aborte und Fehlgeburten ist nichts bekannt, ebensowenig über etwa eingetretene Störungen des Geburtsverlaufs. Die äußeren Lebensverhältnisse waren nicht gerade ungünstig; doch soll es dem Kinde während des 1. Lebensjahres an der nötigen Pflege gefehlt haben. Es war sehr schwächlich, lernte erst gegen Ende des 2. Lebensjahres laufen, überstand im 4. oder 5. Lebensjahre Lungenentzündung ohne nervöse Symptome, entwickelte sich aber körperlich und geistig im übrigen leidlich normal. Von Erscheinungen hereditärer Syphilis wird nichts berichtet.

Im 13. Lebensjahre soll plötzlich ohne besondere äußere Veranlassung ein „Schlaganfall“ aufgetreten sein; im Anschluß daran stellten sich zunächst rudimentäre Anfälle in Form kurz dauernder Ohnmachten und Absencen ein; typische, voll ausgeprägte epileptische Insulte machten sich erst seit dem Einsetzen der Menses im 16. Lebensjahre bemerkbar; eine besondere Schädigung ging ihnen nicht voraus. Zuerst erfolgten kurze Zuckungen, dann fiel die Kranke um, wurde steif, das Bewußtsein schwand; klonische Zuckungen blieben in der ersten Zeit aus, wurden aber später bei großen Attacken nie vermißt, sie breiteten sich vom Gesicht aus über alle Muskeln aus. Während der Krämpfe, die einige Minuten währten, trat blutig tingierter Schaum vor den Mund; dann hielt die Kranke den Mund krampfhaft geschlossen. Oft kam es auch zu kleinen Verletzungen, Zungenbiß, Enuresis u. dgl. m. Hinterher bestand stets volle Amnesie, meist auch länger 
andauernde Benommenheit, Schlafsucht und Unbesinnlichkeit, gelegentlich erschien sie auch eine Zeitlang unklar und verworren. Vor der Unterbringung hierselbst - am 15. V. 1903 - wurde sie in der Regel alle 5-9 Tage von Insulten betroffen, mitunter kamen an einem Tage bis zu 5 Anfällen vor. Eine methodische Behandlung hatte bis dahin nicht stattgefunden.

Spezifische luetische Veränderungen wurden hier nicht wahrgenommen. Die Kranke war regelmäßig gebaut, aber von kleiner, zarter Statur, sah trotz ihrer 20 Jahre noch kindlich aus und litt fortgesetzt an hochgradiger Anämie. Ihr Körpergewicht schwankte zwischen 34-40 kg. Der Puls zeigte sich meist etwas beschleunigt, Struma bestand nicht, auch sonst boten die inneren Organe bemerkenswerte krankhafte Befunde nicht dar. Am rechten Fußrücken und Unterschenkel sich findende ausgedehnte flache Narben sollen von einer früheren Verbrennung herrühren. Der Schädel ist symmetrisch entwickelt, sein Umfang beträgt 53, sein Längenmaß, von der Stirn zum Hinterhaupt gemessen, 26, sein Breitenmaß $21 \mathrm{~cm}$. Die Ohrläppchen sind unschön groß, die Augenbewegungen ungestört, die mittelweiten Pupillen beiderseits gleich, auf Lichteinfall und Akkomodation erfolgt träge, wenig ausgiebige Reaktion, das Sehvermögen zeigt keine Störungen, das Hörvermögen hat durch oft rezidivierende Otitis media chronica eine gewisse Beeinträchtigung erfahren. Alle Körperbewegungen geschehen langsam, aber sonst geordnet, die Sprache ist ungestört, alle Reflexe gelangen prompt zur Auslösung, die allgemeine Schmerzempfindung ist etwas abgeschwächt. Zeichen organischer Gehirnläsionen treten nicht hervor.

Insgesamt gelangten in der hiesigen Anstalt 334 typische epileptische Paroxysmen zur Wahrnehmung, 262 tagsüber, 72 nachts; sie glichen sich untereinander, waren fast stets voll ausgeprägt, wechselten nur nach ihrer Dauer und Heftigkeit, ließen corticale und andere cerebrale Begleiterscheinungen vermissen und entsprachen in jeder Beziehung denen der genuinen Epilepsis. Die größte in eimem Monat erreichte Zahl von Insulten betrug 30; oft summierten sie sich zum Status; die längste anfallsfrei verlaufene Zwischenzeit belief sich auf 5 Wochen. Bei den Anfällen, die stets ohne auffällige Aura, meist auch ohne Schrei einzusetzen pflegten; zog sich die Kranke nicht selten Verletzungen am Kopf, Zungenbiß u. dgl. m. zu. Nach Ablauf derselben bestand oft längere Zeit heftiges Erbrechen. Geistig erschien die Kranke auch in den anfallsfreien Zwischenzeiten stumpf, gleichgültig, teilnahmlos, wenig rege, kurz vorgeschritten schwachsinnig. Gelegentlich machten sich im unmittelbaren Anschluß an Krampfanfälle für kurze Zeit Zustände psychomotorischer Erregung mit Rededrang geltend; nicht selten führte sie dann religiös gefärbte, mehr oder minder verworrene Selbstgespräche. Kombinierte Bromnatrium- und Jodkalikuren erwiesen sich als wenig erfolgreich. Am 20. VI. 1905 setzte ein schwerer Status epilepticus ein, der mit vorübergehenden Besserungen und Nachlässen bis zum Juli anhielt und trotz Amylenhydrat per.Klysma und anderer entsprechender Maßnahmen nicht zu beseitigen war; durch fortgesetztes heftiges Erbrechen, zunehmende Benommenheit und Hinfälligkeit verschlimmerte sich der Zustand zusehends immer mehr. Schließlich trat Koma, Fieber, Bronchitis, Odem usw. hinzu, und unter den Zeichen zunehmender Herzschwäche trat am 20. VII. 1905 nachts 11 Uhr Exitus letalis ein.

Die andern Tags früh vorgenommene Sektion ergab nur wenig belangreiche Befunde. Erwähnenswert ist aus dem Protokoll nur folgendes: Schädeldach massig, schwer, Diploë fast vollkommen geschwunden. Harte Hirnhaut glatt, nicht verwachsen; subdural findet sich in mittlerer Menge seröse Flüssigkeit. Weiche Häute diffus milchig getrübt, besonders an der Hemisphärenkante nach vorn zu; Venen stark gefüllt, Basisgefäße zart, Windungen leicht abgeplattet, Rinde nicht verschmälert, Ventrikel mäßig erweitert, Ependym zart und glatt. Gehirn hyper- 
ämisch, ödematös, Gewicht $1005 \mathrm{~g}$. Sonst fanden sich noch: Herz erschlafft, alle Organe hyperämisch. Aorta nicht verengt, nur wenig sklerosiert. Pleuritis adhaesiva dextra. Bronchitis foetida, Lungenödem, Unterlappen hyperämisch, zum Teil pneumonisch infiltriert. Eine mikroskopische Untersuchung wurde nicht vorgenommen.

Fall III. Elsa U., geb. 10. V. 1895, stammt aus ärmlichen Verhältnissen, litt in der Jugend an Ausfluß aus der Nase, Masern, Diphtheritis, Skrofulose mit Halsdrüsenentzündung und Ohrenfluß. Eine ältere Schwester ist angeblich gesund, ebenso die Mutter. Mehrere Geschwister starben bald nach der Geburt; über Aborte und Fehlgeburten ist nichts bekannt; die Kranke ist rechtzeitig am Ende der Schwangerschaft geboren; der Vater ist einem Lungen- und Rückenmarksleiden erlegen; Potator soll er nicht gewesen sein. Neuropathische Belastung liegt im übrigen nicht vor.

Die Epilepsie trat im 6. Lebensjahr hervor; eine Ursache dafür wird nicht angegeben. Anfangs soll es sich nur um Absencen, Schwindel, stieren Blick und ähnliche kleine Insulte gehandelt haben, später traten spontan ohne besondere Vorboten mit Bewußtseinsverlust und Amnesie einhergehende allgemeine tonischklonische Konvulsionen auf, die beiderseits gleich stark ausgeprägt waren. Ihre Häufigkeit unterlag großem Wechsel; im ganzen sollen sie anfangs seltener gewesen sein als später. Zur Zeit der Unterbringung der Kranken in der hiesigen Anstalt - am 4. II. 1907 - wiederholten sie sich wöchentlich einmal, traten aber nicht selten 3-4 mal und öfter am gleichen Tage auf, meist in den Morgenstunden. Hinterher bestand, Mattigkeit, Schlafsucht, Kopfschmerz, Benommenheit bis zur Dauer mehrerer Stunden, Reizbarkeit, gesteigerte Empfindlichkeit u. a. m.

Bei der Aufnahme erschien die Kranke wenig kräftig, dürftig genährt, hochgradig blaß und anämisch, $142 \mathrm{~cm}$ lang, $311 / 2 \mathrm{~kg}$ schwer; seitdem ist das Körpergewicht auf $54 \mathrm{~kg}$ gestiegen, die Körperlänge beträgt jetzt $153 \mathrm{~cm}$. Ein anfangs bestehender Bronchial- und Lungenspitzenkatarrh erfuhr bald Heilung; dagegen trotzte die Anämie allen therapeutischen Bemühungen. Der Appetit ist ungestört, Urin frei von Zucker und Eiweiß, innere Organe ohne Besonderheiten bis auf Herzhypertrophie mäßigen Grades. Sprach-, Motilitäts- und andere wesentliche Störungen liegen nicht vor, nur die Rachenreflexe zeigen sich etwas herabgesetzt, ebenso die allgemeine Schmerzempfindlichkeit; im übrigen bestehen weder Paresen und Lähmungen, noch Ankylosen usw. Die Pupillen sind rund, mittelweit, beider. seits gleich und reagieren prompt auf Lichteinfall und Akkommodation. Die Lymphdrüsen am Halse sind beiderseits vergrößert. Der Schädel ist normal groß, symmetrisch gestaltet, nur das Hinterhaupt fällt etwas steil ab; sein Umfang beträgt $52 \mathrm{~cm}$, sein größter Querdurchmesser 16, sein größter Längsdurchmesser $15 \mathrm{~cm}$. Beiderseits am Mundwinkel bemerkt man strahlige, in die Gesichtshaut übergreifende Narben, die Lippensäume erscheinen hell, leicht gefältelt. Die knöcherne Nasenscheidewand ist verkrümmt, stellenweise leicht aufgetrieben, der Nasenrücken etwas eingesunken, die Stirn mäßig vorgewölbt, die Zähne sind klein, stark cariös, die Schneidezähne mit Querrillen versehen, am unteren Rande halbmondförmig ausgebuchtet. Beiderseits besteht oft rezidivierende Otitis media chronica mit Beeinträchtigung der Hörfähigkeit. Spezifische luetische Prozesse gelangten hier bis März 1909 nicht zur Wahrnehmung. Um diese Zeit entwickelte sich rechts eine mittelschwere typische Keratitis interstitialis profunda, die auf wiederholte Jodkali- und Quecksilberschmierkuren schnell zurückging und keine bemerkenswerte Trübung der Cornea oder Sehstörung hinterließ. Die im September 1910 erstmalig vorgenommene Wassermannsche Reaktion ergab positives Resultat; auch erneute Untersuchungen ergaben immer wieder positive Befunde. Im Dezember 1910 rezidivierte die Keratitis in schwererer Form, zog bald auch 
das linke Auge in Mitleidenschaft und kombinierte sich rechts mit Iritis luetica. Unter erneuten Quecksilber- und Jodkalikuren, die mit entsprechender Lokalbehandlung Hand in Hand gingen, trat langsam Besserung und schließlich bis etwa Ende August 1911 fast vollkommene Heilung ein. Das Sehvermögen ist wiederhergestellt; nur links nimmt man bei fokaler Beleuchtung noch feinste trübe Streifen in der Hornhaut wahr. Seitdem gelangten erneute luetisehe Affektionen nicht mehr zur Beobachtung. Der Augenhintergrund ist zurzeit normal.

Anfangs erhielt die Kranke nur 2,0-3,0 BrNa täglich; seit dem Auftreten des Rezidivs der luetischen Augenerkrankungen wurde daneben noch fortlaufend Jodkali gegeben, beides jedoch bis jetzt bhne nennenswerten Erfolg. Die Kranke bleibt zwar mitunter 1-3 Monate anfallsfrei, aber solche Remissionen gelangten schon bald nach der Unterbringung der Kranken in der hiesigen Anstalt wiederholt zur Beobachtung. Auch der Eintritt der Menses im 14. Lebensjahre hat eine wesentliche Veränderung in der Häufigkeit und Schwere der Insulte nicht herbeigeführt; nur treten seitdem Zeichen von Charakterentartung deutlicher im Krankheitsbilde hervor. Ein gewisser Einfluß der Bromtherapie ist nur insofern zu konstatieren, als sich anfangs rudimentäre Anfälle in Form tonischer Starrezustände, kurzdauernder Schwindel und Absencen nur selten einstellten, während jetzt solche kleinen Attacken mindestens ebenso häufig sind wie große, voll ausgeprägte Insulte. Die höchste Zahl der in einem Monat erreichten Anfälle betrug 13, und zwar nicht nur früher, sondern auch noch nach Darreichung von Jodkali; die Augenerkrankungen übten überhaupt keinen ersichtlichen Einfluß auf die Zahl und die Verlaufsart der Paroxysmen aus, weder im Sinne einer Steigerung, noch im Sinne einer Abminderung. Stets ließen die Insulte das Gepräge der gewöhnlichen genuinen Epilepsie erkennen; kortikale und andersartige cerebrale Begleiterscheinungen fehlten, ebenso prä- oder postepileptische Dämmerzustände; nach Ablauf der Insulte erscheint die Kranke in der Regel nur kurze Zeit abgeschlagen, benommen und unbesinnlich, meist kehrt sie überraschend schnell zu ihrem gewöhnlichen Verhalten zurück; nur eine gesteigerte Gereiztheit und Empfindlichkeit, verbunden mit Unverträglichkeit, Starrsinn, Aufsässigkeit, Unzufriedenheit, Neigung zu losen Reden und allerhand Bosheiten usw. macht sich in letzter Zeit sowohl im unmittelbaren Anschluß an Krampfanfälle, als gelegentlich auch in den intraparoxysmellen Intervallen in auffälligerem Maße als früher bemerkbar und ist wohl als zunehmende Charakterentartung zu deuten. Im allgemeinen erscheint die Kranke in der Zwischenzeit klar, geordnet, zeitlich und örtlich orientiert, lebhaft und geweckt; sie gibt auf Fragen schnell und bereitwilligst Auskunft, bekundet Interesse, weist leidliche Kenntnisse auf, kurz, bietet in intellektueller Beziehung nur geringfügige Abschwächung dar. Interkurrente psychische Störungen wurden im übrigen nie wahrgenommen. Insgesamt gelangten in der hiesigen Anstalt bis Ende April 1913347 Insulte zur Beobachtung, 211 davon zeigten schwereren, 136 leichteren Verlauf, 264 Paroxysmen traten bei Tage, 83 nachts auf.

Daß diese 3 Fälle in klinischer Beziehung aus dem Rahmen der gewöhnlichen genuinen Epilepsie nicht heraustreten, bedarf nach den mitgeteilten Einzelheiten keiner besonderen Ausführung weiter. Auf organische Gehirnprozesse hindeutende Krankheitszeichen fehlten; auch sonst wurden während der Beobachtungszeit in der Anstalt - und diese betrug für Fall I und II über 2, für Fall III über 6 Jahre - auffälligere cerebrale Begleiterscheinungen nicht wahrgenommen. Das in Fall II nach schwereren Anfallsattacken fast regelmäßig aufgetretene heftige, 
meist länger andauernde Erbrechen ist ein im Laufe der gewöhnlichen Epilepsie zu häufig vorkommendes Ereignis, als daß ihm eine besondere Bedeutung hätte beigemessen werden können; zudem gelangte es während der intraparoxysmellen Intervalle niemals zur Wahrnehmung. Ihrem Charakter und Verlaufe nach blieb die Epilepsie in allen 3 Fällen während der Dauer der Anstaltsbeobachtung im wesentlichen völlig unverändert. Differenzen machten sich nur hinsichtlich der Häufigkeit und Schwere der einzelnen Anfallsattacken und ihrer allgemeinen Folgewirkungen, sowie bezüglich des Grades der eingetretenen intellektuellen Abschwächung bemerkbar. Aber in dieser Beziehung begegnet man auch bei der gewöhnlichen genuinen Epilepsie den allerweitgehendsten Unterschieden. Ein gleiches gilt für den Grad der im Einzelfalle etwa zur Ausbildung gelangten Charakterentartung, die sich nur bei Fall III seit der Pubertät in etwas stärkerem Maße als früher geltend zu machen beginnt, und zwar in einem gewissen Gegensatz zu der gerade hier noch leidlich gut erhalten gebliebenen Intelligenz. Jedenfalls halten sich die bemerkten Differenzen zwischen den einzelnen Fällen stets noch durchaus im Rahmen der bei der gewöhnlichen Epilepsie häufig zur Wahrnehmung gelangenden Verlaufsunterschiede. Interkurrente psychische Störungen kamen in keinem der 3 Fälle zur Beobachtung; nur gelegentlich sollen bei Fall II im unmittelbaren Anschluß an Anfälle Zeichen psychomotorischer Erregung u. a.m. aufgetreten sein. Die Entwicklung der Epilepsie fällt bei Fall III in das 6. Lebensjahr, bei Fall I und II in die Zeit der Pubertätsentwicklung; eine besondere äußere Veranlassung, ein besonderer schädigender Einfluß wird dafür in keinem Falle verantwortlich gemacht. Allerdings soll in Fall II dem Ausbruch der Epilepsie ein ,Schlaganfall" vorausgegangen sein; da derselbe aber eingehender nicht beschrieben wird, auch keinerlei nachweisbare Residuen hinterließ, so wird die Vermutung nicht wohl zurückgedrängt werden können, daß dieser sogenannte "Schlaganfall" vielleicht nur den ersten epileptischen Insult dargestellt hat. Die Annahme einer neuropathischen Belastung, der die meisten Autoren ja eine große Rolle bei Entstehung der Epilepsie überhaupt einzuräumen geneigt sind, ist für Fall I und III wohl kaum ganz von der Hand zu weisen, während bei Fall II keine sicheren Anhaltspunkte dafür gegeben sind. Als Moment von auschlaggebender Bedeutung tritt uns in allen 3 Fällen im übrigen allein der Einfluß einer kongenitalen Syphilis entgegen. Zwar fehlten in allen 3 Fällen zunächst Anzeichen für spezifische luetische Prozesse; aber für Fall I und II war Syphilis des Vaters bzw. der Mutter anamnestisch von vornherein sichergestellt und für Fall III konnten Zweifel von dem Augenblicke an nicht mehr Platz greifen, wo eine spezifische Augenerkrankung, nämlich eine Keratitis interstitialis profunda zur Entwicklung gelangt war. Es darf nach Lage der Sache wohl auch ohne weiteres angenommen 
werden, daß die Zeugung der 3 Kranken zu einer Zeit erfolgt ist, in der manifeste Symptome der Syphilis beim Vater resp. bei der Mutter noch bestanden, bzw. die Möglichkeit einer direkten Keiminfektion oder einer Keimschädigung noch vorlag. Für Lues der Erzeuger verwertbar erschienen ferner der positive Ausfall der Wassermannschen Reaktion im Falle I und III, das Bestehen mehr oder minder charakteristischer hereditär-luetischer Stigmata in allen 3 Fällen, sowie die bei Fall II und III bemerkte Polymortalität der Geschwister. Daß im Fall I und III die lebenden Geschwister dauernd gesund geblieben sein sollen, spricht nach allem, was wir über die Vererbungsgesetze der Syphilis auf die Nachkommenschaft wissen, jedenfalls nicht gegen die Annahme einer Syphilis bei den Erzeugern; denn nach Fo urniers oft bestätigtem Lehrsatze ist bei luetischer Anamnese der Eltern ,ein gesundes Kind durchaus kein Freibrief für die Zukunft". Ebensowenig Bedenken kann es erregen, daß in allen 3 Fällen nach der Geburt spezifische luetische Prozesse nicht zur Wahrnehmung gelangt zu sein scheinen und daß im Falle III erst im 14. Lebensjahre eine als spezifisch anzusprechende Augenaffektion zum Vorschein kam; hier könnten sich ja einesteils Sekundärsymptome der Syphilis - und der bei Fall III in der Jugend vorhandene „Ausfluß aus der Nase“" usw. deutet fast darauf hin - der Beobachtung entzogen haben, wie es gewiß häufig geschieht; andererseits aber ist es ein durchaus nicht ungewöhnliches Vorkommnis, daß sich spezifische Symptome der vererbten Syphilis zum ersten Male während des Pubertätsalters einstellen, wie wir zur Genüge aus mehr oder weniger einwandfreien Mitteilungen über Fälle sogenannter Syphilis hereditaria tarda wissen. Schließlich brauchen, wie allem Anscheine nach in Fall I und II, spezifische Erscheinungen der Syphilis überhaupt nie zur Entwicklung gekommen zu sein, da viele Kinder den Darlegungen S. 533 gemäß eben nicht die Syphilis selbst erben sollen, sondern nur ein weniger resistentes Nervensystem, das zur Epilepsie geneigter macht. Daß die Beeinträchtigung der intellektuellen Fähigkeiten, welche übrigens nur im Fall I und II etwas höhere Grade erreichte, und die in Fall III hervorgetretene Charakterdepravation für die Beurteilung des Krankheitsbildes differentialdiagnostisch kaum verwertbar erscheint, wurde bereits bemerkt; abgesehen davon, daß sich die gewöhnliche genuine Epilepsie nicht selten mit mehr oder minder erheblichen Störungen in dieser Richtung kombiniert, treten, wie Binswanger, Nonne u. a. hervorheben und durch entsprechende Beispiele illustrieren, gelegentlich eben auch ohne Epilepsie Hemmungen der geistigen Entwicklung und Charakteranomalien als Stigmata einer von der früheren Lues der Eltern herrührenden Minderwertigkeit der Nervenkraft in die Erscheinung. Der Umstand, daß die Epilepsie in Fall I und II erst zur Zeit der Pubertätsentwicklung voll ausgeprägt zum Vorschein gelangte, stimmt mit 
der allgemein gemachten Erfahrung überein, daß der Ausbruch der Epilepsie überhaupt weitaus am häufigsten in diese Zeit fällt. Zudem weist schon Gowers ausdrücklich darauf hin, daß bei der auf hereditärluetischer Grundlage entstehendenden Epilepsie die Anfälle nur in sehr wenigen Fällen in der Kindheit beginnen, in den meisten aber erst gegen Ende derselben oder selbst noch später; ja gerade diese Tatsache ruft Zweifel gegen die Annahme bei ihm wach, daß ein durch toxische Blutbeschaffenheit zustande gekommener Einfluß der Syphilis auf das Nervensystem vorliegen könne, da ein solcher sich doch wohl früher und häufiger bemerkbar machen müsse, als es tatsächlich beobachtet werde. Indessen scheint der positive Ausfall der Wasser ma n nsche n Reaktion in Fall I und III - Fall III stammt aus älterer Zeit und konnte daher eine entsprechende Blutuntersuchung nicht vorgenommen werden einen ziemlich sicheren Beweis dafür zu liefern, daß irgendein durch die elterliche Syphilis übertragenes "Gift" eine geraume Zeit im Körper kreisen kann, ohne andere Symptome hervorzurufen als eben die Epilepsie und ihre Begleiterscheinungen. Fall III gewinnt speziell noch dadurch besonderes Interesse, daß er anschaulich erkennen läßt, wie dieser Giftstoff unter Umständen sogar noch spät zur Entwicklung spezifisch luetischer Veränderungen an anderen Organen als dem Gehirne Anlaß geben kann. Gleichwohl läßt er sich nicht zu dem von Binswanger geschilderten, S. 534 kurz referierten Fall in Parallele setzen, da hier die Epilepsie schon lange vorher voll zur Ausprägung gelangt war und das Auftreten der spezifischen Affektion auch in keiner Weise verändernd auf den bisherigen Verlauf der Epilepsie einwirkte; es kann daher für unseren Fall auch nicht wohl die von Binswanger ins Auge gefaßte Möglichkeit Geltung gewinnen, daß die als Keratitis interstitialis lokalisierte Syphilis durch ihre Toxine erst in späteren Lebensjahren das Zentralnervensystem geschädigt hat. Wohl aber lag in allen drei Fällen ausgesprochene „Dyskrasie“ vor, und damit gewinnt die Annahme an Wahrscheinlichkeit, daß sie der ,dyskrasischen" Form der hereditärsyphilitischen Epilepsie zuzuweisen sind, d. h. derjenigen Form der Epilepsie, die nach Binsw angers Darlegungen zuweilen bei rachitischen skrofulösen, anämischen, debilen, von luetischen Erzeugern abstammenden Kindern zur Entwicklung gelangt. Auf alle Fälle aber kann es einem Zweifel kaum unterliegen, daß die klinisch-ätiologischen Ermittlungen dazu berechtigen, die geschilderten 3 Fälle als parasyphilitische Formen der Epilepsie im Sinne Fourniers in Anspruch zu nehmen. Das refraktäre Verhalten gegen antiluetische Maßnahmen stützt eine solche Annahme eher noch, als daß es dagegen spräche. Fall II speziell scheint diese Auffassung auch pathologisch-anatomisch zu bekräftigen; denn wenn auch eine genauere mikroskopische Durchforschung des Zentralnervensystems hier nicht vorgenommen worden ist, so rief der 
makroskopisch erhobene Befund jedenfalls nach der Richtung hin nicht den geringsten Verdacht hervor, daß etwa ein organischer Gehirnprozeß das ursächliche Moment für die im Leben aufgetretenen epileptischen Krampfanfälle abgegeben haben könnte; von Piatrübung und allgemeinen letalen Gehirnerscheinungen abgesehen, ergab sich im wesentlichen ja nur ein negatives Resultat.

Demgegenüber dürfte der nachstehend mitgeteilte Fall, welcher einen im Jahre 1891 hier verstorbenen Kranken betrifft, wohl der 2. Gruppe der auf hereditär-luetischer Basis sich entwickelnden Epilepsieformen zuzuweisen sein. Soweit darüber noch Einzelheiten zu erlangen waren, sei er hier kurz skizziert wiedergegeben:

Fall IV. Ernst Gr., geb. 12. II. 1851. Einige Verwandte des Kranken sollen melancholisch gewesen sein. Syphilis des Vaters war anamnestisch sicher gestellt; über die Mutter, welche am 11. I. 1878 starb, ist näheres nicht bekannt. Einige Kinder starben in jungen Jahren; 2 nach dem kranken Kinde geborene Töchter sollen sich gesund entwickelt haben. Ob der Kranke selbst je an spezifisch luetischen Erscheinungen gelitten und entsprechende Kuren durchgemacht hat, ist leider nicht zu eruieren gewesen. Auch sonst lassen die klinischen Feststellungen in mannigfacher Hinsicht zu wünschen übrig; mit Sicherheit hat sich nur etwa folgendes ermitteln lassen: In seiner Jugend entwickelte sich der Knabe körperlich und geistig durchaus regelmäßig. Im 16. Lebensjahre trat, ohne daß früher oder in letzter Zeit besondere Schädigungen vorausgegangen wären, plötzlich ein „Schlaganfall" auf, an den sich weiterhin als „typisch epileptisch“ bezeichnete, periodisch wiederkehrende, allmählich an Zahl und Heftigkeit zunehmende Krampfanfälle anschlossen. Gleichzeitig gelangte im Anschluß an den "Schlaganfall" eine rechtsseitige Hemiparese der unteren, sowie eine komplette Lahmung und Contractur der rechten oberen Extremität zur Entwicklung; daran schlossen sich noch Sprachlosigkeit, Taubheit und zunehmende geistige Abschwächung, die allen therapeutischen Maßnahmen unzugänglich blieben und andauernd als unveränderliche Residuen der erlittenen Apoplexie fortbestanden. Im 20. Lebensjahre in der Anstalt untergebracht, war trotz ausgiebigster Behandlung mit Bromkalium wesentliche Besserung der Epilepsie nicht zu erzielen; im Durchschnitt wurde der Kranke in jedem Monat von 5-12 mehr oder minder schwer verlaufenen epileptischen Insulten heimgesucht. Über auffälligere Begleiterscheinungen, von den erwähnten Residuen der Apoplexie abgesehen, wird nichts berichtet; in korperlicher Hinsicht wird nur erwähnt, daß die rechte Pupille andauernd etwas weiter gewesen sei als die linke, während die Reaktion auf Lichteinfall beiderseits ungestört erschien. In geistiger Hinsicht wird der Kranke als im Verlaufe der Jahre tief verblödet bezeichnet. Der Tod trat am 3. I. 1891 im Alter von 393/4 Jahren im Anschluß an mehrere schwere Anfälle unter den Erscheinungen zunehmender Herzschwäche ein.

Aus dem Sektionsprotokoll sind die folgenden Befunde hervorzuheben: Der Leichnam war $1,70 \mathrm{~m}$ lang, $41 \mathrm{~kg}$ schwer. Ohne weiteres fiel schon bei oberflächlicher Betrachtung die Schmalheit des Brustkastens, die geringe Stärke des rechten Armes und des rechten Beines sowie die Contracturstellung der rechten Hand auf. Das Schädeldach zeigte sich massig entwickelt, die Substantia spongiosa trat stark zurück, die Gefäßfurchen an der Innenfläche waren ausnehmend deutlich, tief und reich ausgebildet. Nach Abnahme des Schädeldaches entleerte sich aus der harten Hirnhaut eine große Menge blutiger Flüssigkeit. Nach Entleerung derselben fällt die harte Hirnhaut auf der vorderen linken Halbkugel zusammen, so da B man eine Kinderfaust in die Vertiefung hineinlegen kann. Die harte Hirnhaut selbst ist 
nicht krankhaft verändert. Die weiche Hirnhaut ist besonders auf der linken Seite getrübt und zum großen Teil sulzig verdickt; beim Einschneiden in die sulzige Masse entleert sich wässerige Flüssigkeit. Der Schädelgrund ist sehr blutreich, die Subduralflüssigkeit beträgt $370 \mathrm{~cm}$. Nach Abfluß der in der sulzig verdickten weichen Hirnhaut enthaltenen Flüssigkeit kann man das krankhaft veränderte Gebiet in der linken Halbkugel übersehen. Es stellt sich als eine von der Fossa Sylvii ausgehende Vertiefung dar, welche sich $8 \mathrm{~cm}$ nach aufwärts zieht; im Vergleich zu der rechten Halbkugel ist die linke vordere Hälfte wesentlich kleiner, so zwar, daß die Oberfläche der linken ca. $2^{1 / 2} \mathrm{~cm}$ tiefer liegt als die der rechten. Überzogen ist die erkrankte Partie mit einer sulzigen Haut, welche teilweise von sehnigen Strängen durchzogen wird. Bei dem Gleiten der Finger über die erkrankte Fläche wechseln weichere Stellen mit festeren ab. Das erkrankte Gewebe zeigt an der Übergangsstelle ins gesunde Gewebe eine feste dunkelgelbe Zone. Der Blutgehalt sämtlicher Hirnteile ist ein sehr starker. Die Konsistenz sämtlicher Partien mit Ausnahme der beschriebenen ist sehr fest. Die Gefäße, besonders der Grundfläche des Gehirns, sind in ihren Wandungen sehr verdickt. Das Hirngewicht beträgt $1100 \mathrm{~g}$, die Hirnflüssigkeit $15 \mathrm{ccm}$. Im übrigen fanden sich noch: Hyperämie aller Organe, Herzerschlaffung, Sklerose der Aorta und der Coronararterien, Oedema cerebri, Hyperaemia pulmonum und stark verfettete Leber.

Die wissenschaftliche Verwertung dieses Falles ist zwar im Hinblick auf die Lückenhaftigkeit der Krankengeschichte etwas erschwert; doch läßt sich so viel mit Sicherheit sagen, daß ätiologisch, von indirekter hereditärer Belastung abgesehen, allein kongenitale Syphilis in Frage kam und klinisch Epilepsie vorlag. Dem Ausbruch der Epilepsie soll im 16. Lebensjahre freilich eine Apoplexie vorausgegangen sein, als deren Folgeerscheinungen irreparable rechtseitige Hemiparese und Contractur, sowie Aphasie, Taubheit und schwere allgemeine intellektuelle Schädigung sich geltend machten. Úber etwa aufgetretene syphilitische Affektionen erfahren wir nichts sicheres; immerhin liegt der Verdacht nahe, daß der Apoplexie eine spezifisch syphilitische Gefäßerkrankung zugrunde gelegen hat; mögen solche auf syphilitischer Grundlage im jugendlichen Alter auftretenden apoplektischen Insulte auch kein häufiges Ereignis darstellen, so läßt sich ihr Vorkommen doch angesichts mannigfacher einschlägiger Beobachtungen nicht bezweifeln ${ }^{1}$ ). Jedenfalls liegt unseres Erachtens nichts im Wege, den später bei der Sektion im Bereiche der linken Fossa Sylvii aufgefundenen kinderfaustgroßen Hirndefekt als durch eine Apoplexie hervorgerufen $\mathrm{zu}$ betrachten und ihn als anatomisches Substrat für die im Leben vorhanden gewesenen Störungen in Anspruch zu nehmen. Auch die bald nach der Apoplexie zum Vorschein gekommene Epilepsie, die dann bis zu dem im 40. Lebensjahre erfolgten Tode im ganzen unverändert fortbestanden zu haben scheint, wird dementsprechend als sekundär bedingt aufzufassen sein; als ihre Grundlage würde eben die grob-anatomische Gehirnläsion zu gelten haben. Wir stehen nach alledem nicht an, den Fall der 2. Gruppe der hereditär-syphilitischen Epilepsieformen

\footnotetext{
1) Vgl. u. a. Nonne, Syphilis u. Nervensystem S. 553.
} 
zuzuweisen und neigen zu der Annahme, daß der ganze Krankheitsprozeß durch eine spezifisch luetische Gefäßaffektion im Bereiche der linken Fossa Sylvii hervorgerufen worden ist. Jedenfalls dürfte dieser Auffassung der Pathogenese des Falles weder die Anamnese und die klinische Entwicklung des Leidens, noch der erhobene Sektionsbefund im Wege stehen. Ob freilich die Epilepsie selbst in ihrem Charakter durchaus der gewöhnlichen genuinen Epilepsie entsprochen hat, muß mangels eingehenderer Schilderungen des Verlaufes und der Begleiterscheinungen der einzelnen Insulte dahingestellt bleiben. Die schließlich eingetretene hochgradige Demenz ist zum Teil wohl auf die Apoplexie, zum Teil vielleicht auch auf die spätere Epilepsie zurückzuführen.

Für die folgenden zwei Fälle kommt ätiologisch wohl gleichfalls mehr oder minder ausschließlich eine hereditäre Lues in Frage; doch treten hier neben der Epilepsie noch andere cerebrale Phänomene hervor, die die Zuweisung derselben zu sog. postsyphilitischen Erkrankungsformen berechtigt erscheinen lassen dürften.

Fall V. Rolf J., geb. 16. IV. 1900. Vater, Kaufmann, war syphilitisch krank. Bei der Mutter und Schwester ließ sich positive Wassermannsche Reaktion im Blute nachweisen. Ein Bruder des Vaters litt an Epilepsie; in der Familie des Vaters befindet sich ein Somnambule. Der Kranke war schwächlich von Jugend auf, lernte erst mit $2^{1} / 2$ Jahren laufen, mußte wegen körperlicher Schwäche ein Jahr von der Schule zurückgestellt werden. Er war als Kind zunächst ruhig und still, spielte wie die anderen Kinder, kam aber in der Schule mit den anderen Schülern nicht fort. Die Zeit der Zahnung verlief ohne Besonderheiten. Im 3. Lebensjahre machte er einen heftigen Brechdurchfall, im 4. Lebensjahre Masern ohne besondere Störungen durch. Bevor die Epilepsie auftrat, fiel nur eine gewisse Schreckhaftigkeit sowie eine leichte Erregbarkeit an ihm auf, wenn Besuch kam. Im Frühjahr 1910 stellten sich zum ersten Male anfallsweise Zuckungen ein, welche von den Eltern für epileptische gehalten wurden und sie veranlaßten, den Kranken am 24. X. 1910 in der Irrenanstalt zu Dr. unterzubringen. Am 16. I. 1912 wurde er in die hiesige Anstalt überführt.

Der in Dr. und hier festgestellte Zustand war etwa folgender: Herz, Lungen, Bauchorgane zeigen keine Besonderheiten. Der Kranke ist schwächlich, blaß, anämisch, mittelgroß, regelmäßig entwickelt, sein Körpergewicht schwankte zwischen $25-30 \mathrm{~kg}$. Am Schädel finden sich keine Besonderheiten. Es bestehen $\mathrm{H}$ u tchins o nsche Zahnbildung, lichtstarre, etwas verzogene Pupillen, rechtseitige geringe Facialisschwäche, deutliche artikulatorische Sprachstörungen. Wegen adenoider Wucherungen in der Nase wurde er am 12. XI. 1910 operiert. Die Tonsillen sind etwas vergrößert. Die Sensibilität ist bei der vorgeschrittenen Demenz nicht zu prüfen, Sehnen- und Hautreflexe bieten Besonderheiten nicht dar. Herderscheinungen fehlen; auch sonst ist in korperlicher Hinsicht etwas wesentliches nicht nachzuweisen. Mehrfach angestellte Untersuchungen des Blutes auf Wasser. mannsche Reaktion waren positiv.

Die zur Beobachtung gelangten epileptischen Insulte äußerten sich stets in der gleichen Weise: Plötzlich treten ohne oder mit initialem Schrei Zuckungen der Extremitäten und des Kopfes auf, der Kranke verdreht die Augen, es besteht Bewußtlosigkeit, mitunter erfolgt Urinabgang. Schwere Anfälle mit heftigen, krampfartigen, beiderseits gleich stark ausgeprägten Zuckungen und tiefer Bewußtlosigkeit von 1-2 Minuten Dauer wechseln ab mit leichteren, weniger heftigen Zuckun- 
gen, auch mit kurzen sekundenlangen Bewußtseinstrübungen und Schwindeln ohne Zuckungen. Nach schwereren Anfällen ist der Kranke matt, abgeschlagen, schwer besinnlich, oft längere Zeit benommen; heftigere Erregungs- oder Verwirrtheitszustände gelangten darnach nicht zur Wahrnehmung. Die Insulte treten bald tags, bald nachts auf, immer spontan, meist vereinzelt und in unregelmäßigen Zwischenräumen, oft auch täglich oder in Gruppen; die längsten bisher beobachteten Zwischenpausen betrugen ca. 3 Wochen.

In der anfallsfreien Zeit erscheint der Kranke in hohem Grade schwachsinnig. Seine Schulkenntnisse sind äußerst gering, fast gleich Null. Nachhaltigere Interessen läßt er vermissen. Die Orientierung ist stark beeinträchtigt; über Vergangenes oder Gegenwärtiges vermag er in keiner Weise Bescheid zu geben. Er zeigt ein zappeliges, zerfahrenes Wesen, ist unaufmerksam, nicht zu fixieren. Seinem Wesen nach zeigt er sich freundlich, gutmütig, anhänglich, heiter und willig.

J. erhielt zunächst einige Tage Bromkalium ohne bemerkbaren Erfolg, darauf mehrere Wochen lang Jodnatrium; in dieser Zeit traten die Krampfanfälle seltener auf. Im Februar-März 1911 erhielt er 3 mal 0,3 Salvarsan intravenös. Die Injektion wurde ohne Störung vertragen; die Krampfanfälle traten im Änschluß daran seltener auf, wurden aber bald wieder häufiger. Anfang Mai 1911 wurde eine Schmierkur mit graver Salbe vorgenommen, 6 Touren à täglich 2,0. Anfang Juli erhielt J. wieder einige Zeit Bromsalz, dann ca. 8 Wochen Jodkali, schließlich wieder Bromkali; endlich wurde noch ein längerer erfolgloser Versuch mit Spasmosan unternommen. Eine günstige Beeinflussung des psychischen Zustandes wurde nie erreicht; die Zahl der Anfälle schien unter dem Einflusse irgendeiner neuen Therapie zuweilen zurückzugehen; doch war Zufall nie sicher auszuschließen. So wurden beispielsweise in der Zeit vom 26. I. 1911 bis zum 8. II. 1911, also innerhalb vierzehn Tagen, insgesamt 49 Insulte, in den ersten 14 Tagen des August 1911 hingegen nur 2, des Sptember 4, des Oktober 7, des November wiederum nur 2 Anfälle beobachtet. In der hiesigen Anstalt gelangten innerhalb der Zeit vom 16. I. 1912 bis Ende April 1913 insgesamt 200 Insulte zur Wahrnehmung, annähernd gleichviel bei Tage und nachts; $193 \mathrm{mal}$ handelte es sich um voll ausgeprägte, durchaus nach dem Typus bei gewöhnlicher Epilepsie verlaufende Paroxysmen, 7 mal um rudimentäre Insulte resp. um Schwindel; die Zahl der Anfälle wechselte innerhalb der einzelnen Monate zwischen 4-28, mehr als 2-4 Anfälle gelangten an einem Tage nie zur Auslösung; meist traten sie vereinzelt auf, oft mehrere Tage hintereinander, oft innerhalb ganz unregelmäßiger Zwischenräume; die größte anfallsfreie Zwischenpause betrug ca. 3 Wochen.

Geistig und körperlich ist ein zunehmender Verfall festzustellen; der allgemeine Kräftezustand hat in der letzten Zeit einen immer weitergehenden Rückgang erfahren, zumal da der Kranke mit der Nahrungsaufnahme gelegentlich Schwierigkeiten bereitet. Auf Sauberkeit und Reinlichkeit achtet er kaum noch und läßt daher jetzt noch öfter als früher Kot und Urin unter sich gehen. Er reagiert auf äußere Reize nur noch wenig, erkennt selbst seine Angehörigen nicht mehr und macht jetzt einen total dementen Eindruck. Doch sind weitere somatische Reizund Lähmungserscheinungen nicht deutlich hervorgetreten.

Auch in diesem Falle ist die Syphilis des Vaters anamnestisch sichergestellt, und der positive Ausfall der Wassermannschen Reaktion bei der Mutter, bei der Schwester und bei dem Kranken selbst scheint dafür zu sprechen, daß das syphilitische Virus auch auf die Mutter und die Nachkommenschaft übergegangen ist. Außer der kongenitalen Lues kommt ätiologisch hier nur noch indirekte erbliche Belastung von Vaters Seite her in Betracht. Ob bei dem Kranken selbst spezi- 
fische luetische Krankheitsprozesse vorgelegen haben, ist nicht erwiesen; denn die 1910 durch Operation entfernten adenoiden Wucherungen in der Nase brauchen nicht unbedingt spezifischen Ursprungs gewesen zu sein. In somatischer Hinsicht freilich liegen eine Reihe von Erscheinungen vor, die wohl ohne weiteres als hereditär-syphilitische Stigmata anzusehen sind: so die seit frühester Jugend bestehende allgemeine körperliche Schwäche, die Anämie, die Hutchinsonsche Zahnbildung usw. Die geistigen Kräfte und Fähigkeiten liegen, wie das gleichfalls bei hereditärer Lues nicht selten der Fall ist, schon seit früher Kindheit brach. Insulte von typisch epileptischem Gepräge stellten sich erst im 10. Lebensjahre ein, nachdem vorher bereits eine gewisse Schreckhaftigkeit und Erregbarkeit an dem Knaben aufgefallen war. Trotz ausgiebiger antisyphilitischer und antiepileptischer Kuren sind aber seitdem, also seit nunmehr drei Jahren, immer wieder solche konvulsionären Attacken in wechselnder Häufigkeit und Schwere hervorgetreten; jedenfalls kann von einer erfolgreichen Beeinflussung der Insulte durch die angewandten Heilverfahren bis jetzt nicht die Rede sein. Seit dem Auftreten der Insulte macht sich zugleich ein stetig zunehmender Verfall der Intelligenz bemerkbar, ja seit etwa einem Jahre ist dieser Verfall, der sich auch auf die somatische Sphäre erstreckt, rapid fortgeschritten. Für spezifische organische Gehirnprozesse liegen sichere Anhaltspunkte nicht vor; doch lassen die seitens des Nervensystems bestehenden Störungen (konvulsionäre Attacken von epileptischem Gepräge, artikulatorische Sprachstörungen, lichtstarre, etwas verzogene Pupillen, rechts vorhandene Facialisparese) in Verbindung mit dem schnell fortschreitenden körperlichen und geistigen Verfall des Kranken den Verdacht aufkommen, daß es sich hier nicht um eine in der gewöhnlichen Weise verlaufende Epilepsie, sondern um progressive Paralyse handelt. Eine absolut sichere Diagnose wird allerdings auf Grund der klinisch bis jetzt hervorgetretenen Krankheitszeichen allein nicht gestellt werden können, da die Störungen von seiten des Nervensystems auch als einfache Stigmata der hereditären Lues angesehen werden können und eine Demenz erheblicheren Grades von eventuell sogar progressivem Charakter sich auch bei gewöhnlicher Epilepsie einstellen oder sich ohne Epilepsie und Paralyse auch als Stigma einer auf hereditär-luetischer Grundlage erwachsenen eigentümlichen Gehirnveränderung bemerkbar machen kann.

Können im voranstehend geschilderten Falle noch Zweifel an der Zugehörigkeit desselben zur Gruppe der postsyphilitischen Erkrankungsformen entstehen, so sind solche Zweifel bei der folgenden Beobachtung im Hinblick auf die Ergebnisse der klinischen Feststellungen und der Autopsie nicht mehr möglich.

Fall VI. Minna Gl., geb. 14. XII. 1882. Der Großvater väterlicherseits 
soll jähzornig gewesen sein; die Eltern sind angeblich gesund. Ob Lues vorliegt, war nicht zu ermitteln; doch liegt der Verdacht um so näher, als mehrere Kinder bald nach der Geburt gestorben sind und nur eines, nämlich die Patientin, am Leben blieb. Im Jahre 1895 oder 1886 soll die Kranke einmal zwei Treppen hoch heruntergestürzt sein; sie war einige Stunden bewußtlos, erschien aber nachher wieder geistig normal. Im Alter von 7 Jahren überstand sie Scharlach ohne Nachteil für ihren sonstigen Gesundheitszustand. In der Schule blieb sie zurück; vom 10. Jahre an wurde sie zeitweise traurig gestimmt. Sie war stets gleichmäßig ruhig, kümmerte sich wenig um die andern, blieb als Kind immer gern für sich. Bis 1909 lebte sie stets bei ihren Eltern, ohne sich sehr zu betätigen; sie beschäftigte sich in ihren gesunden Tagen nur mit Stricken von Strümpfen und Polieren von Geigenbrettern. Die Menstruation blieb dauernd aus.

Die gegenwärtige Seelenstörung begann 1897, also im 15. Lebensjahre der Kranken. Die Krankheit setzte mit Krämpfen, Bewußtlosigkeit, Zuckungen in den Armen und Beinèn ein; doch ist nicht mit Sicherheit festzustellen gewesen, ob auch in der Folgezeit regelmäßig Krampfanfälle zur Auslösung gelangt sind. Bald nach dem Auftreten der ersten Krankheitserscheinungen beobachteten die Angehörigen weiter, daß die Kranke beim Gehen die Beine und Füße auffallend hoch hob, der Gang unsicher und sehr geschraubt und geziert wurde. Später wuṛden auch bei Armbewegungen und beim Gebrauch der Hände derartige "katatonische" Zeichen beobachtet. Die Stimmung war dabei eine niedergeschlagene, traurige. Die Kranke hörte auf zu sprechen. Später aß und trank sie nicht mehr freiwillig, lag viel im Bett, bekam ab und zu heftige Erregungszustände, schrie, warf alle erreichbaren Gegenstände um sich, so daß sie einige Male von den Angehörigen gebunden wurde. In den letzten Jahren stand sie fortwährend unter dem Einflusse schreckhafter Halluzinationen, so daß sie öfter aufschrie und Zeichen der Angst und Furcht an den Tag legte. In diesem Zustande bedurfte sie seit Jahren unausgesetzter Beaufsichtigung, zumal da die Erregungszustände immer häufiger und schwerer sich einstellten. Am 15. II. 1909 in der Anstalt U. untergebracht, gelangte eine größere Reihe von durchaus epileptischen Anfällen zur Beobachtung. Denselben ging gewöhnlich Unruhe und gereiztes Verhalten voran. Die Insulte bestanden in kurzem tonischen Krampfe und nachfolgenden klonischen Zuckungen unter Beteiligung der gesamten Körpermuskulatur in beiderseits gleich stark ausgeprägtem Maße. Gelegentlich erfolgte dabei Urinabgang und Zungenbiß. Hinterher war die Kranke längere Zeit benommen und schlafsüchtig und dabei rei $b$ bar und heftig. Sie sprach nur äußerst wenig; das artikulierte Sprechen bereitete ihr sichtlich große Schwierigkeiten. Im übrigen wird bemerkt, daß sie den Eindruck hochgradiger geistiger Beschränktheit machte und nur selten Fragen richtig beantwortete; Aufforderungen kam sie kaum noch nach. Die Sensibilität sei mit Sicherheit nicht zu prüfen; im übrigen biete sie die Zeichen juveniler Ataxie mit besonders hervortretender Atrophie der Rückenund Beckenmuskulatur dar, so daß sie nicht ohne Haltepunkt aufrecht sitzen könne. Die Stimmung sei eine vorwiegend gedrückte, zeitweise gereizte; gelegentlich exazerbiere sie zu tobsüchtigem Verhalten, wobei die Kranke laut schreie, um sich schlage und beiße.

Am 8. VII. 1909 wurde sie in der hiesigen Anstalt untergebracht. In körperlicher Hinsicht handelte es sich um eine $156 \mathrm{~cm}$ lange, im Körpergewicht sehr reduzierte, nur $39,5 \mathrm{~kg}$ schwere Kranke. Das Fettpolster war dürftig entwickelt, die Muskulatur an den oberen Extremitäten schlaff, an den unteren spastisch contracturiert. Der Kopf war mesocephal und symmetrisch geformt, das Gesicht länglich. Die gewöhnlich mittelweiten Pupillen reagierten gut bei Konvergenz, träge und wenig ausgiebig auf Lichteinfall. Die Augenbewegungen erschienen 
nach allen Richtungen hin ungestört. Auch in der Ruhe, besonders beim Blick nach der Seite, bestand sehr starker Nystagmus verticalis. Die Gesichtsmuskulatur fand sich gleichmäßig innerviert, nur etwas schlaff. Gehör- und Sehvermögen zeigten sich, soweit das bei der fortgeschrittenen Demenz der Kranken festzustellen war, nicht geschwächt. Die Zunge wurde auf Erfordern langsam über die Zahnreihe vorgeschoben und zeigte dann beträchtlichen Tremor. Auch die Lippen ließen oft schon in der Ruhe, viel markanter noch beim Sprechen, stark fibrilläre Zuckungen erkennen; sie breiteten sich in der Regel auf die angrenzenden Wangenpartien aus, schließlich, wenn die Kranke intendierte Bewegungen ausführen sollte oder wenn sie zum Nachdenken und zur Aufmerksamkeit aufgefordert wurde, ergriffen sie oft auch noch die Rumpfmuskulatur und die Muskulatur der Extremitäten: der ganze Muskelapparat geriet dann in ein konvulsivisches Zittern und Schütteln. Die Mundhöhle war sonst o. B. Der Thorax erschien schlank geformt, die unteren Brust- und die Lendenwirbel sprangen stärker nach hinten vor; es bestand im Gegensatz zur physiologischen Lendenlordose Kyphose mäßigen Grades. Die Herztöne waren rein, die Herzdämpfung normal gro $B$, der Puls etwas klein, aber regelmäßig und nicht beschleunigt. Der Leib war eingezogen, die Bauchmuskeln fanden sich für gewöhnlich bretthart gespannt. Ganz erhebliche Funktionsstörungen wiesen die unteren Extremitäten auf: es bestand eine hochgradige ataktisch-spastische Paraparese. Pat. vermochte nur mit Unterstützung von zwei Seiten zu gehen. Forderte man sie auf, still zu stehen und sich selbst aufrecht zu erhalten, so fiel sie sogleich um. Es bestand also hochgradig entwickeltes Rom. bergsches Phänomen und eine spinale Ataxie. Der Gang hatte gleichfalls ein spinal ataktisches Gepräge. Pat. hob die Beine hoch empor beim Gehen, setzte sie schleudernd und unsicher, mit den Fersen aufstampfend, nieder. Zu diesen Störungen, die mit ziemlicher Sicherheit auf eine Läsion der Hinterstränge des Rückenmarks schließen ließen, gesellten sich noch Störungen, die auf gleichzeitige Destruktion der Pyramiden-Seitenstrangbahnen hinzuweisen schienen. Die unteren Extremitäten zeigten nicht die für Tabes charakteristische Hypotonie der Muskeln und Gelenke, sondern befanden sich andauernd in einem stark spastisch-hypertonischen Zustande. Beim Liegen und Sitzen der Kranken im Bett wurden die Beine spastisch gestreckt gehalten. Bei passiven Flexionsversuchen im Kniegelenk hatte man einen beträchtlichen Muskelrigor zu überwinden. Auch konnte Fuß. klonus wiederholt nachgewiesen werden, mehrmals auch das Babinskische Phänomen. Die Untersuchung der Reflexe stieß auf die größten Schwierigkeiten, da es in der ersten Zeit überhaupt nicht gelang, die spastisch gestreckten Beine zur Erschlaffung zu bringen. Am 26. VII. gelang es jedoch, rechts bei völlig erschlafftem Beine mittelstarke Patellarsehnenreflexe zur Auslösung zu bringen; links freilich nur ganz undeutlich. Die Sensibilität, speziell die Schmerzempfindung war am ganzen Körper, ganz beträchtlich aber an den unteren Extremitäten, herabgesetzt. Die Sprache ließ ganz grobe artikulatorische Störungen mit fibrillären Zuckungen im Gesicht erkennen; gelegentlich traten auch Mitbewegungen in den Gliedmaßen hervor. Auch bestand hochgradiges Silbenstolpern bei Paradigmen: Artilleriebrigade $=$ „Tilleriebrade“" usw. Wie die unteren, zeigten auch die oberen Extremitäten Ataxie, die sich besonders bei Greifbewegungen nach vorgehaltenen Gegenständen offenbarte.

In psychischer Hinsicht erschien Pat. in hohem Grade abgeschwächt. Sio bot alle Zeichen einer weit vorgeschrittenen Demenz dar. Für gewöhnlich lag sie mit stumpfem, blödem Gesichtsausdruck in contracturierter Haltung im Bett. $\mathrm{Ab}$ und zu war sie ganz unzugänglich und geriet entweder spontan oder wenn man sich mit ihr beschäftigte, in einen heftigen elementaren Frregungszustand, in dem sie unartikulierte Laute ausstieß, mit den Füusten auf ihren Kopf und 
ihre Beine losschlug, aus dem Bett zu klettern versuchte, dabei aber vor dem Bett zusammenbrach. Zeitweise erschien Patientin auch freier und zugänglicher. Sie gab dann meist bereitwillig Auskunft, freute sich, wenn sie eine Frage einmal richtig beantwortet hatte, nahm auch etwas mehr Anteil an ihrer Umgebung. Doch zeigten sich die intellektuellen Fähigkeiten stets ganz erheblich reduziert. Patientin wußte nicht, wo sie sich befand, welche Jahreszahl man jetzt schrieb, kannte nicht ihr Alter, ihren Geburtstag, ihr Geburtsjahr, behauptete stets, $1^{1 / 2}$ Jahre aus der Schule zu sein; sie brauche nicht mehr in die Schule zu gehen, sei doch raus". Utber ihre Angehörigen machte sie ganz unzuverlässige Angaben; den Arzt erkannte sie bei der Visite meist wieder; das Pflegepersonal bezeichnete sie sachgemäß als „Schwestern“. Eine Prüfung komplizierterer assoziativer Leistungen verlief ganz resultatlos. Vorgehaltene Gegenstände wurden teils richtig, teils falsch benannt; die Schulkenntnisse waren dürftig und lückenhaft. Sie liest zweistellige Zahlen richtig, drei- und mehrstellige nur dann, wenn keine Nullen vorkommen: z. B. 1245 richtig, nicht aber 1000 , statt 606,660 ", statt $1010,110^{\prime \prime}$. Bej 12345 liest sie „1245", bei $12473,1273^{\star 4}$. Es bestanden also typisches Silbenstolpern und typische Elisionen, wie auch sonst beim Sprechen und Iesen. Druckschrift wurde nämlich höchst mangelhaft gelesen, längere Worte gar nicht; oft ließ sie Silben, Worte, Sätze aus, sprang in andere Zeilen über usw., ohne sich zu korrigieren. Die Merkfähigkeit war erheblich beeinträchtigt; größere Zahlen, zusammengesetzte Hauptworte vermochte sie nicht nachzusprechen. Auch typische Perseverationen kamen oft vor, indem sie vorher nachgesprochene Worte immer wiederholte, selbst wenn ihr ganz anders klingende Worte vorgesprochen wurden. Im Laufe der Zeit nahmen Stumpfheit und Apathie immer mehr zu, zwischendurch aber traten immer wieder freiere Intervalle oder hochgradigere psychische Erregungen ein.

Während der Beobachtungszeit in der hiesigen Anstalt gelangten insgesamt 35 Insulte zur Wahrnehmung, deren Verlauf sich in nichts von dem typischer epileptischer Anfälle unterschied. Immer handelte es sich um voll ausgeprägte allgemeine Krampfparoxysmen, 9 traten bei Tage, 26 nachts auf. Hinterher ließ die Kranke oft Kot und Urin unter sich gehen und war dann noch eine Zeitlang tief apathisch und benommen; besondere Lähmungserscheinungen, aphasische Störungen, Halbseitenphänomene usw. traten indessen nicht hervor.

Ende Februar 1910 machten sich Erscheinungen zunehmenden Verfalls bemerkbar. Gleichzeitig stellten sich Diarrhöen, Husten, flache Atmung, Dämpfung über beiden Lungenunterlappen, hohe Fiebertemperaturen bis gegen $40^{\circ} \mathrm{C}$ mit zeitweisen Remissionen usw. ein. Infolge heftigen Widerstrebens war eine genauere Untersuchung andauernd sehr erschwert. Am 21. III. 1910 nachmittags $73 / 4 \mathrm{Uhr}$, erfolgte schließlich nach langer Agone Exitus letalis.

Die am nächsten Morgen vorgenommene Sektion ergab in der Hauptsache folgendes: Das Körpergewicht war auf $281 / 2 \mathrm{~kg}$ gesunken; der Leichnam befand sich im Zustande hochgradiger Emaziation. Das Schädeldach bot auffällige krankhafte Veränderungen nicht dar. Nach Umschneidung der harten Hirnhaut floß reichlich seröse Flüssigkeit ab. Die weichen Häute fanden sich stellenweise verdickt und mäßig getrübt, namentlich nach vorn zu. Das Gehirn wog unzersehnitten 960 g. Die Basisgefäße waren zart. Die Ventrikel zeigten sich erweitert und reichlicher von seröser Flüssigkeit erfüllt; das Ependym war nicht deutlich gekörnt. Die Windungen erschienen namentlich im Stirnhirn beiderseits deutlich verschmälert und abgeplattet; die Sulci waren auffällig vertieft und klafften stark. Außerdem fanden sich noch: Hyperämie in allen Organen, Herz schlaff, keine bemerkenswerte Arteriosklerose, rechts Pleuritis adhaesiva, links eitrig fibrinöse Pleuritis, beiderseits Lungengangrän, besonders in den Unterlappen, in der Gallen-

7. f. d. g. Neur. u. Psych. O. XVII. 
blase einige kleine, erbsengroße Steine, am Coecum einige erbsengroße oberflächliche, mutmaßlich tuberkulöse Schleimhautgeschwüre, im übrigen Darmkanal stellenweise katarrhalische Schleimhautschwellungen.

Die mikroskopische Untersuchung beschränkte sich auf Stücke aus der linken und rechten mittleren Stirn-, aus der Mitte der rechten vorderen Zentral- und der Mitte der linken Schläfenwindung, sowie auf Querschnitte durch verschiedene Bezirke des Rückenmarks. Überall fanden sich die für progressive Paralyse und für kombinierte Strangdegenerationen charakteristischen Veränderungen. Im Vordergrunde standen durchgehends die degenerativen und atrophischen Prozesse der nervösen Elemente: die markhaltigen Nervenfasern und die Ganglienzellen der Großhirnrinde waren größtenteils degeneriert und dem Untergang verfallen; die Rindenarchitektonik war beträchtlich gestört; im Rückenmark erstreckten sich die Entartungen über die Hinterstränge und die Pyramidenbahnen wie gewöhnlich bei Paralyse. Das Stützgewebe fand sich mehr oder weniger gewuchert, ins. besondere bestand erhebliche Randverdickung der Glia. Auch die Gefäßwände waren zum Teil deutlich verdickt und infiltriert, zum Teil aber auch in unverkennbarer Rückbildung begriffen. Die Pia zeigte sich mit Plasmazellen und lymphocytären Elementen infiltriert; stellenweise fanden sich reichlich auch Mastzellen.

Mit einer gewissen Wahrscheinlichkeit darf auch bei diesem Krankheitsfall eine indirekte erbliche Belastung angenommen werden. Die familiäre Anamnese ist freilich unvollständig und läßt daher über etwaige nervöse und andere Krankheiten der Eltern und Geschwister im unklaren. Dem im 3. oder 4. Lebensjahre erlittenen Unfall wird eine maßgebende ätiologische Bedeutung kaum beigemessen werden können, ebensowenig der im 7. Lebensjahre aufgetretenen Scarlatina; auch sonst sind schädigende Momente nicht nachgewiesen worden. Selbst über Lues der Erzeuger verlautet nichts, obwohl durch die Polymortalität der Geschwister und durch die Art der bei dem einzig überlebenden Kinde, eben der Kranken, aufgetretenen Krankheitserscheinungen die Annahme einer Lues congenita nahegelegt wurde; für Lues acquisita waren Anhaltspunkte um so weniger gegeben, als die seit Jahren schwer leidende Kranke bis zu ihrer Unterbringung in der Irrenanstalt stets im elterlichen Hause verblieben war. Residuen einer überstandenen Lues waren nicht vorhanden; die Kranke erschien nur körperlich sehr heruntergekommen und elend. In ihrer geistigen Entwicklung war sie offenbar von Jugend auf zurückgeblieben. Schon seit dem 10. Lebensjahre machten sich gelegentlich unmotivierte Stimmungsschwankungen bemerkbar; aber erst im 15. Lebensjahre stellten sich konvulsionäre Attacken vom Typus der gewöhnlichen genuinen Epilepsie ein. Bald darnach traten in ausgesprochenem Maße allerhand Störungen in der psychischen und somatischen Sphäre hervor; namentlich machten sich neben auffälligen Gehstörungen immer häufigere und schwerere Stimmungsanomalien, oft auch Angstanfälle oder halluzinatorische Verwirrtheits- und Erregungszustände mehr oder minder heftiger Art $u$. dgl. m. bemerkbar. In welcher Weise sich die Krankheit im Verlaufe der nächsten Jahre weiter entwickelte, ist im einzelnen 
freilich nicht klargestellt; insbesondere ist darüber Genaueres nicht bekannt geworden, ob konvulsionäre Attacken auch in der Folgezeit regelmäßig wiederkehrten; seit der Unterbringung in der Anstalt, die aber erst im 27. Lebensjahre erfolgte, gelangten jedenfalls andauernd wieder Krampfparoxysmen zur Wahrnehmung. Im ganzen scheint die Krankheit seit dem 15. Lebensjahre, von vorübergehenden Stillständen abgesehen, eine fortschreitende Verschlimmerung erfahren zu haben.

Daß bei dieser Kranken nicht nur eine gewöhnliche Epilepsie, sondern ein schweres progressives Leiden vorlag, das das ganze Zentralnervensystem in Mitleidenschaft gezogen hatte, konnte nach dem ganzen Verlaufe und nach dem Ergebnisse der klinischen Feststellungen von vornherein einem Zweifel kaum begegnen. Von den festgestellten Krankheitserscheinungen kamen für die Diagnose in Betracht: die konvulsionären Attacken, die psychischen Störungen, die vorgeschrittene Demenz, die schweren artikulatorischen Sprachstörungen, das Silbenstolpern, der Tremor linguae et labiorum, der Nystagmus, die träge Pupillenreaktion, die Ataxie der oberen Extremitäten, die sich besonders deutlich bei Greifbewegungen nach vorgehaltenen Gegenständen offenbarte, die statische und lokomotorische Ataxie, die sich in dem typisch spinal-ataktischen Gange und in der Unfähigkeit, sich von selbst aufrecht zu erhalten, kundgab, die spastische Paraparese der unteren Extremitäten, die Hypalgie, der Fußklonus und das Babinskische Phänomen. Das Krankheitsbild setzte sich darnach nicht nur aus cerebralen und psychischen Erscheinungen, sondern auch aus Rückenmarkssymptomen zusammen. Von seiten des Rückenmarks schien eine Affektion mehrerer Strangsysteme vorzuliegen, und zwar: 1. der Hinterstränge, 2. der Pyramiden-Seitenstränge, 3. im Hinblick auf die statische Ataxie mutmaßlich auch der Kleinhirnseitenstränge. Als Rückenmarksleiden kam daher eine spastisch-ataktische Paraplegie, bzw. eine kombinierte Strangdegeneration in Frage. Die cerebralen und psychischen Erscheinungen wiesen aber zugleich auf ein fortschreitendes Hirnleiden, nämlich auf die progressive Paralyse hin, insbesondere die vorgeschrittene Demenz, die träge Pupillenreaktion, das Silbenstolpern, die fibrillären Zuckungen an Zunge und Lippen. Die Frage lag nahe, ob der Hirn- und Rückenmarksprozeß etwa eine klinische Einheit darstellte. Differential-diagnostisch kamen vor allem spezifisch luetische Affektionen, eine kombinierte Systemerkrankung, eine hereditäre Ataxie im Sinne der Friedreichschen Krankheit, die multiple Sklerose, die diffuse Hirnsklerose, die Dementia paralytica und deren Kombination mit anderen Krankheitsprozessen in Frage. Für spezifische luetische Veränderungen lagen ausreichende Anhaltspunkte weder klinisch noch anamnestisch vor, die familiäre Anamnese versagte, eine kombinierte Systemerkrankung allein war angesichts der sonst 
noch bestehenden cerebralen und psychischen Störungen wenig wahrscheinlich; so konnte die Diagnose immer mehr eingeengt werden. Bei multipler Sklerose können die erwähnten Krankheitserscheinungen wohl mit wenigen Ausnahmen zur Wahrnehmung gelangen, so z. B. eine kombinierte Strangsklerose, Nystagmus usw.; wie aber Oppenheim, Redlich, Schlesinger u. a. bemerken ${ }^{1}$, kommen Silbenstolpern, Zittern und Beben der Lippen, früh einsetzende und rasch fortschreitende Demenz der multiplen Sklerose im allgemeinen nicht zu, wohl aber der progressiven Paralyse. Auch die von Westphal geschilderte und später namentlich von Strümpell und v. FranklHochwart studierte Pseudosklerose, sowie die echte diffuse Hirnsklerose kann, wie einschlägige Beobachtungen von Strü m pell, He u bner u. a. erkennen lassen, ein der Dementia paralytica ähnliches Krankheitsbild hervorrufen und mit allmählich zunehmender spastischer Paraparese der Beine einhergehen ${ }^{2}$ ). Schließlich mußte auch noch die Möglichkeit einer Mischform, einer Kombination der multiplen Sklerose mit der Dementia paralytica ins Auge gefaßt werden, wie sie z. B. Tigges, Claus, Fürstner u. a. beschrieben haben und Siemerling auch anatomisch wahrscheinlich $\mathrm{zu}$ machen versucht hat $\left.{ }^{3}\right)$. Am allerungezwungensten ließen sich alle hervorgetretenen Krankheitserscheinungen, wie von vornherein feststand, jedenfalls durch die Annahme einer mit kombinierter Strangsklerose einhergehenden progressiven Paralyse erklären. Nystagmus tritt bei Paralyse zwar nur selten auf ${ }^{4}$ ), zeigt aber gelegentlich ganz den gleichen Charakter wie bei multipler Sklerose. Im übrigen verbindet sich die progressive Paralyse bekanntlich häufig mit der kombinierten Strangsklerose und waren die klinisch hervorgetretenen Symptome aus einer solchen Annahme heraus dann jedenfalls leicht zu verstehen; speziell die konvulsionären Attacken stellten in diesem Falle eben nur paralytische Insulte in Form totaler epileptiformer Krämpfe dar, wie sie ja bei progressiver Paralyse gleichfalls vorkommen können, wenn auch freilich Krämpfe in Form apoplektiformer Insulte und konvulsionärer Zustände von corticalem Typus hier häufiger aufzutreten pflegen. Die schließlich erhobenen makro- und mikroskopischen Befunde brachten denn auch die anatomische Bestätigung für diese Auffassung des ganzen Krankheits-

1) Vgl. u. a. Oppenheim, Lehrb. d. Nervenkrankheiten, 4. Aufl. 1905, S. 356; Redlich, Uber multiple Sklerose, Dtsch. Klinik 6, 1906, Abt. I, S. 557ff.; ebendarüber Schlesinger in Cursch manns Lehrb. d. Nervenkrankheiten 1909, S. 307, O. Marburg in Lewandowskys Handb. d. Neurol. 2, 1911, S. $934 \mathrm{ff.}$ usw.

$\left.{ }^{2}\right)$ Vgl. u. a. Oppenheim, l. c. S. 359 .

3) Vgl. Oppenheim, 1. c. S. 356 und S. 982.

4) Vgl. z. B. Ziehen, Psychiatrie, 3. Aufl. 1908, S. 674. 
bildes. Die Dauer der Krankheit betrug, wenn man den Beginn derselben ins 15. Lebensjahr setzt, bis zum Tode ca. 13 Jahre.

Kam in den bisher geschilderten Krankheitsfällen ätiologisch vor allem eine hereditäre Syphilis in Frage, so dürfte für alle nachstehend noch mitgeteilten Fälle mehr oder minder ausschließlich eine akquirierte Lues als bestimmend wirkender Faktor in Anspruch zu nehmen sein. Freilich war bei Fall VII im Hinblick auf die Anamnese der Verdacht nicht ganz zurückzuweisen, daß durch die Abstammung bereits eine entsprechende cerebrale Disposition zustande gekommen war und die spätere syphilitische Infektion nur noch als direkt auslösendes Moment in Wirksamkeit getreten ist; ja manches in der Anamnese scheint sogar die Annahme nahezulegen, daß hier eine Lues der Erzeuger als solches keimschädigendes Moment mit in Frage kommen könnte. Im Hinblick auf diese Möglichkeit - ein sicherer Beweis dafür war nicht zu erlangen - wurde diese Krankengeschichte gewissermaßen als Utbergangsfall denn auch an die Spitze der nachfolgenden kasuistischen Beiträge gestellt; da es im übrigen aber einem Zweifel kaum unterliegen kann, daß auch hier das ausschlaggebende Moment schließlich die spätere syphilitische Durchseuchung gebildet hat, so wurde der Fall ohne weitere Bedenken der Gruppe der auf dem Boden einer akquirierten Syphilis entstehenden Epilepsieformen angegliedert.

Wie wir nun oben ausführten, bilden die Grundlage für die Annahme einer syphilitisch-epileptischen Neurose im Sinne Fourniers und Férés Fälle, in denen die Syphilis stimulierend auf die Auslösung von Anfällen wirkte, resp. eine bestehende Epilepsie durch die luetische Infektion gesteigert oder neu hervorgerufen wurde ${ }^{1}$ ). Einen ganz ,,reinen“" Fall dieser Art vermochten wir unter dem hiesigen Material leider nicht aufzufinden; doch verfügen wir über zwei Beobachtungen (Fall $\mathrm{X}$ und $\mathrm{XI}$ ), in denen die Akquirierung der Syphilis zur Entwicklung einer Psychose bei bereits epileptisch gewesenen Kranken geführt zu haben scheint, während in zwei weiteren Fällen (XII und XIII) die deletäre Weiterentwicklung des Krankheitsprozesses wenigstens mit einer gewissen Wahrscheinlichkeit darauf zurückzuführen sein dürfte. Eben dieser Psychosen wegen, durch die sich das Krankheitsbild hier kompliziert zeigte, sollen diese Fälle jedoch erst an späterer Stelle und in anderem Zusammenhange analysiert werden und hier zunächst nur solche Fälle mitgeteilt werden, in denen die Epilepsie erst nach erfolgter syphilitischer Infektion zum Vorschein gelangte und während einer längeren Beobachtungszeit im wesentlichen immer den gleichen Verlauf und Charakter bewahrte. Nonne.

1) Vgl. S. 525 die erwähnten Fälle von Fournier, Féré, Binswanger und 
Fall VII. Auguste B., geb. 24. IX. 1875, wuchs in ärmlichen, aber geordneten Verhältnissen auf. Beide Eltern sind vor kurzem gestorben; die Mutter litt viel an „Reißen“, der Vater soll sich in den letzten Jahren mehr und mehr dem Trunke ergeben haben und wird als „geistig etwas schwerfällig“" bezeichnet. Von 10 Kindern sind 8 tot; einige wurden tot geboren, einige starben bald nach der Geburt; nur eine Schwester der Kranken lebt, soll aber augenleidend sein. Ob Syphilis in Frage kommt, ist nicht sichergestellt.

Die Kranke ist das drittletztgeborene Kind. Schon während der ersten Zahnung soll es leichte, nicht näher beschriebene „Krämpfe“ gezeigt haben, die sich aber bald wieder verloren; im übrigen entwickelte es sich kräftig und regelmäßig und überstand Diphtheritis, Masern und Gelenkrheumatismus ohne nachteilige Folgen für ihren sonstigen Gesundheitszustand. In der Schule lernte es schwer und machte nur mäßige Fortschritte. 1895 verheiratete sich die bis dahin angeblich stets gesund gewesene Kranke und wurde, wie erwiesen ist, durch ihren Ehemann syphilitisch infiziert. Ob sie freilich schwerere spezifische Krankheitserscheinungen dargeboten hat, ist nicht bekannt; sie selbst berichtet nur, während ihrer zweiten Schwangerschaft an allgemeinem Hautausschlag gelitten zu haben. Eine antiluetische Behandlung hat früher nicht stattgefunden. Im ganzen hat sie sechs Schwangerschaften und Geburten durchgemacht. Das erste Kind wurde totfaul geboren, das zweite lebte 10 Tage, das dritte etwa $1 / 2 \mathrm{Jahr}$, die drei folgenden blieben nur wenige Wochen am Leben. 1905 wurde sie von ihrem Manne, der nach Amerika auswanderte, verlassen.

Von sonst etwa zur Wirksamkeit gelangten schädigenden Einflüssen verlautet nichts. Die ersten Erscheinungen von Epilepsie stellten sich im 4. Monat der dritten Schwangerschaft, etwa seit Anfang 1898, ein. Schon vorher hatte sich oft periodisch wiederkehrender heftiger Kopfschmerz in beiden Schläfengegenden geltend gemacht. Die anfangs aufgetretenen Krampfanfälle sollen meist leicht gewesen sein; allmählich erfuhren sie nach Heftigkeit und Häufigkeit eine Steigerung. Große, voll ausgeprägte Insulte wechselten ab mit leichteren rudimentären Attacken. Immer handelte es sich um Insulte vom Charakter der gewöhnlichen genuinen Epilepsie; corticale Reizerscheinungen, Halbseitenstörungen usw. fehlten; nur klagte sie in der ersten Zeit oft auch in den intraparoxysmellen Intervallen über heftige Kopfschmerzen in beiden Schläfengegenden; später verloren sich dieselben; die Kranke erschien dann in der $Z$ wischenzeit körperlich und geistig völlig gesund.

Am 6. IX. 1899 wurde sie zum ersten Male der Anstalt zugeführt, aber bereits am 9. XII. 1899 wieder entlassen. Vor der Unterbringung soll sie etwa alle zwei Tage, mitunter aber auch 'täglich von mehr oder minder schweren epileptischen Insulten befallen worden sein, gelegentlich 4-5mal am gleichen Tage; meist freilich stellten sich nur vereinzelt ohne besondere äußere Veranlassung Anfälle ein. Eine methodische Behandlung hatte bis dahin nicht stattgefunden. Während des etwa 13wöchigen Aufenthalts der Kranken in der hiesigen Anstalt gelangten trotz täglich $6,0 \mathrm{~g} \mathrm{BrNa}$ insgesamt 26 Insulte zur Wahrnehmung, 24 bei Tage, 2 nachts; ihr Verlauf war meist ein leichter. Schweren Anfällen pflegten Aurasymptome in Gestalt von Angst-, Schmerz- und Hitzeempfindungen in der Magengegend vorauszugehen; dann folgte ein initialer Schrei, die Kranke stürzte bewußtlos nieder, hatte während etwa 2 Minuten tonisch-klonische, beiderseits gleichstark ausgeprägte Krämpfe, zog sich dabei gelegentlich Zungenbisse und andere kleine Verletzungen zu, verharrte dann noch einige Zeit - meist nicht sehr lange in bewußtlosem Zustande oder blieb eine Zeitlang traumhaft benommen und erwachte schließlich ohne alle Erinnerung an das Vorgefallene. Bei den leichteren Attacken handelte és sich oft nur um Schwindelanfälle, vorübergehende Bewußt. seinstrübungen mit kurzen flüchtigen Zuckungen, Augenverdrehungen usw. Auf 
materielle Gehirnveränderungen hindeutende Krankheitszeichen waren nie zu bemerken. Somatisch bestand damals absolutes Wohlbefinden. Geistig erschien die Kranke bis auf eine gewisse intellektuelle Abschwächung in den intraparoxysmellen Intervallen völlig normal. Interkurrente psychische Störungen lagen nicht vor.

In den nächsten Jahren nahm die Epilepsie eine immer schwerere Form an, obwohl besondere Schädlichkeiten nicht zur Einwirkung gelangten. Die inzwischen noch eingetretenen Schwangerschaften übten auf die Epilepsie weder einen steigernden, noch einen abschwächenden Einfluß aus. Seit 1905 stellten sich im Anschluß an die Krampfanfälle mitunter psychische Erregungszustände mit Unruhe, Zerfahrenheit, Verwirrrtheit usw. ein, die bis zu 14 Tagen anhielten. Am 19. III. 1908 wurde die Kranke zum zweiten Male der Anstalt zugeführt. Von etwa in der Zwischenzeit aufgetretenen luetischen Affektionen ist nichts bekannt; eine methodische Behandlung der Epilepsie hatte nicht mehr stattgefunden.

Körperlich handelt es sich um eine kräftige, anscheinend durchaus gesunde Frau, ohne alle Störungen seitens der inneren Organe. Das Körpergewicht schwankt zwischen $54-67 \mathrm{~kg}$; die Körperlänge beträgt $161 \mathrm{~cm}$. Auffällige Degenerationszeichen fehlen. Der Schädel ist mesocephal, symmetrisch entwickelt, sein Umfang beträgt $53 \mathrm{~cm}$, die Stirn ist auffällig schmal. Störungen der Motilität, der Sensibilität, der Reflexerregbarkeit usw. sind nicht nachzuweisen, Sprache und Schrift sind ungestört, beide Pupillen sind gleich, mittelweit und reagieren prompt auf Lichteinfall und Akkommodation. Auch sonst sind auf ein organisches Leiden hindeutende körperliche Störungen in keiner Weise festzustellen; speziell fehlen alle auf spezifisch luetische Affektionen hindeutenden oder als Residuen einer früheren Lues anzusprechenden Stigmata. Die einzigen Störungen bestehen in: unregelmäßig wiederkehrenden Menses, oft sich geltend machender Obstipation, leichtem vasomotorischen Nachröten und oberflächlichen, seichten Narben an beiden Zungenrändern. Wiederholt vorgenommene Wassermannsche Reaktionen fielen stets positiv aus.

Vom 19. III. 1908 bis Ende April 1913 wurden insgesamt 1754 epileptische Insulte registriert; 1566 davon ereigneten sich bei Tage, nur 188 nachts. Die Zahl der in einem Monat zur Auslösung gelangten Insulte schwankte zwischen 14 und 46, durchschnittlich gelangten in jedem Monat etwa 28 Anfälle zur Wahrnehmung. Nur selten sehiebt sich zwischen 2 Anfälle ein freies Intervall von 5 bis höchstens 8 Tagen ein. Mehr als 8 Paroxysmen an einem Tage gelangten hier bis jetzt nie zur Wahrnehmung; meist ereigneten sich an einem Tage nur 1-2 Paroxysmen. Nur relativ selten kommen schwere Anfälle vor; in der Hauptsache handelt es sich um leichtere Attacken; von den registrierten 1754 Insulten blieben 1435 rudimentär, 319 waren voll ausgeprägt. Im übrigen hat sich nach Charakter und Verlauf derselben gegen früher eine bemerkenswerte Veränderung nicht vollzogen; die großen wie die kleinen Attacken gleichen in jeder Hinsicht denen der gewöhnlichen Epilepsie. Nur psychisch erscheint die Kranke jetzt in stärkerem Maße geschädigt als früher. Im unmittelbaren Anschluß an die Insulte zeigt sie sich oft verstimmt oder erregt, oft gereizt, aufbrausend, ausfällig, zu Schimpfreden und Streitereien geneigt, oft auch erotisch und sehr aufdringlich. Mitunter macht sich ein hypomanischer Zustand bemerkbar: die Kranke ist dann heiter erregt, sehr schwatzhaft und beweglich, mehr oder minder zerfahren, nicht selten geradezu verwirrt. Sinnestäuschungen oder Wahnideen wurden nie konstatiert. Solche stärkeren psychischen Alterationen halten meist nur wenige Tage an und erstreckten sich bis jetzt nie über eine Dauer von 2 Wochen hinaus; besonders auffällig treten sie hervor, wenn einmal große, voll ausgeprägte Anfälle während eines längeren Zeitraums ganz ausgeblieben sind. Kommt die psychische Alteration durch einen oder mehrere schwere Insulte zur Lösung, so erscheint die Kranke zunächst normal: 
sie zeigt sich ruhig, freundlich, geordnet und zufrieden und gibt durch ihr äußeres Gebahren und Verhalten zu Klagen keinen Anlaß. Unterwirft man jedoch ihr Wissen und Können einer eingehenderen Prüfung, so bemerkt man bald einen ziemlichen Tiefstand ihrer intellektuellen Kräfte und Fähigkeiten und ihres geistigen Besitzes; ihr Vorstellungskreis ist eng begrenzt, ihr Denken verlangsamt und schwerfällig, ihr Interesse abgestumpft.

Kombinierte Jodkali- und Bromnatriumkuren erwiesen sich bis jetzt völlig erfolglos; doch läßt sich die Abschwächung der epileptischen Insulte vielleicht als eine Wirkung der fortgesetzten $\mathrm{BrNa}$-Therapie betrachten.

Fall VIII. Ida L., geb. 27. I. 1851, erblich nicht belastet; die Eltern waren angeblich ganz gesund, ebenso vier ältere Geschwister und eine jüngere Schwester. Bis nach dem 15. Lebensjahre befand sich die Kranke im Elternhause, dann war sie als Näherin tätig. Potus wird negiert, im übrigen aber scheint sie sehr unsolid gelebt zu haben; einige Jahre stand sie unter sittenpolizeilicher Aufsicht, 1885 wurde sie für 6 Monate in einer Arbeitsanstalt untergebracht. Geburten hat sie nicht durchgemacht. Im 18. Lebensjahre erkrankte sie an Lues und stand von 1869 bis 1887 achtmal im Krankenhause zu Dr. in Behandlung, teils wegen Geschlechtskrankheiten (Geschwüre an den Genitalien und im Rachen, Fluor albus usw.), teils wegen Krampfanfällen, teils wegen oft rezidivierender Rhinitis und Otitis media. Vor dem Auftreten der venerischen Erkrankungen will sie stets ganz gesund gewesen sein.

Epilepsie besteht seit dem 22. Lebensjahre. Sie äußerte sich damals in folgender Weise: Gewöhnlich traten 2-3 Tage vor Eintritt der Menses allgemeine tonischklonische Krämpfe mit totalem Bewußtseinsverlust auf; während derselben kam es oft zu Verletzungen und Zungenbissen; hinterher bestand Amnesie für die Zeit des Anfalls. Später wurde gelegentlich auch Petit mal und isolierter Kinnbackenkrampf ohne Bewußtseinsverlust beobachtet. In der anfallsfreien Zeit erschien die Kranke harmlos, klar, geordnet, ruhig, fleißig mit Handarbeiten beschäftigt. Nach epileptischen Anfällen war sie meist sehr gereizt und empfindlich; die geringfügigste Kleinigkeit versetzte sie dann in höchste Erregung, so daß sie alle Selbstbeherrschung verlor, sich in wüstesten Schimpf-, Schmäh- und Drohreden erging und oft kaum zu beruhigen war; einige Male unternahm sie dabei Strangulationsversuche, um, wie sie später angab, "das Personal zu erschrecken".

Am 13. II. 1894 - nach vollendetem 43. Lebensjahre und etwa 21 Jahre langem Bestehen der Epilepsie - hier untergebracht, bot sie bis heute ein im ganzen sich stets gleichbleibendes Krankheitsbild dar.

Somatisch handelt es sich um eine mittelgroße, gutgenährte, zurzeit $60 \mathrm{~kg}$ schwere, früher auffällig blasse, jetzt kaum noch anämische Person. Wesentliche Entartungszeichen sind nicht vorhanden. An der linken Seite des Schädels, an der Grenze von Schläfen- und Seitenwandbein, 2 Finger breit über der Höhe der Ohrmuschel, findet sich eine $4-5 \mathrm{~cm}$ lange, $1 \frac{1}{2} \mathrm{~cm}$ breite Knochenverdickung, welche ihrer Angabe nach von einem in den ersten Lebenswochen erlittenen Sturze herrührt. Am rechten hinteren Gaumenbogen, in der Nähe des Zäpfehens, bemerkt man ein bohnengroßes Loch, dessen glatte Ränder weder gewulstet noch gerötet sind, am rechten vorderen Gaumenbogen eine etwa pfenniggroße Narbe. Die Tonsillen sind leicht geschwellt. Die Sprache ist infolge des Gaumendefekts und infolge Residuen der früheren, mutmaßlich syphilitischen Rhinitis näselnd, sonst aber ohne Störung. Motilitäts-, Sensibilitäts-, Schreibstörungen usw. sind nicht vorhanden, ebensowenig Contracturen oder Lähmungen $u$. dgl. m. Früher bestand eine Zeitlang Otorrhöe, jetzt ist sie schon seit geraumer Zeit schwerhörig. Die Pupillen sind mittelweit, rund und reagieren prompt auf Lichteinfall und Akkommodation; der Augenhintergrund ist normal; die Sehschärfe ist infolge Myopie 
etwas herabgesetzt. Die Patellarreflexe gelangen beiderseits normal stark zur Auslösung. Deutliche hysterische Stigmata werden vermißt. Der Urin ist eiweißund zuckerfrei. An den inneren Organen sind bemerkenswerte krankhafte Befunde nicht $z u$ erheben. Die Wassermannsche Reaktion ist positiv. In der Anstalt wurden luetische Rezidive bis jetzt nicht wahrgenommen; sie litt hier nur vorübergehend einmal an nicht spezifischer Angina und Bronchitis, im übrigen erschien sie körperlich stets gesund. Seit etwa 1896 befindet sie sich im Klimakterium. In der letzten Zeit klagte sie wiederholt über Reißen in den Beinen, ohne daß positive objektive Befunde zu erheben gewesen wären. Wiederholte Jodkalikuren blieben ohne jeden Einfluß auf die Epilepsie; ebensowenig Erfolg brachte die Behandlung mit BrKa und BrNa in Dosen von 1,0-3,0 g täglich.

Ganz im Anfange sollen Krampfanfälle seltener aufgetreten sein, dann stellten sie sich allmählich häufiger und wohl auch in schwererer Form ein; seit etwa dem 30. Lebensjahre ist eine bemerkenswerte Veränderung im Verlaufe und Charakter der Epilepsie nicht mehr zu beobachten gewesen. Der Eintritt der Anfälle erfolgt stets plötzlich, ohne alle Vorboten, der Typus entspricht stets dem bei gewöhnlicher genuiner Epilepsie: allgemeine tonisch-klonische Krämpfe, beiderseits gleich stark ausgeprägt, dabei immer völlige Bewußtlosigkeit, oft kleine Verletzungen, Zungenbiß, Enuresis, stets Amnesie. Nur einmal - im Juli 1896 traten kurz hintereinander 18 solche Anfälle auf, sonst gelangten nie mehr als höchstens 7-10 Anfälle in einem Monat, meist noch weniger, zur Auslösung. In der Regel kehren die Insulte alle drei bis vier Wochen wieder. Gelegentlich wird auch Petit mal in Form kurzdauernder Schwindel mit vorübergehender Bewußtseinstrübung und tonischer Muskelanspannung beobachtet. Nach psychischen Erregungen treten gelegentlich auch hysterische oder simulierte Anfälle von epileptoidem Typus auf. Nie bestanden Halbseitenerscheinungen oder corticale motorische Reizphänomene; zwischen die echten epileptischen Anfälle schieben sich stets völlig freie Intervalle ein. Nie bestand nach Ablauf der Anfälle Erbrechen u. dgl. m.; nur über Kopfschmerzen klagt die Kranke nicht selten im unmittelbaren Anschluß an die Insulte, sonst nie. Insgesamt wurden hier bis Ende April 1913559 Paroxysmen wahrgenommen, 427 bei Tage, 132 nachts; 402 mal handelte es sich um voll ausgeprägte, $157 \mathrm{mal}$ um rudimentäre Attacken. Die längste anfallsfrei verlaufene Zwischenpause betrug 12 Wochen.

Vor und nach den Anfällen erscheint die Kranke nicht selten gereizt, heftig, und jähen Stimmungsschwankungen unterworfen, mitunter auch argwöhnisch und mißtrauisch oder beängstigt; nur ab und zu einmal machte sich bis zur Dauer von 8 Tagen geistige Zerfahrenheit und Unklarheit geltend; Sinnestäuschungen und Wahnideen wurden nie festgestellt. Sonst zeigt sich die Kranke in den anfallsfreien Zwischenzeiten stets durchaus klar, geordnet und besonnen; Zeichen geistiger Abstumpfung machen sich bis jetzt kaum bemerkbar. Das Erinnerungsund Urteilsvermögen hat nicht auffällig gelitten, ebensowenig die Merkfähigkeit, die zeitliche Orientierung über die Ereignisso der Vergangenheit, die Kombinationsfähigkeit usw.

Fall IX. Sophie F., geb. 4. I. 1859, wuchs in auskömmlichen und geordneten Verhältnissen auf. Eltern und Geschwister sind angeblich frei von Krämpfen; auch sonst soll erbliche Belastung nicht vorliegen. Als Kind entwickelte sich die Kranke kräftig und regelmäßig; sie war gut beanlagt, lernte leicht und gut. Seit dem 15. Lebensjahre menstruiert, bot sie früher weder Krämpfe noch andere Krankheitserscheinungen dar und blieb bis zu ihrer Verheiratung im Jahre 1884 angeblich auch stets gesund. Dann litt sie infolge des geringen Verdienstes ihres Mannes mitunter direkte Not. Von ihr selbst wird Lues negiert; doch werden zwei Fehlgeburten zugegeben; ausgetragene lebende Kinder hat sie nicht gehabt. 
Erst 1901 wurde vom Bruder der Kranken in Erfahrung gebracht, daß ihr Gatte an Lues gelitten hat. Alkoholismus liegt nicht vor, wenn sie auch gelegentlich Bier oder Wein getrunken hat.

Der erste typische epileptische Anfall gelangte im 36. Lebensjahre bei der Kranken zur Auslösung. Seit dem 1. VII. 1896 befand sie sich in neurologischpsychiatrischer Beobachtung und Behandlung; am 30. X. 1896 wurde sie in der hiesigen Anstalt untergebracht.

Somatisch handelte es sich um eine mittelgroße, kräftig entwickelte, rüstige, gut genährte Frau. Nervöse Reiz- und Lähmungserscheinungen fehlten; die Pupillen waren mittelweit, beiderseits gleich und reagierten prompt auf Lichteinfall und Akkommodation. Die Ohren waren etwas asymmetrisch entwickelt, die Ohrläppchen angewachsen, die unteren Schneide- und Eckzähne leicht abgeschliffen. An der Unterlippe in der Mittellinie fand sich eine kreuzförmige Narbe, einige kleinere strahlige Narben waren am linken Mundwinkel zu bemerken; sonst waren auf Lues verdächtige Erscheinungen nicht wahrzunehmen. Im übrigen wurden bemerkenswerte krankhafte Befunde auf körperlichem Gebiete nicht erhoben. Das Körpergewicht hob sich von $71,5 \mathrm{~kg}$ bei der Zuführung auf $90,5 \mathrm{~kg}$ bei der Entlassung.

Im Dezember 1898 überstand die Kranke eine Pleuropneumonie. Im März 1899 stellten sich zum ersten Male verdächtige Anschwellungen des linken Fuß. gelenks und Auftreibungen am linken und rechten Schienbein ein. Sie erhielt von dieser Zeit ab außer täglich $3,0 \mathrm{~g} \mathrm{BrNa}$ noch Jodkalilösung. 1901 wurden wiederholt Klagen über Halsschmerzen, Beschwerden beim Schlucken, Kopfschmerzen und allgemeine Schmerzen geäußert, an der Unterlippe und in der Nase traten gummöse Geschwüre auf. Es wurden nun bis 1903 bald gründliche Quecksilber-, bald Jodkalikuren vorgenommen mit dem Effekt, daß die Anschwellungen und sonstigen auf Lues hindeutenden Erscheinnugen immer schnell zurückgingen und schließlich ganz verschwanden. Im Oktober 1904 gelangte nach vorausgegangener Angina catarrhalis typisches Erythema nodosum zur Entwicklung: unter Fieber traten leicht erhabene rote Flecke an den unteren Extremitäten auf, die unter Darreichung von Natr. salicylicum, resp. Aspirin und einfachen Verbänden mit Lanolin, Salicylsalbe, essigsaurer Tonerdelösung $u$. dgl. m. binnen 14 Tagen bis 3 Wochen wieder abblaßten; daneben bestanden Jucken, Brennen, rheumatische Beschwerden, aber keine Polyserositis. In den folgenden Jahren traten mehrfach Rezidive auf, zuletzt noch im März 1907. Im Februar 1908 wurde an der Innenseite des linken Oberschenkels oberhalb des Kniegelenks ein harter, walnußgroßer, auf der Oberfläche leicht geröteter Knoten festgestellt, der beim Gehen Beschwerden verursachte und zunächst als Erythema nodosum betrachtet wurde. Da er trotz täglich 3,0 Aspirin und Verbänden nicht zurückging, auch keine Tendenz zur Erweichung zeigte, im Gegenteil eher allmählich an Größe zunahm, wurde Verdacht auf Sarkom rege und daher Ende März 1908 unter Chloroformnarkose der ganze Knoten exstirpiert. Die Heilung der Wunde ging normal vonstatten. Die mikroskopische Untersuchung des Tumors ergab: Granulationsgeschwulst, am Rande bostehend aus Fibroblasten, in der Mitte aus multiplen kleinen Knötchen mit zum Teil verkästem Zentrum, außerdem fanden sich reichlich epitheloide Zellen, Langhanssche Riesenzellen, oft in Gruppen, um die Gefäße reichlich Rundzelleninfiltrate. Die Färbung auf Tuberkelbacillen lieferte negatives, die Untersuchung auf Spirochaete pallida unsicheres Resultat; gleichwohl durfte die Diagnose Gumma wohl als gesichert gelten. Eine daraufhin vorgenommene genauere Untersuchung ergab noch vereinzelte höckerige, druckempfindliche, etwas schmerzhafte Erhabenheiten an den Tibiakanten, daneben allgemeine rheumatoide Beschwerden. Von Anfang April 1908 ab erhielt die Kranke 
wieder regelmäßig Jodkali. Mitte Januar 1909 zog sie sich durch Sturz beim Rodeln eine Fraktur am rechten Schulterblatt und im rechten Schultergelenk zu, die bis Ende März völlig zur Ausheilung gelangte. Nach Mitte April fing sie an, über Schmerzen im sternalen Ende des rechten Schlüsselbeins zu klagen. Dasselbe zeigte sich im Gegensatz zu links etwa $1 \mathrm{~cm}$ dicker, deutlich aufgetrieben, auf Druck schmerzhaft. Wegen Verdachts auf luetische Periostitis erfolgte erneute Quecksilberkur, abwechselnd mit Jodkaliverabreichung. Ende Mai ist die periostale Auftreibung am rechten Schlüsselbein ziemlich verschwunden. Im Juni wurde die Inunktionskur beendet, das Befinden war dann ein im ganzen ungestörtes. Mitte Juni gelangte eine neue Auftreibung am Tuber calcanei links unterhalb der Achillessehne zur Entwicklung, die sich derb anfühlte und auf Druck stärker schmerzhaft war. Unter fortgesetzter Verabreichung von Jodkali und Einreibung mit Jodvasogene ging die Auftreibung allmählich zurück. Mitte September traten von neuem Hautgummata in beiden Wadengegenden auf. Unter protrahierter Jodkalimedikation verschwanden auch diese bis Ende November, rezidivierten aber Mitte Februar 1910 nochmals, um schließlich erst gegen Mitte Juni 1910 ganz zu weichen. Seitdem blieb die Kranke bis zur Entlassung völlig frei von Beschwerden und Krankheitserscheinungen; doch fiel die 1910 ausgeführte Wasser mannsche Reaktion noch positiv aus.

Während der ersten Zeit ihres Aufenthaltes in der hiesigen Anstalt gelangten relativ oft voll ausgeprägte Krampfanfälle zur Auslösung: vom 31. X. bis 31. XII. 1896 insgesamt 24, die Frequenz während der folgenden Jahre betrug: 189790 , 1898 18, 1899 23, 1900 57, 1901 47, 1902 55, 1903 58, 190416 Anfälle. Vom 28. V. 1904 bis zum 10. IX. 1907 blieb die Kranke völlig anfallsfrei. Dann traten im September 1907 wieder kurz hintereinander 4 typische voll ausgeprägte universelle Insulte auf, sämtlich nachts. Seitdem gelangten Krampfanfälle nicht mehr zur Wahrnehmung.

Die Kranke erhielt anfangs täglich 3,0-6,0 $\mathrm{BrKa}$, seit März $1899 \mathrm{BrNa}$ in Dosen von täglich 1,0-3,0 g; seit Januar 1910 wurden antiepileptische Mittel nicht mehr verabreicht.

Bei den Anfällen handelte es sich meist um vollentwickelte tonisch-klonische Krämpfe, gelegentlich aber auch um leichtere rudimentäre Paroxysmen. Alle Insulte traten mit Vorliebe nachts auf, und zwar ohne besondere Vorboten; von den hier registrierten 388 Anfällen ereigneten sich 316 nachts. Bei den großen Attacken war das Bewußtsein stets völlig erloschen, bei den leichteren wenigstens vorübergehend in stärkerem Maße getrübt; für die Zeit des Anfalls bestand stets Amnesie. Früher traten die Anfälle gelegentlich in Gruppen auf, mitunter innerhalb 24 Stunden bis zu 20 und mehr Anfällen, später kehrten sie nur noch vereinzelt in Zwischenräumen von 2-8 Wochen und mehr wieder. Manchmal stellten sich danach Dämmerzustände bis zur Dauer von mehreren Tagen ein, namentlich im Anfange; unter dem Einflusse der antiepileptischen Therapie ließen die Krampfanfälle an Häufigkeit und Heftigkeit auch schon vor Einleitung antiluetischer Kuren nach. Für Annahme einer anatomisch nachweisbaren direkten oder indirekten Affektion der Hirnrinde lagen sichere Anhaltspunkte nie vor. Auch in der Intervallärzeit bestanden nie Lähmungen, Contracturen, Zuckungen in einzelnen Muskelgruppen, Kopfschmerzen, cerebrales Erbrechen u. dgl. m.

Psychisch scheint die Kranke im Anfange stärker beeinträchtigt gewesen zu sein als später; wenigstens wird angegeben, daß ihr Gedächtnis gelitten hat, daß sie sich auf manches oft erst lange besinnen müsse, z. B. auf ihren Geburtstag, ihren Hochzeitstag usw., daß sie selbst klage, Jüngstvergangenes schlechter als früher behalten zu können. Später war eine intellektuelle Schädigung in den anfallsfreien Intervallen nicht mehr zu bemerken; die Kranke erschien stets durch- 
aus klar, besonnen, zeitlich und ortlich orientiert, regsam, kurz völlig frei von irgendwie auffallenden psychischen Störungen. Im Anschluß an Anfälle freilich machten sich oft eine gesteigerte Reizbarkeit und Empfindlichkeit bei ihr geltend, die oft zu Zerwürfnissen und Krakeelen mit der Umgebung führte. In dem Maße, wie die Anfälle zurücktraten, besserten sich auch diese Schwankungen der Stimmung und des äußeren Verhaltens.

Am 29. VII. 1911 wurde die Kranke als ,genesen“ aus der Anstalt entlassen; doch schien der positive Ausfall der erneut vorgenommenen Wasser mannschen Reaktion zu beweisen, daß das syphilitische Virus noch im Körper kreiste. Bis Anfang 1912 ist es ihr in der Außenwelt andauernd ,gut" ergangen; seitdem verloren wir sie aus den Augen.

Das klinische Bild der vorstehend geschilderten drei Fälle entspricht trotz mancher im Verlaufe hervortretenden Abweichungen im wesentlichen dem der gewöhnlichen genuinen Epilepsie. Neben großen vollausgeprägten Krampfanfällen traten in allen drei Fällen auch kleine, rudimentäre Attacken auf, bald mit, bald ohne Aura und initialen Schrei; nur nach Häufigkeit und Heftigkeit bestanden nicht unerhebliche Unterschiede, ganz abgesehen davon, daß wohl in allen drei Fällen die Insulte im Beginne der Erkrankung seltener und in leichterer Form sich einstellten als später. Wenn auch die eingetretene methodische Behandlung modifizierend auf die Zahl und Schwere der Anfälle einwirkte, so behielten die Paroxysmen doch im ganzen ihren Charakter während der Dauer der Beobachtung unverändert bei und verliefen jedenfalls immer durchaus nur nach dem Typus der gewöhnlichen epileptischen Krampfattacken. Bei Fall VIII und IX gelangten vorwiegend große, vollausgeprägte Krampfanfälle zur Wahrnehmung, bei Fall VII handelte es sich zumeist um kleine rudimentäre Attacken; bei allen Fällen kam es gelegentlich zu einer Häufung der Insulte, in der Regel blieben sie jedoch vereinzelt; bei Fall VII und VIII traten die Paroxysmen meist am Tage, bei Fall IX vorzugsweise nachts auf. Nie machten sich corticale Reizerscheinungen, Halbseitenphänomene und sonstige sicher auf organische Gehirnläsionen zu beziehende Symptome geltend. Der Beginn der Epilepsie fällt bei Fall VII ins 23, bej Fall VIII ins 22., bei Fall IX ins 36. Lebensjahr, lag also nur bei dem letzten Falle jenseits derjenigen Altersgrenze, bei der nach Fourniers Meinung ohne weiteres der Verdacht einer luetischen Ätiologie gegeben war. Unmittelbare Schädigungen gingen weder dem ersten noch den späteren Krampfanfällen voraus; immer setzten sie spontan ohne erkennbare äußere Veranlassung ein. Bei Fall VIII und IX war bis zum Auftreten der Epilepsie nie über Störungen von seiten des Nervensystems geklagt worden, bei Fall VII dagegen sollen schon während der ersten Zahnung leichte Krampfanfälle zur Wahmehmung gelangt sein; da sie aber nicht näher beschrieben wurden und sich später wieder völlig verloren, läßt sich über ihre Natur Sicheres nicht aussagen. Im Gegensatz zu den anderen Fällen gingen hier dem Ausbruche der 
Insulte periodisch wiederkehrende Kopfschmerzen in beiden Schläfengegenden voraus, die sich in der ersten Zeit oft auch in der intraparoxysmellen Zeit einstellten, später aber ganz verschwanden. Von sonstigen Besonderheiten des Verlaufs, durch die sich die einzelnen Fälle voneinander unterschieden, sind nur noch hervorzuheben das gelegentliche Auftreten isolierter Kinnbackenkrämpfe ohne Bewußtseinsverlust und psychogener Attacken neben echten epileptischen Insulten bei Fall VIII. Aber ähnliche Vorkommnisse sind im Verlaufe der gewöhn lichen genuinen Epilepsie nicht allzu selten; jedenfalls können sie differentialdiagnostisch kaum in anderer Richtung Verwendung finden und würden, wenn eine genauere Erkenntnis der Ätiologie nicht durch die Anamnese gewährleistet wäre, auf die Pathogenese der Erkrankung wohl kaum ein Licht zu werfen imstande sein. Auch das differente psychische Verhalten im unmittelbaren Anschluß an die Krampfanfälle und in der intraparoxysmellen Zeit spricht an sich weder gegen gewöhnliche genuine Epilepsie noch für rein symptomatisch verursachte Krampfanfälle: die in allen drei Fällen teils nur andeutungsweise, teils in ausgesprochenerem Maße sich bemerkbar machende Charakterdepravation, die bei Fall VIII und IX nur gelegentlich und ganz vereinzelt, bei Fall VII seit dem 30. Lebensjahre in zunehmendem Maße hervorgetretenen postepileptischen Dämmerzustände und sonstigen psychischen Alterationen sind auch im Verlaufe einer gewöhnlichen Epilepsie oft zu beobachtende Vorkommnisse; selbst bei Fall VII, der die auffälligsten Störungen in der psychischen Sphäre darbot, schoben sich zwischen die einzelnen Anfälle immer auch freie Intervalle ein, während deren die Kranke geistig klar und geordnet erschien. Die Intelligenz blieb bei Fall VIII und IX relativ intakt, während bei Fall VII, bei dem freilich schon von vornherein eine gewisse geistige Minderwertigkeit vorgelegen zu haben scheint, die intellektuelle $\mathrm{Ab}$ schwächung im Verlaufe der Jahre weitere Fortschritte gemacht und sich mehr und mehr auch mit ethisch-moralischen Defekten vergesellschaftet hat. Aber auch die in dieser Hinsicht bei den einzelnen Fällen hervorgetretenen Unterschiede fügen sich durchaus dem sonst häufig bei gewöhnlicher Epilepsie zur Entwicklung gelangenden Krankheitsbilde ein. So bleibt man in allen drei Fällen im wesentlichen auf die Ergebnisse der sonstigen klinisch-ätiologischen Ermittelungen angewiesen.

In dieser Beziehung ergibt die Analyse folgendes: Erbliche Belastung darf bei Fall VII wohl mit großer Wahrscheinlichkeit vorausgesetzt werden, während bei Fall VIII und IX Anhaltspunkte dafür nicht gegeben sind. Auf eine cerebrale Prädisposition wies bei Fall VII schon das Auftreten von Krampfanfällen während der ersten Zahnung und das offenbare Zurückbleiben in der intellektuellen Entwicklung 
hin; außerdem deutet hier die Polymortalität der Geschwister direkt auf eine eingetretene Keimschädigung hin. Ob etwa Alkoholismus des Vaters oder Lues der Eltern oder beides in Frage kommt, ist mit Sicherheit nicht zu entscheiden; die Möglichkeit einer Keimschädigung durch solche Faktoren wird aber im Hinblick auf die Anamnese, vielleicht auch im Hinblick anf das bei der einzig überlebenden Sehwester der Kranken vorhandene Augenleiden nicht ganz von der Hand gewiesen werden können. Bei Fall VIII ist angeblich in den ersten Lebenswochen ein Sturz auf den Kopf erfolgt; die links am Schädel vorhandene Knochenverdickung läßt auch in der Tat einen verhängnisvollen traumatischen Einfluß nicht ganz ausgeschlossen erscheinen; da man aber lediglich auf die Angaben der Kranken selbst angewiesen bleibt und diesen leicht ein Erinnerungsfehler oder ein Irrtum zugrunde liegen kann, wird man mit deren Verwertung vorsichtig sein müssen. Übereinstimmend gilt jedenfalls für alle drei Fälle, daß die Entwicklung in normaler Weise vor sich ging und daß bis zum Ausbruch der Epilepsie wesentliche Störungen der cerebralen Vorgänge, von den bei Fall VII vorausgegangenen paroxysmellen Kopfschmerzen und der hier wohl seit der Jugend bestehenden geistigen Minderwertigkeit abgesehen, nicht zur Wahrnehmung gelangt sind. Als Moment von ausschlaggebender Bedeutung tritt uns so in allen drei Fällen allein die Syphilis entgegen.

Daß eine syphilitische Durchseuchung erfolgt ist und ein entsprechendes Virus noch jetzt im Blute zu kreisen scheint, läßt in allen drei Fällen schon der positive Ausfall der Wassermannschen Reaktion erkennen. Ausgetragene, lebende Kinder sind in keinem der drei Fälle vorhanden, bei Fall VII wird ein totfaul zur Welt gekommenes Kind erwähnt, bei Fall IX haben 2 Fehlgeburten stattgefunden, außerdem gingen in Fall VII die 5 lebend geborenen Kinder schon nach kurzer Zeit zugrunde. Bei Fall VIII liegen Exzesse in venere und eine extramatrimonielle Infektion vor, bei Fall VII und IX haben erwiesenermaßen die Ehemäner an Lues gelitten. Die Infektion erfolgte bei Fall VIII im 18. Lebensjahre, bei Fall VII und IX mutmaßlich wohl bald nach der Eheschließung, also bei Fall VII etwa im 20, bei Fall IX im 25. Lebensjahre. Spezifische Prozesse sind bei Fall VII weder anamnestisch noch klinisch sicher nachzuweisen; denn ob der während der zweiten Schwangerschaft hier aufgetretene allgemeine Hautausschlag spezifischer Natur gewesen ist, muß dahingestellt bleiben; Residuen einer früheren Lues aber fehlen. Bei Fall VIII und IX dagegen gelangten eine Reihe luetischer Erscheinungen zur Entwicklung, bei Fall IX sogar erst während der Behandlung in der hiesigen Anstalt, und zwar zwischen dem 41. bis 45. und erneut zwischen dem 50.-52. Lebensjahre. Úber etwa aufgetretene Sekundärsymptome der Lues 
ist bei diesem Falle Zuverlässiges freilich nicht bekannt geworden. Denn ob die in der Umgebung des Mundes vorhandenen Narben als Residuen früherer luetischer Geschwüre anzusprechen waren, ist zweifelhaft. Eine antiluetische Behandlung hat bei Fall VII und IX früher angeblich nicht stattgefunden; bei Fall VIII sind wiederholt ausgiebige und sachgemäße Kuren vorgenommen worden mit dem Effekt, daß seit etwa dem 30. Lebensjahre luetische Rezidive nicht mehr zum Vorschein kamen. Als Residuen der Syphilis treten hier Schwerhörigkeit infolge von Otitis media chronica, näselnde Sprache infolge eingetretener rhinitischer Deformierungen, sowie Narben und Defekte am Gaumen entgegen, während bei Fall IX von den verschiedenen im Rachen, in der Haut und an den Knochen aufgetretenen gummösen Erscheinungen lediglich einige Knochenrauhigkeiten der Tibien zurückblieben.

Die Epilepsie gelangte in allen drei Fällen erst nach der spezifischen Infektion zum Vorschein, und zwar bei Fall VII ca. 3, bei Fall VIII ca. 4, bei Fall IX ca. 11 Jahre nach der Infektion. Sie konnte durch kombinierte antiepileptische und antiluetische Kuren nur bei Fall IX völlig zur Heilung gebracht werden: in dem Maße, wie die gummösen Erscheinungen schwanden, traten hier auch die Krampfanfälle mehr und mehr zurück und vom 46. bis 49 . Lebensjahre blieb die Kranke völlig frei von Insulten, um allerdings etwa 5 Monate vor dem Auftreten der luetischen Rezidive nochmals kurz hintereinander 4 vereinzelt gebliebene nächtliche Anfälle zu bekommen. Fall VII und VIII erwiesen sich gegen die Kuren refraktär; die anscheinend erfolgte Abschwächung der Krampfattacken war hier wohl lediglich als Effekt der verabreichten antiepileptischen Mittel zu betrachten; eine Heilung konnte hier jedenfalls durch kombinierte antiepileptische und antiluetische Heilverfahren nicht erzielt werden; ja bei Fall VII muß wohl im Hinblick auf die zunehmende Häufigkeit rudimentärer Attacken und im Hinblick auf die seit dem 30. Lebensjahre hervorgetretene stärkere Beeinträchtigung in der psychischen Sphäre eher von einer allmählich eingetretenen Verschlimmerung des Gesamtzustandes gesprochen werden.

Für ein etwa vorliegendes ,postsyphilitisches“ Leiden waren in keinem der drei Fälle auch nur die geringsten Anhaltspunkte gegeben. In somatischer Beziehung handelte es sich in allen drei Fällen keineswegs etwa um ,dyskrasische“, sondern vielmehr um normal und regelmäßig entwickelte, durchaus robuste Individuen; wären hier nicht die luetischen Affektionen oder deren Residuen, resp. die anamnestischen Hinweise auf eine erfolgte syphilitische Durchseuchung vorhanden gewesen, so hätten sie in körperlicher Hinsicht jedenfalls als durchaus gesund gelten müssen. Der Charakter der Krankheit ist bei Fall VII trotz einer gewissen Verschlimmerung des Gesamtzustandes im ganzen 
seit etwa 15 Jahren der gleiche geblieben, bei Fall VIII zeigt die Epilepsie schon seit etwa 41 Jahren im wesentlichen denselben Typus und auch bei Fall IX hat sie während der seit dem Ausbruche bis zur Heilung verflossenen 13-17 Jahre keine bemerkenswerte Veränderung in ihren Erscheinungen erfahren.

Klinisch und pathogenetisch dürften diese drei Fälle wohl unbedenklich den von Gros und Lancereaux, Fournier, Nonne u. a. geschilderten "parasyphilitischen" Epilepsieformen zuzurechnen sein. Von „Verstärkung einer hereditär-epileptischen Anlage durch Lues" im Sinne Binswangers und Vogts könnte höchstens bei Fall VII gesprochen werden; bei Fall VIII kann zwar ein Schädeltrauma, wie wir sahen, nicht absolut sicher ausgeschlossen werden, doch ist die ätiologische Bewertung dieses angeblich bereits in den ersten Lebenswochen erfolgten Traumas um so mehr erschwert, als man lediglich auf die Aussage der Kranken selbst angewiesen bleibt und bei ihrer An. erkennung zur Annahme einer mehr als 20jährigen latenten epileptischen Gehirnveränderung gezwungen würde; individueller Alkoholmißbrauch und andere schädigende Einflüsse fehlen in allen drei Fällen; als ursächliches Moment von ausschlaggebender Bedeutung tritt uns anamnestisch überall allein eine syphilitische Durchseuchung entgegen. Ob zur Zeit des Ausbruchs der Epilepsie - sie trat, wie erwähnt, bei den drei Fällen 3, 4, bzw. 11 Jahre nach der Infektion hervor - manifeste Erscheinungen der Syphilis bestanden haben, ist ungewiß; jedenfalls aber trifft für keinen der drei Fälle die Behauptung Fourniers zu, daß die ,parasyphilitische“ Form der Epilepsie mit der Sekundärperiode der Syphilis zugleich entstehe und wieder verschwinde. Tertiäre Erscheinungen der Syphilis bildeten sich während des Bestehens der Epilepsie bei Fall VIII und IX aus, konnten aber durch antiluetische Kuren bis auf einige Residuen wieder beseitigt werden. Für materielle und speziell für spezifische Hirnprozesse waren einwandfreie klinische Symptome in keinem der 3 Fälle vorhanden; wenigstens konnten die bei Fall VII erwähnten prodromalen paroxysmellen Kopfschmerzen und die bei Fall IX angeblich im Anfang vorhanden gewesenen Gedächtnisschädigungen als ausreichende differentialdiagnostische Merkmale um so weniger in Anspruch genommen werden, als sie später völlig zurücktraten. Die klinischen Besonderheiten, durch die sich die geschilderten drei Fälle von denen Nonnes z. B. unterscheiden ${ }^{1}$ ), sind unseres Erachtens nicht so schwerwiegender Natur, daß eine „,parasyphilitische", resp. eine in der gewöhnlichen Weise verlaufende Form der Epilepsie ausgeschlossen werden müßte. Das epileptische Leiden selbst war durch kombinierte antiepileptische und antiluetische Kuren bei Fall VII und VIII nicht in zweifelloser Weise zu beeinflussen,

1) Vgl. oben S. 526 . 
während bei Fall IX allerdings Heilung herbeigeführt wurde. Die Möglichkeit, daß es sich hier nicht um eine rein funktionelle Störung der cerebralen Vorgänge, sondern um die ersten Anfänge neoplastischer Prozesse, resp. um räumllch nur wenig ausgedehnte und einer Rückbildung noch zugängliche spezifische Hirnveränderungen im Sinne Binswangers gehandelt hat, ist angesichts des erzielten therapeutischen Erfolges nicht ganz von der Hand zu weisen. Gegen die Annahme einer durch ,syphilitische Dyskrasie" herbeigeführten Störung der cerebralen Vorgänge spricht die Tatsache, daß man es in allen drei Fällen mit sehr rüstigen und keineswegs ,dyskrasischen“ Individuen zu tun hatte, während der Annahme einfacher ,irritativer", d. h. entzüindlicher Vorgänge im Sinne Bins wangers ${ }^{1}$ ) der Umstand entgegenstehen dürfte, daß die Epilepsie hier erst 3,4 und 11 Jahre nach der Infektion zum Ausbruch gelangte und auf alle Fälle auch noch nach Ablauf des Sekundärstadiums der Syphilis fortbestand. Wir halten daher auch für unsere Fälle mit Binswanger und Nonne toxische molekulare Schädigungen der Nervensubstanz durch das syphilitische Virus für am meisten wahrscheinlich, zum mindesten für die Fälle VII und VIII, während bei Fall IX möglicherweise spezifische gummöse Hirnveränderungen leichtester Art vorgelegen haben könnten. Eine gewisse Stütze findet diese Annahme, von den im Anfange angeblich vorhanden gewesenen Gedächtnisschädigungen abgesehen, hier vielleicht noch in der Tatsache, daß dem Ausbruche der Epilepsie bald tertiär-luetische Prozesse am Körper nachfolgten, vielleicht auch in dem Umstande, daß die Epilepsie mit den gummösen Affektionen zugleich zurückging und schließlich verschwand, während erneute, wenn auch vereinzelt gebliebene epileptische Insulte in auffälligem zeitlichen Zusammentreffen mit den aufgetretenen luetischen Rezidiven sich wieder einstellten. -

Die im folgenden noch mitgeteilten Fälle zeigen sich sämtlich durch hinzugetretene oder von vornherein mit den epileptischen Insulten vergesellschaftete Psychosen kompliziert. Als wichtigste klinische Aufgabe galt es hier, für jeden einzelnen Fall die Frage zu entscheiden, ob die im Zusammenhange mit Lues und epileptischen Insulten aufgetretenen Geistesstörungen etwa auf grob anatomische Gehirnveränderungen zu beziehen waren oder nicht. Nach Binswanger u. a. hängt es ja im besonderen von der Individualität des einzelnen ab, ob gewisse Schädigungen des Nervensystems bei ihm eine funktionelle Störung der Gehirntätigkeit oder eine organische Psychose zur Auslösung bringen. Aber abgesehen davon, daß sich die individuelle Disposition des syphilitisch infizierten Individuums zu der einen oder anderen nervösen oder psychischen Erkrankung klinisch nur selten mit einiger Sicherheit feststellen läßt, herrscht wohl auch darüber allgemeine Utbereinstimmung,

1) Vgl. oben S. 528.

Z. f. d. g. Neur, u. Psych. O. XVII. 
daß die differentielle Abgrenzung der verschiedenen auf syphilitischer Basis entstehenden Krankheitsbilder oft die erheblichsten Schwierigkeiten bereiten kann. Besonders in Betracht kommen hier echte Gehirnsyphilis, progressive Paralyse und rein funktionelle Störungen der Gehirntätigkeit. Wie nicht bei jeder im Verlaufe der Tabes dorsalis auftretenden psychischen Alteration ohne weiteres eine Tabesparalyse angenommen werden darf, so wird auch bei den mit epileptischen Insulten einhergehenden Geistesstörungen nicht ohne weiteres eine „postsyphilitische" oder eine spezifisch-syphilitische Erkrankung des Zentralnervensystems vorausgesetzt werden dürfen. Daß aber bei Individuen mit anamnestisch oder klinisch sicher gestellter Syphilis gelegentlich einfache funktionelle Psychosen ohne spezifische eigenartige Symptome vorkommen können, haben uns Lag nea u, Wille, Albers, Leidesdorf, Leubuscher, Engelstedt, Erlenmeyer, Fournier, Heubner, Kowalewsky, Jolly, Nonne u. a. gelehrt ${ }^{1}$ ); auch mit epileptischen Insulten einhergehende Geistesstörungen bei Syphilitischen finden sich seit B. Bell wiederholt in der einschlägigen Literatur erwähnt, und wenn die Zugehörigkeit der beschriebenen Fälle zu den rein funktionellen Störungen der Gehirntätigkeit auch nicht immer allen Zweifeln standhält, so darf wohl unbedenklich der auf die einschlägige Literatur und auf eigene Erfahrungen sich stützenden Meinung Nonnes beigepflichtet werden, daß es ,,keine Form psychischer Störung gibt, von den diffusen Zustandsbildern einer allgemeinen Ernährungsstörung im Gehirn an durch die verschiedenen Formen der bisher noch ohne bekannte anatomische Veränderungen verlaufenden einfachen Psychosen bis zu den auf dem Boden lokaler und diffuser organischer Hirnerkrankung entstandenen Psychosen, die nicht im Gefolge der Syphilis zur Beobachtung gelangen könnte".

Nach diesen Vorbemerkungen mögen zunächst zwei Fälle ausführlicher geschildert werden, in denen, wie erwähnt, die Akquirierung der Syphilis sich allem Anscheine nach insofern als äußerst verhängnisvoll erwies, als sie die bereits vorhanden gewesene Epilepsie neu entfachte (Fall XI), resp. zur Entwicklung einer schweren Psychose und bei Fall XI zugleich zur Entwicklung einer schweren organischen Rückenmarkserkrankung Anlaß gab.

Fall X. Albin P., geb. 28. X. 1875, wuchs in günstigen äußeren Verhältnissen auf, entwickelte sich körperlich und geistig normal, überstand Scharlach ohne nervöse Störungen und soll im übrigen früher stets völlig gesund gewesen sein. Familienanlage soll nicht bestehen; doch ist näheres über seine Eltern, seine Geschwister und Verwandten nicht bekannt geworden. Im 16. Lebensjahre traten zum ersten Male Erscheinungen von Epilepsie auf; eine Ursache wird dafür nicht

1) Vgl. u. a. die Arbeiten von Kowalewsky, sowie die zusammenfassende Vorlesung 8 in Nonnes ,Syphilis und Nervensystem“, 2. Aufl., wo sich die einschlägige Literatur eingehend berücksichtigt findet. 
verantwortlich gemacht; auch scheinen keine bemerkenswerten Schädigungen vorausgegangen zu sein. Anfangs handelte es sich nur um rudimentäre Attacken, oft in Form von Schwindelanfällen, später stellten sich immer häufiger schwerere typische allgemeine Krampfanfälle ein, meist früh beim Aufstehen. Den leichteren wie den schwereren Insulten gingen in der Regel stets in der gleichen Weise sich wiederholende Auraerscheinungen voraus: der Kranke fühlte sich schon einen Tag zuvor bedrückt, verstimmt, von allerhand unangenehmen Körperempfindungen und innerer Unruhe gequält. Die voll ausgeprägten Krampfanfälle begannen oft mit einem lauten Aufschrei und endigten stets in tiefer Bewußtlosigkeit; nach Ablauf derselben erschien der Kranke nicht selten bis zur Dauer eines Tages matt, angegriffen, schwach und schlafsüchtig; an die Vorgänge während des Anfalle bestand nie auch nur die geringste Erinnerung. Der Eintritt der Anfälle erfolgte immer spontan, meist vereinzelt, oft täglich, oft auch in Pausen von etwa 8 Tagen, gelegentlich aber auch in Gruppen bis zu 4 Insulten, über einen Tag verteilt. Wiederholte Bromkaliumkuren waren von nennenswertem Erfolge nicht begleitet; nur nach einer 10 Wochen lang fortgeführten Opium-Brom-Kur nach Flechsig sollen einmal 6-8 Wochen lang keine Anfälle mehr aufgetreten sein, dann aber stellten sie sich ohne nachweisbare äußere Veranlassung wieder ein, angeblich sogar in schwererer Form und häufiger als früher. Eine Lungenentzündung, dieder Kranke im 18. Lebensjahre überstand, übte einen bemerkenswerten Einfluß auf das epileptische Leiden nicht aus; ebensowenig Einfluß auf die Häufigkeit und Heftigkeit der Anfälle soll eine Lues gehabt haben, die sich der Kranke im 21. Lebensjahre zuzog und die in der Folgezeit zu wiederholten Quecksilber-Schmierkuren Anlaß gegeben hat.

Zeichen geistiger Störung wurden bis zur Unterbringung hierselbst - am 22. II. 1900 - nicht beobachtet; nur unmittelbar vor und insbesondere nach Anfällen zeigte er sich zuweilen mürrisch, verstimmt, gereizt, heftig und streitsüchtig und explodierte dann bei den geringsten Anlässen leicht zu heftigsten Wut- und Zornparoxysmen. In intellektueller Hinsicht wird er wohl als vergeBlich und etwas abgeschwächt bezeichnet; doch bestand bei der Aufnahme kein höherer Grad von Demenz; er erschien durchaus klar, geordnet, orientiert und besonnen.

In körperlicher Hinsicht wird er als mittelkräftig, gut genährt geschildert. Am Schädel fanden sich keine Besonderheiten. Der Gesichtsausdruck war wenig lebhaft, etwas leer, Innervationsstörungen waren nicht vorhanden, die weiten, beiderseits gleichen Pupillen reagierten prompt auf Lichteinfall und Akkommodation. Auch sonst lagen keinerlei somatische Störungen vor, insbesondere wurden alle für progressive Paralyse sprechenden Symptome seitens des Nervensystems vermißt. Als Folge der Epilepsie fanden sich an der Zunge und am Hinterhaupt alte Narben, als einziges Residuum der Lues bestand oberhalb der Zäpfchenwurzel ein etwa fünfpfennigstückgroßer, erst vor etwa $3 / 4$ Jahren zur Entwicklung gelangter Gaumendefekt. Im März 1900 stellte sich am rechten hinteren Gaumenbogen wieder ein Geschwür ein, das unter Jodkalibehandlung bis Mitte Mai 1900 zur Abheilung gelangte. Im August 1900 rezidivierte dasselbe, gleichzeitig bestanden allgemeine Erscheinungen der tertiären Rachensyphilis, die aber unter erneuter Jodkalikur in kurzer Zeit zum Verschwinden gebracht wurden. Seit dieser Zeit machte sich als einziges objektives „Stigma der Lues" eine geringfügige Erweiterung der rechten gegenüber der linken Pupille bemerkbar; im übrigen blieb die Reaktion beider Pupillen dauernd gut erhalten. Bei einer erneuten genauen Untersuchung im Juni 1901 zeigten sich noch die Dornfortsätze der Wirbelsäule druckempfindlich, besonders von der Mitte der Brustwirbelsäule an abwärts. Sonst konnten nie - auch in der Folgezeit nicht - für progressive Paralyse oder sonstige organische Läsionen und Erkrankungen sprechende Störungen seitens 
des Gehirns und Rückenmarks festgestellt werden. Erneute Erscheinungen von Lues traten nicht mehr auf.

Insgesamt gelangten in der hiesigen Anstalt 296 epileptische Insulte zur Wahrnehmung, die sich ziemlich gleichmäßig über die hier verbrachte Zeit verteilten; 204 davon traten tagsüber, 92 nachts auf; 271 mal handelte es sich um voll ausgeprägte typisch epileptische Krampfanfälle, 25 mal um Schwindel und rudimentäre Attacken. Der Verlauf derselben entsprach stets demjenigen bei gewöhnlicher genuiner Epilepsie. Nie machten sich corticale Reiz- und Lähmungserscheinungen dabei geltend, auch sonst fehlten andauernd auf organische Gehimläsionen hindeutende Symptome. Die Zahl der in einem Monat zur Auslösung gelangten. Insulte betrug durchschnittlich 7 ; nie lagen zwischen 2 Anfällen mehr als höchstens 2 Wochen; nur gelegentlich kamen an einem Tage mehr als 2 Anfälle vor, in der Regel blieben die Insulte vereinzelt. Nach Ablauf derselben pflegte der Kranke noch eine kurze Zeit lang benommen und matt zu sein. Die Therapie erwies sich den epileptischen Anfällen gegenüber vollkommen erfolglos; der Kranke hatte anfangs täglich 4,0-6,0 NaBr, später - seit dem 27 . VIII. 1900 - neben Kal, jodat. noch fortlaufend täglich $3,0 \mathrm{Kal}$. bromat. erhalten.

Gegen Mitte Juni 1900 machten sich allmählich immer auffälliger nicht nur im Anschluß an Anfälle, sondern auch während der intraparoxysmellen Intervalle Zeichen geistiger Störung bei dem Kranken bemerkbar. Die Symptome der Psychose unterlagen häufigem Wechsel: Phasen der Depression wechselten ab mit Phasen der Erregung; vorübergehend trat völlige Verwirrtheit ein. Daneben traten oft Halluzinationen des Gesichts und Gehörs auf, verbunden mit Personenverkennung und Wahnideen. Die letzteren wurden oft wochenlang in stereotyper Weise wiederholt, erfuhren zum Teil auch eine gewisse Systematisierung. Inhaltlich standen im Vordergrunde hypochondrische und persekutorische Wahnvorstellungen; andeutungsweise traten gelegentlich auch megalomanische Ideen auf, Stimmung und Handeln wurde stets maßgebend davon beeinflußt. So wähnte der Kranke: er werde beschimpft, man spotte über ihn, mache ihm ungerechtfertigte Vorwürfe, trachte ihm nach dem Leben, suche ihn zu erschießen oder zu vergiften, auch Verwandte, die er zu sehen und zu hören meint, hätten ihre Hand im Spiele usw. Andere Male brachte er allerhand Klagen über körperliche Beschwerden vor oder äußerte unklare Befürchtungen: zu Hause sei etwas passiert, er oder Verwandte würden wohl sterben müssen, er habe Särge im Zimmer gesehen usw. Gelegentlich entwickelte er eine gewisse Großmannssucht, forderte z. B. eine größere Zahl Zigarren, um sie verschenken zu können, verlangte ,,von P.“ tituliert zu werden, gab an, mit in China gewesen zu sein, er erinnere sich noch genau der Landung in England: da habe ein Stern sehr schön am Himmel geglänzt; ein Chinese habe ihm mit der Flinte den Schädel eingeschlagen, so daß er operiert werden mußte u. a. m. Aber soweit die Auffassung der Umwelt nicht etwa durch Sinnestäuschungen und Wahnideen beeinflußt war, ließ sich in auffälligem Kontrast zu ihnen in der Regel leidliche Besonnenheit, Klarheit der Gedanken und der Auffassung sowie Orientiertheit konstatieren. Die Merkfähigkeit blieb bis zuletzt gut erhalten, ebenso das Rechenvermögen, die sonst noch in früherer Zeit erworbenen Kenntnisse; eine progressive Demenz machte sich in keiner Weise geltend; die Sprache und Schrift erschien bis zuletzt völig intakt; auch sonst fehlten somatisch andauernd Zeichen von progressiver Paralyse. Im Anschluß an Anfälle schien die psychische Störung meist eine gewisse Verschlimmerung zu erfahren; oft machte sich dann vorübergehend größere Erregtheit und Gereiztheit, gelegentlich aber auch größere Bedrücktheit bemerkbar, die zuweilen bis zu völliger Reaktionslosigkeit auf Anreden und vorübergehender Nahrungsverweigerung fortschritt. Auch allerhand Maniriertheiten in der Sprache und in den Bewegungen traten dann interkurrent in die Erseheinung; 
immer aber schoben sich auch längere oder kürzere Phasen leidlichen Wohlbefindens ein. Unter Schwankungen im Sinne von Steigerungen oder Nachlässen hielt die psychische Störung etwa bis Anfang Oktober 1900 an. Um diese Zeit begannen die Sinnestäuschungen, die er nun als „Träume“, als „Eingebungen“ usw. zu bezeichnen begann, abzublassen, ebenso die jähen Stimmungsschwankungen; doch wurde erst im Verlaufe des Jahres 1901 wieder ein größeres Maß geistiger Klarheit und Freiheit erreicht.

Guten Einblick in die schließliche Ausgestaltung seines Geisteszustandes gewähren einige Aussagen, die er im Entmündigungsverfahren am 18. XII. 1900 machte, sowie ein $3 / 4$ Jahre später in durchaus korrekten Schriftzügen niedergeschriebener Brief, in dem er an diese und ähnliche Aussagen anknüpft. Er hatte damals auf Befragen u. a. erklärt, daß nach dem sächsischen Kalender wohl der 18. XII. sei; doch glaube er nicht, daß wir uns jetzt in Sachsen aufhielten; vielmehr - das sagte er mit geheimnisvoller Miene - befänden wir uns wohl in "Sadras"; das liege aber in Ägypten. Daß er dort gewesen sei, habe er sozusagen geträumt; auch sei es ihm, als habe er sich dort verheiratet und die größte Pyramide geerbt bzw. gewonnen. Sozusagen im Traume sei er dann einmal in der Pyramide gewesen, in der große Kühle geherrscht habe. Später habe er in Ägypten ein Geschäft angefangen und beim Spiele sehr viel gewonnen, auch fortgesetzt viele Bekannte dort getroffen usw. Auf die Frage, ob er das wirklich nur geträumt habe, antwortete er: „Ich will lieber sagen: man hat es mir vorgemacht." Ebenso habe man ihm ,,vorgemacht": er sei vielleicht ein Sohn Sr. Majestät des Königs Albert, oder: er sei früher als General mit großen Epauletten herumgelaufen, oder: er sei hier als großer Geistlicher angestellt. Wiederholt meinte er auch: er sei hier ,,kultiviert" worden. Früher sei er ein weibliches Wesen gewesen und habe Eva, bzw. Evi geheißen; hier sei er „umgearbeitet" worden. Dazu brachte er dann noch eine große Reihe allgemeiner Anschauungen über ,den Wahn" der religiösen Lehren, den „Wahn" vom Sterben und von der Auferstehung usw. vor, auf die er sich viel zugute tat.

Der am 2. IX. 1901, also $3 / 4$ Jahre später, niedergeschriebene, an den behandelnden Arzt gerichtete Brief lautet, von einigen einleitenden Höflichkeits- und Entschuldigungsfloskeln sowie einigen belanglosen Zwischenbemerkungen abgesehen, mit Beibehaltung der vom Kranken angewandten Orthographie und Interpunktion im Auszuge folgendermaßen:

„Zunächst erlaube mir einige Fragen, welche zur Zeit Herr Dr..... mir gestelt, zu beantworten. Auf die mir gestelten Fragen, wer ich wohl früher gewesen sei, antwortete ich nach einigem Überlegen mit den Worten, daß ich wohl als Theologe studirt habe $\mathrm{u}$. Geistlicher gewesen sei. Ebenso befand ich mich in dem Glauben, daß ich früher als Weib gelebt, später aber von den Hr. Ärzten zum Mann umgearbeitet wurde, auf einem Eisenbahnfahrt nach Rußland. Ferner stet mir noch eine Oceanfahrt nach Amerrika in teuschender Erinnerung, wo ich auf dem unteren Koridor der Innenabtheilung erschossen wurde. Auch weiß ich mir noch zu entsinnen, daßich vor langer Zeit Herrn Oberarzt dringend gebeten habe, mich gütigst als Soldat mit nach China ziehen lassen zu wollen, was mir zu meinem Bedauern abschlägig beschieden wurde. Hr. Dr .... . hatte mich bei Seinem Verhör zur Zeit auch gefragt, ob ich denn später, wenn ich hier entlassen sei, Lust habe, die Familie P. noch zu besuchen? Was ich allerdings mit Ja beantwortete. $\mathrm{Ob}$ dies der Fall sein wird, kann ich augeblicklich noch nicht bestimmen, wer weiß, ob ioh später diesen Namen noch kenne".....

Über seineWelt- und Lebensanschauungen läßt er sich dann folgendermaßen aus: „Zunächst will ich die Frage laut werden lassen, von der Entstehung der Menschen u. von Himmel u. Erde? Daß es je vor Jahrtausenden einen Gott gegeben 
habe, welcher die Welt $u$. den Menschen geschaffen, ist ja jeder geistig klaren Person begreiflich. Wie soll jener Gott wohl ausgesehen? Was soll wohl Him̄el u. Erde sein? Unterzeichneten Ansichten sind, daß dies alles Sache der Natur ist, u. wohl schon Milliarden von Jahren vergangen sind, seit Entstehung der Welt u. der Menschen. Es ist doch handgreiflich, dass im Laufe der Zeiten dies alles sich langsam herangebildet, hat sowie sich allerlei Thiere und Gewürm durch Luft, Licht u. Wärme bildet. Gleichso ist von ieher jedes Geschöpf immer mehr zur Kultur gelangst $u$. damit zuletzt auch der Mensch entstanden ist. Daß derselbs natürlich durch seine Vorgänger und Mithelfer stets mehr zur Einsicht und Vernunft gelangst ist ja klar. Daß dazu natürlich die medizinische Kunst, Ihr moglichstes thut, soll später erwähnt werden." - _ -

„Hiermit erlaubt sich Unterzeichneter, seine religiösen Ansichten im allgemeinen zu offenbaren. Daß der Mensch von Kind auf im Glauben an einen Gott erzogen wird, ist ja ganz zustimmens werd. So wie es Gesetze, Strafen, Vorgesetzte Untergebene gleich Konservative wie Sozialisten und Reiche und Arme geben muB, ebenso muß es eine Religion geben. Dass es einen wirklichen Gott gebe, welcher mit Allmacht die Welt regiere, ist ja nur ein Glaube, bez. eine Einbildung der Menschen, von jeher gewesen, sogut wie es keinen Teufel gibt (eine Sage). Der Mensch ist sein eigener Gott wie sein eigener Teufel. Fest überzeugt ist Schreiber dieses von der Annahme, dass alle die studirten und höher gebildeten Personen sicher zu den Freigläubigen gehören. Auch glaube sicher, daß die Hr. Geistlichen, obgleich Sie den Menschen bieblischen Text vormachen, sicher an keine Allmacht glauben, sondern durch die Worte jede einzelne Person doch immer wieder an einen göttlichen Glauben mehr binden wollen."

„Daß es eine Zeitrechnung gibt, ist ja auch nur der Menschen Werk und muß dies so gut existieren, wie Reichthum und Armut, gleich noch vielem anderen, wozu oft ein allmächtiger Gott dazu als Schöpfer desselben berufen wird. Daß die Katholiken an eine Unfehlbarkeit des Papstes glauben, ist ja nur Wahn, denn wie kann je ein Mensch unfehlbar sein? Erwäht soll noch sein, daß bei der Geburt eines jeden Menschen, sicher auch dessen Tod sofort mit in die Ackten eingetragen wird. Eine gewisse Zeit des Lebens u. des Todes, wird wohl jedem besimt sein gleich bei Geburt eines jeden durch die höhere Regierung. Auch ist meine Annahme dass der Tod eines jeden nur einen Scheintod vorstellt $u$. nach einer bestimmten Zeit wieder zum Leben zurückberufen wird. $O b$ ich gegenwärtig dieser betreffende $P$. . bin, kann Unterzeichneter natürlich nicht mit Bestimmtheit behaupten u. kann selbiger schon viele Male auf dieser Erde gewandelt haben. Einst wurde mir die Frage gestellt, ob ich noch wüsste, daß ich schon im Sarge gelegen habe? Was ich zwar abschlägig beantwortete. Wer ich gewesen u. was noch aus mir werden soll, stelle ich ganz in die Macht der Herren Ärzte. Daß Epilepsie sicher nur eine Kunstsache der Medizin, sowie manche andere Krankheit ist, nehme ich mit Bestimmtheit an. Der Grundsatz, welchen sich die Anstalt gesetzt, ist die Bildung u. Kultivierung der Menschen im sittlichen u. zugleich dem feineren Benehmen.

Eine Bitte, welche Schreiber dieses zum Schlusse noch äußert, wäre die eine, doch sein Leben in möglichst brauchbarer Weise zu verwerden $u$. nicht als Bummler anderen Leuten zur Last zu fallen. Sein Handwerk als Buchbinder würde demselben zur Zeit wohl sehr schwer fallen, da er sich davon gar nichts mehr bewußt ist."........

In der Folgezeit wurde er nur noch gelegentlich im Anschluß an Anfälle für kürzere Zeit erregt und heftig und erschien dann gelegentlich auch wieder geistig in etwas höherem Grade zerfahren als gewöhnlich. Wohl kehrten dann vorübergehend auch einmal ähnliche Sinnestäuschungen und Wahnideen, wie sie oben erwähnt wurden, in seinen Äußerungen wieder; doch hafteten sie nie mehr so lange 
im Bewußtsein wie früher und übten auch kaum noch erheblicheren Einfluß auf seine Stimmung und sein Handeln aus; der Kranke erschien vielmehr in der anfallsfreien Intervallärzeit meist ruhig und geordnet, gab klare und besonnene Auskünfte und bot in geistiger Hinsicht lediglich das Bild eines mäßig schwachsinnigen, in seiner Weise nach Paranoikerart philosophierenden Kranken dar. Nach Anfällen fühlte er sich in der letzten Zeit trotz sonstiger körperlicher Rüstigkeit oft ziemlich matt und angegriffen. Wiederholt fiel er während heftiger Insulte auf den Hinterkopf, so auch am 10. VI. 1903. Er wurde ganz bewußtlos ins Bett gebracht, sah tief blaß aus, zeigte auf 42 Schläge verlangsamten Puls, links sehr verengerte, rechts stark erweiterte Pupille und starb ca. 5 Stunden nach dem Anfalle mittags 11/4 Uhr.

Die am nächsten Tage früh vorgenommene Sektion ergab im. wesentlichen folgendes: Der Leichnam war $168 \mathrm{~cm}$ lang, $52 \mathrm{~kg}$ schwer, regelmäßig und kräftig entwickelt. Am Hinterhaupt fanden sich die Hautdecken infolge der Kontusion blutig durchtränkt. Das Schädeldach selbst war unverletzt, im übrigen sehr verdickt, die Diploe spärlich entwickelt, die Gefäßfurchen an der Innenfläche stark ausgeprägt. Aus dem rechten Subduralraum entleerte sich reichlich größtenteils geronnenes dunkelschwarzrotes Blut. Die Innenfläche der Dura erscheint links glatt und glänzend, rechts ist sie überall mit einer fibrinösen, leicht abziehbaren Haut von rötlicher Farbe bedeckt. Die weichen Häute sind etwas verdickt, diffus milchig getrübt, sehr blutreich und leicht abziehbar. Die Basisgefäße sind zart, die Windungen breit, leicht abgeflacht, die Ventrikel nicht erweitert, das Ependym ist glatt und zart, das Gewebe mäßig durchfeuchtet; auf der ersten und zweiten rechten Stirnwindung bemerkt man eine etwa fünfmarkstückgroße, oberflächliche, gelbrötliche Verfärbung; das Gewebe ist hier leicht zerklüftet und erweicht. Das Hirngewicht beträgt $1240 \mathrm{~g}$. Sonst fanden sich noch: Herz schlaff, leicht ver* fettet, Bronchitis, Lungen ödematös, zum Teil blutreich, Leber verfettet. Im übrigen ergaben sich keine bemerkenswerten Befunde weiter. Eine mikroskopische Untersuchung des Zentralnervensystems wurde nicht vorgenommen.

Der Fall ist von vornherein dadurch ausgezeichnet, daß bei ihm Epilepsie bereits vor dem Eintritt einer syphilitischen Infektion bestand. Uber ihre Ursache ist anamnestisch nichts bekannt. Erbliche Belastung soll nicht vorliegen, die körperliche und geistige Entwicklung soll in normaler Weise erfolgt sein, krankhafte Störungen von seiten des Nervensystems sollen früher nicht bestanden haben, auch den zum ersten Male im 16. Lebensjahre zur Auslösung gelangten epileptischen Insulten sollen besondere äußere Schädigungen nicht vorausgegangen sein. Anfangs traten nur rudimentäre Attacken auf, später steigerten sich die Anfälle nach Schwere und Häufigkeit; im übrigen verliefen sie, wie sich aus der Schilderung ergibt, mochte es sich nun um große vollausgeprägte oder um kleine rudimentäre Insulte handeln, stets nur nach dem Typus der gewöhnlichen genuinen Epilepsie. Im 18. Lebensjahre überstand der Kranke eine Lungenentzündung, im 21. Lebensjahre zog er sich eine Lues zu, derentwegen er sich in der Folgezeit wiederholt spezifischen Kuren unterwarf. Auf die Zahl und Heftigkeit der Krampfanfälle sollen diese Erkrankungen aber und das unterscheidet den Fall von den S. 525 angeführten Fällen einen modifizierenden Einfluß zunächst nicht ausgeübt haben. Auch in der Folgezeit behielten die epileptischen Insulte trotz der in- 
zwischen eingetretenen antiepileptischen und antiluetischen Kuren und der später hinzugetretenen Psychose ihren Charakter im wesentlichen stets unverändert bei. Als der Kranke im 25. Lebensjahre hier untergebracht wurde, erschien er körperlich kräftig, rüstig und gesund; auf organische Gehim-Rückenmarksleiden hindeutende Krankheitszeichen waren in keiner Weise vorhanden; als einziges Utberbleibsel der zwischen dem 21. und 25. Lebensjahre aufgetretenen luetischen Affektionen bestand ein ca. $3 / 4$ Jahre vorher zur Entwicklung gelangter Gaumendefekt. Bald machten sich indessen emeut Erscheinungen tertiärer Rachensyphilis bemerkbar; unter spezifischer Behandlung gelangten sie jedoch schnell wieder zur Abheilung. In der Folgezeit traten dann luetische Prozesse nicht mehr hervor. Als einzige auffällige symptome konnten in somatischer Beziehung stets nur eine geringfügige Erweiterung der rechten, im übrigen normal reagierenden Pupille und eine Druckempfindlichkeit der Dornfortsätze der Wirbelsäule festgestellt werden. Jedenfalls boten sich sonst nie auch nur die geringsten Anhaltspunkte dar für die Annahme eines spezifischen oder eines ,,postsyphilitischen" Gehirnleidens; die erwähnten somatischen Befunde wurden daher lediglich als "Stigmata der Lues" betrachtet.

$\mathrm{Zu}$ den epileptischen Insulten gesellten sich aber im 25. Lebensjahre die Zeichen einer schweren geistigen Störung. Wohl waren schon vorher Zeichen von Charakterdepravation, mit Stimmungsanomalien gepaart, hervorgetreten, aber immer nur im unmittelbaren Anschluß an Krampfanfälle, wie das ja bei gewöhnlicher Epilepsie in der Regel geschieht; in der Intervallärzeit dagegen erschien der Kranke bis zum Ausbruch der Psychose immer klar, geordnet und besonnen, wenn auch intellektuell vielleicht etwas abgeschwächt und vergeßlich. Gewisse Einzelsymptome dieser Psychose schienen freilich unter dem Einflusse von Anfällen nicht selten eine Steigerung zu erfahren; im ganzen aber wurde die Psychose in ihrem Verlaufe und in der Art der Verknüpfung und der zeitlichen Aufeinanderfolge ihrer Symptome durch die mit den Anfällen sich einstellende stärkere seelische Erregtheit nicht auffällig bereichert oder modifiziert. Charakterisiert war sie, wie sich aus der Beschreibung ergibt, durch jäh wechselnde Stimmung, plötzlich auftretende und schnell wieder abklingende Erregungs- und Verwirrtheitszustände, gelegentlich vorhandene Personenverkennung, mitunter sich geltend machende katatonische Symptome leichteren Grades, massenhaft auftauchende Sinnestäuschungen und daran anknüpfende Wahnideen hypochondrischen, persekutorischen und andeutungsweise auch megalomanischen Inhalts, die oft wochenlang festgehalten und stereotyp wiederholt, zum Teil auch systematisiert wurden. Die Orientierung, die Auffassung der Umwelt, die Merkfähigkeit, das Rechenvermögen usw. blieben in auffälligem Kontrast dazu im allgemeinen 
gut erhalten oder erfuhren wenigstens nur in Zeiten größerer seelischer Erregtheit, insbesondere im unmittelbaren Anschluß an Anfälle vorübergehend eine gewisse Beeinträchtigung. Unter mannigfachen Steigerungen und Nachlässen gelangte die Psychose im Verlaufe eines Jahres allmählich zu einem gewissen Stillstand und Abschluß. Es kam zur Ausgestaltung eines mehr stabilen chronischen Geisteszustandes, in' den nur noch die Krampfanfälle alterierend eingriffen. Die Besonnenheit erschien nun in der intraparoxysmellen Zeit nicht mehr auf. fällig gestört, der logische Apparat funktionierte formal stets korrekt, nur noch gewisse fortbestehende residuäre Bewußtseinsverfälschungen und die etwas abstrus und phantastisch ausgebauten Welt- und Lebensanschauungen, auf die sich der Kranke etwas einzubilden schien, erinnerten an die vorausgegangenen schweren akuten Störungen in der psychischen Sphäre. So blieb der Zustand im wesentlichen bis zu dem im 28. Lebensjahre im Anschluß an einen heftigen Anfall mit konsekutiver Schädelkontusion und Hirnerschütterung eingetretenen Tode des Kranken. Die Autopsie ergab, von den traumatisch nach früheren und dem letzten Anf́all zustande gekommenen Schädigungen abgesehen (Sugillationen in den Hinterhauptsdecken, Haematom der Dura mater, Plaques jaunes über der ersten und zweiten rechten Stirnwindung), am Zentralnervensystem im wesentlichen nur Befunde, wie sie auch sonst bei gewöhnlicher Epilepsie, resp. bei „funktionellen“ Psychosen oft erhoben werden (Verdickung des Schädeldachs, mäßige Trübung der verdickten weichen Hänte usw.); Jedenfalls fanden sich keinerlei Anhaltspunkte dafür, daß etwa eine gummöse Affektion oder ein ,postsyphilitisches" degeneratives Rindenleiden zur Störung der zerebralen Vorgänge Anlaß gegeben hatte.

Um freilich eine progressive Paralyse mit absoluter Sicherheit auszuschließen, wäre noch eine genaue mikroskopische Durchforschung des Zentralnervensystems geboten gewesen; aber auch ohne solche läßt sich der Fall wohl mit größter Wahrscheinlichkeit den rein funktionell bedingten Störungen der cerebralen Vorgänge beizählen. Auch klinisch wurden ja andauernd auf Paralyse oder andere organische Prozesse verdächtige Erscheinungen vermißt; nie traten nach Anfällen etwa vorübergehende Lähmungen, Paresen, aphasische oder dysphasische Störungen, Anomalien der Schrift u. dgl. m. hervor, ebensowenig konnte je ein bemerkenswerter Rückgang der intellektuellen Kräfte und Fähigkeiten danach konstatiert werden. Die zur Beobachtung gelangte Psychose selbst stellte ein in sich abgeschlossenes, von den Krampfanfällen relativ unabhängiges Krankheitsbild dar, das in dieser Form ebensogut auch bei einem nicht epileptischen Individuum hätte zur Entwicklung kommen können. Am nächsten steht es nach seinen klinischen Erscheinungen wohl dem Kraepelinschen Begriffe der 
Dementia praecox paranoides. Daß sich selbständige funktionelle Psychosen in den Verlauf einer gewöhnlichen Epilepsie einschieben können, muß nach mannigfachen Erfahrungen als erwiesen angesehen werden; daß speziell auch paranoische Krankheitsbilder auftreten können, lehren uns einschlägige Mitteilungen von Hoff mann, Magnan, Gnauck, Respaut, Kirchhof, Pohl und Buchholz'). Auf der anderen Seite zeigten Klein, Jolly, Nonne u. a., daß paranoiaähnliche Krankheitsbilder auch bei Syphilitischen vorkommen können, nicht nur als Initialstadium einer progressiven Paralyse oder neben Zeichen organischer luetischer Hirnerkrankungen, sondern auch als primäre, resp. einfache funktionelle Psychosen. Da sich die geschilderte und nach den aufgetretenen klinischen Krankheitserscheinungen als „funktionell“ zu betrachtende Psychose erst im Anschluß an die syphilitische Durchseuchung eingestellt hat, so liegt es nahe, sie nicht als eine zufällige akzidentellle Erkrankung anzusprechen, sondern als „parasyphilitisch" im Sinne der obigen Ausführungen bedingt anzusehen; ja wir dürfen vielleicht auch in unserem Falle im Hinblick auf das spätere Hinzutreten der Psychose zum Krankheitsbild der Epilepsie von einem ,stimulierenden" Einflusse der Syphilis auf die Störung der cerebralen Vorgänge sprechen. -

Größere differentialdiagnostische Schwierigkeiten bereitete der nächste Fall, der auch sonst in mannigfacher Beziehung lebhaftes Interesse zu erwecken geeignet erscheint.

Fall XI. Emilie Sch., geb. 22. XI. 1864 in Brzezinka. Utber die Eltern, die in der frühesten Kindheit der Kranken starben, ist Genaueres nicht bekannt, ebensowenig über Erziehung und Entwicklung der Kranken. Ein Bruder soll geisteskrank gewesen sein. Eine Schule hat die Kranke nicht besucht; sie ist Analphabetin, aber von Durchschnittsintelligenz. Thr Lebenswandel war im ganzen geordnet. Mißbrauch alkoholiseher oder narkotischer Mittel fand nicht statt; sexuelle Exzesse werden negiert; doch ist Näheres über das sexuelle Leben der Kranken nicht bekannt. $\mathrm{Ob}$ schon früher Krampfanfälle oder psychische Störungen bestanden haben, ist zwar nicht absolut klar gestellt, doch behauptete die Kranke in einem Zustande relativen geistigen Wohlbefindens im November 1904 einmal glaubhafterweise, sie habe bereits als Kind an Krämpfen gelitten; diese hätten dann aber jahrelang ausgesetzt, bis sie im 25. Lebensjahre ohne besondere äußere Veranlassung wieder zum Vorschein kamen. In der Folgezeit wiederholte sie diese Aussage öfter in ähnlicher Weise.

Zunächst Dienstmädchen, später in Fabriken tätig, heiratete sie, zum vierten Male schwanger, am 23. XI. 1899 einen wegen verschiedener Vergehen vorbestraften Fabrikarbeiter, von dem sie aber sehon am 29. V. 1901 wieder geschieden wurde. Anla $B$ zur Scheidung gab seine Internierung im Zuchthause $W$. wegen eines schweren Sittlichkeitsattentates. Daß die Kranke syphilitisch infiziert worden ist, steht fest; wann die Infektion eintrat, und ob sie durch den späteren Ehemann, mit dem sie

1) Vgl. hierzu namentlich Gnauck, Uber die Entwicklung von Geisteskrankheiten aus Epilepsie. Arch. f. Psych. 1882, Bd. 12, S. 337 ff. und Buchholz, Uber die chron. Paranoia bei epileptischen Individuen, Leipzig 1895. 
schon lange vorher verkehrt hatte, erfolgte, war nicht zu ermitteln; doch darf wohl angenommen werden, daß die Kranke bereits zur Zeit ihres ersten Abortes - im 21. Lebensjahre - luetisch durchseucht war. Bei den 4 zwischen dem 21. bis 35. Lebensjahre überstandenen Geburten handelte es sich 3 mal um Fehlgeburten, während das letzte ausgetragene Kind bald nach der Geburt starb. Im übrigen ist über den Verlauf der Schwangerschaften und Wochenbetten näheres nicht bekannt. Bis 1900 litt sie an Ulous cruris, dessen syphilitische Natur in einem kurzen ärztlichen Zeugnisse ausdrücklich bestätigt wird. Seit Herbst 1901 klagte sie über „reißende" Schmerzen in beiden Beinen. Seit Ende 1902 oder Anfang 1903 ist sie auf dem rechten Auge völlig erblindet, auf dem linken hat sie seit Mitte 1903 nur noch einen ganz schwachen Lichtschein.

Am 7. II. 1903 erfolgte die Unterbringung der Kranken in der psychiatrischen Klinik zu L. Vorher hatte sie im Krankenhause ihres letzten Aufenthaltsortes eine Quecksilberschmierkur durchgemacht. Von L. aus wurde sie am 6.XI. 1903 in die Anstalt Zsch., am 21. XI. 1904 von dort in die hiesige Anstalt überführt. Behandelt wurde sie seitdem ohne sichtlichen Erfolg mit großen Dosen Jodnatrium, resp. mit Bromkalium und Bromnatrium, daneben im Bedarfsfalle mit narkotischen Mitteln.

Ans der umfänglichen Krankengeschichte sei auszugsweise nur das Wichtigste erwähnt: Wiederholte somatische Untersuchungen ergaben im wesentlichen stets die gleichen schon 1903 erhobenen Befunde. Es fanden sich: doppelseitige einfache Opticusatrophie, daneben - später festgestellt - Chorioiditis disseminata, beides rechts in ausgedehnterem und fortgeschrittenerem Maße als links; seit Beginn 1905 bestand totale Amaurose; die Pupillen waren mittelweit, die rechte etwas größer als die linke, beide entrundet, bei Konvergenz reagierend, nicht aber auf Lichteinfall. Die Iris läßt beiderseits am Pupillarrande etwa 1 bis $11 / 2 \mathrm{~mm}$ breit, gleichmäßig rund um die Pupille herum, oberflächliche Defekte bzw. narbig veränderte Substanzverluste erkennen. Die Patellarreflexe zeigen sich andauernd total erloschen. Bewegungsempfindungen, auch große Bewegungen des Kopfes, sowie in den Fuß- und Handgelenken, gelangen nicht zum Bewußtsein. Das Lagegefühl scheint zu fehlen; die Kranke legt zwar richtig das linke Bein auf das rechte, fragt man sie aber, welches oben liegt, so behauptet sie beharrlich, das rechte. Die Sensibilität wurde anfangs nicht herabgesetzt gefunden, später ergab sich Hypästhesie bzw. Hypalgesie im Bereiche des $\mathrm{N}$. occipitalis und von den Klavikeln abwärts, sowie völlige Analgesie an den Beugeseiten beider Unterschenkel, rechts in stärkerem Maße als links. Die Gesichtsmuskulatur fand sich schlaff, aber beiderseits gleich innerviert; im Mundfacialisgebiet soll nach einer aus dem Jahre 1903 stammenden Notiz einmal Beben und Flimmern beobachtet worden sein; gleichzeitig wird bemerkt, daß die Zunge leicht nach links abweiche. Später konnten dergleichen Störungen nicht mehr festgestellt werden. Die Beine vermochte die Kranke nicht zu heben; sie schleppt das linke Bein beim Gehen nach. Wegen angeblich auftretenden Schwindelgefühls fällt sie sofort zurück. Der Gang ist leicht ataktisch; später bedurfte die Kranke wegen fortschreitender Ataxie in zunehmendem Maße beim Gehen und Stehen der Unterstützung und Hilfe. Die artikulatorische Funktion der Sprechmuskeln blieb andauernd eine ganz normale; die Sprache ist sicher, bestimmt, sonor; es besteht weder Silbenstolpern noch Häsitieren, noch Kleben. Hörfähigkeit und Geruch sollen beiderseits etwas herabgesetzt gewesen sein, das Geschmacksvermögen dagegen soll keine wesentliche Beeinträchtigung gezeigt haben. Bestehende lanzinierende Schmerzen werden oft in wahnhafter Weise umgedeutet (man quäle, zwicke, schlage sie usw.). Im Dezember 1907 klagte Patientin wiederholt über heftige bohrende und reißende Schmerzen in den total erblindeten Augen, die als tabische Augenkrisen angesprochen wurden. 
Im übrigen zeigte sich die Kranke regelmäßig und kräftig entwickelt, aber im Ernährungszustande heruntergekommen; das Körpergewicht schwankte von 1903 bis 1909 zwischen 39 - $31 \mathrm{~kg}$. Die Zähne waren defekt, die Ohrmuscheln klein, der Helix fand sich beiderseits wenig angelegt. Am Unterschenkel links fanden sich alte Ulcusnarben, auch unterhalb der Patella beiderseits strahlige geschrumpfte Hautnarben. Ein anfangs bestehender Lungenspitzenkatarrh besserte sich bald. Der Urin war und blieb frei von Eiweiß und Zucker. Weitere bemerkenswerte krankhafte Befunde wurden auf körperlichem Gebiete im übrigen nie erhoben.

Während des Aufenthalts der Kranken in der Klinik zu L. wurden wiederholt im Anschluß an hochgradige Erregungen universelle tonisch-klonische Krampfanfälle mit Bewußtseinsverlust und nachfolgender Amnesie beobachtet. Seit der Unterbringung in Zsch. und hier gelangten Krampfanfälle epileptischen Gepräges ungemein häufig zur Auslösung. Sie traten bald vereinzelt, bald in Gruppen, bald am Tage, bald nachts, bald in kürzeren Intervallen, bald nach längeren Pausen auf, glichen sich untereinander, wechselten jedoch nach Intensität, Dauer und Charakter einzelner Symptome. Immer handelte es sich um allgemeine tonischklonische Krämpfe, die akut, mitten aus klarem Bewußtsein heraus, einsetzten und plötzliche BewuBtlosigkeit herbeiführten. Nach Ablauf derselben zeigte die Kranke noch eine Zeitlang getrübtes Bewußtsein oder traumhafte Benommenheit, verbunden mit allgemeiner Abgeschlagenheit, pflegte sich aber in der Regel sehr bald wieder zu erholen. Die sonstigen Begleiterscheinungen waren die gewöhnlichen der echten Epilepsie: nicht selten initialer Schrei oder inspiratorisches gurgelndes Geräusch im Anschluß an gesteigert hervorgetretene Störungen in der psychischen Sphäre, stets charakteristische zyanotische Verfärbung im Gesicht, vor den Mund tretender Schaum, Speichel und Schleim, oft Zähneknirschen, unwillkürliche Harnentleerung, zum Schluß starkes inspiratorisches Giemen usw. Nach dem Erwachen klagte die Kranke oft über Kopfschmerzen, zeigte nicht selten auch heftiges, lang anhaltendes Erbrechen. Die Amnesie war für die Zeit des Anfalls stets eine totale. Lähmungen oder sonstige postepileptische Erscheinungen, von den noch zu erwähnenden psychischen Störungen abgesehen, wurden nicht beobachtet, ebensowenig cortical-epileptische Phänomene; außerhalb des epileptischen Anfalls liegt die Kranke ruhig da, die Muskulatur hat dabei normalen Tonus. Vereinzelt. wurde auch petit mal oder Epilepsia procursiva wahrgenommen; in der Regel jedoch handelte es sich um typische Anfälle.

In Zsch. wiederholten sich Paroxysmen der erwähnten Art anfangs alle 3-4 Tage, später noch häufiger. Zwischen Januar und Oktober 1904 entwickelte sich oft ein förmlicher Status epilepticus, wennschon Patientin zwischen einer größeren Gruppe kurz aufeinanderfolgender Krampfanfälle in der Regel für einige Zeit das Bewußtsein wieder erlangte. Über die hier beobachteten, genau registrierten Insulte sei kurz folgendes bemerkt: Völlig anfallsfrei verliefen die Monate August und November 1905, Februar bis Juni 1906, Juni und November 1907; nur vereinzelt traten Anfälle auf im März, Juli und Oktober 1905, im Juli und August 1906, im April, Mai, Juli und Oktober 1907, sowie innerhalb der Zeit vom 9. Januar 1909 bis zum Tode. Die Zahl der in einem Monat registrierten Anfälle schwankte zwischen 1 und 50. Insgesamt wurden hier beobachtet 508 typische Insulte, 365 tagsüber, 143 nachts. Die Mehrzahl derselben entfällt auf die Zeit vom November 1904 bis zum Juni 1905, ferner auf die Zeit vom September 1906 bis zum März 1907, sowie auf die Monate August, September, Dezember 1907 und Januar 1908. Auch hier entwickelte sich oft ein förmlicher Status epilepticus.

Das psychische Verhalten der Kranken unterlag während der Dauer der Krankheit fortgesetzten Schwankungen, im ganzen aber bot die Kranke in geistiger Hinsicht ein ziemlich gleichförmiges, sich von Anfang bis zu Ende gleichbleibendes 
Bild dar. Zeitweise ruhig, freundlich, besonnen, klar, gut zugänglich und geordnet, erschien sie $\mathrm{zu}$ anderen Zeiten psychisch mehr oder minder erheblich alteriert. Namentlich vor und nach den Anfällen machten sich in gesteigertem Maße Störungen in der psychischen Sphäre geltend, die aber dann immer wieder - insbesondere auch während ihres letzten Krankheitsjahres - für kürzere oder längere Intervalle ganz zurücktraten; in der Regel fielen die Phasen relativen Wohlbefindens zusammen mit anfallsfreien Zwischenzeiten. Im Vordergrunde standen oft plastische Gesichts- und Gehörstäuschungen und daran anknüpfende Wahnvorstellungen und Stimmungsschwankungen. Die Sinnestäuschungen und Wahnvorstellungen ließen systematische Verarbeitung vermissen, blieben sich aber ihrem Inhalte nach im ganzen stets gleich. Besonders oft spielte ihr Mann darin eine Rolle; sie meinte ihn nicht selten in zerrissenen Kleidern mit zwei Hunden u. dgl. an ihrem Bett stehen zu sehen, hörte ihn reden, schimpfte dann in gemeinster Weise auf ihn, bedachte ihn mit den ordinärsten Titulaturen usw. Andere Male wähnte sie sich geschlachtet, vergiftet, verhext, geschlagen, irgendwie gequält und gezwickt; man wirft ihr Faulheit, Diebstahl u. dgl. m. vor, gibt ihr zur Mahlzeit nur die Überbleibsel der anderen Kranken usw. Harmlose Äußerungen Mitkranker bezieht sie oft auf sich und deutet sie in einem ihr feindlichen Sinne um. Reaktiv auf peinigende Gefühlstäuschungen, Beeinträchtigungs- und Verfolgungsideen, gerät sie leicht in maßlose Erregung, ergeht sich in wüsten Schmäh-, Schimpf- und Drohreden, wird nicht selten auch aggressiv. Auch sonst wechselt die Stimmung oft, teils infolge der eingetretenen Erblindung und Hilflosigkeit, teils infolge der Sinnestäuschungen und Wahnvorstellungen, teils aus unklaren inneren Gründen. Sie erscheint dann störend, abweisend, unzugänglich, unzufrieden, mürrisch und verstimmt, oft auch, wenn depressive Stimmungen, eventuell mit Angstanfällen verbunden, vorherrschen, von Selbstmordneigung beherrscht. So zerriß sie wiederholt z. B. Bettzeug, um sich Schlingen zum Aufknüpfen oder zur Umschnürung des Halses zu verschaffen; wiederholt brachte sie sich auch Verletzungen bei, teils infolge von Selbstmordneigung, tells infolge von Zerstörungssucht, z. B. durch plötzliche Zertrümmerung von Fensterscheiben. In ihren Ausdrücken oft nur wenig wählerisch, erscheint sie in der Erregung nicht selten geradezu obszön, masturbiert in schamlosester Weise, denudiert sich, führt Coitusbewegungen aus usw. Andere Male wieder singt sie zotige Gassenhauer oder umgekehrt fromme Lieder. Verschiedene Momente schienen darauf hinzudeuten, da $\beta$ hierbei wohl mit sexuellem Orgasmus einhergehende Klitoriskrisen stattfanden, während gelegentlich freilich auch nur psychische sexuelle Erregungen vorzuliegen schienen. Mitunter wechselten delirante Zustände mit sinnloser Erregung auch ab mit Zuständen völliger Benommenheit und Katalepsie. Krankheitseinsicht fehlte in solchen Phasen psychischer Alteration, die Kranke hielt sich dann vielmehr für völlig gesund und drängte beständig nach Hause.

War die Kranke frei von Störungen in der psychischen Sphäre, so gab sie bis zuletzt klare, besonnene Auskünfte, oft bis in die feinsten Details. Ihre Umgebung beurteilte sie dann richtig, äußerte sich zutreffend über ihre körperlichen Defekte, ließ keine gröberen Gedächtnislücken oder sonstigen Störungen auf intellektuellem Gebiete wahrnehmen. Verfügte die Kranke auch nur über ein mäßiges geistiges Inventar, so war doch nie ein geistiger Verfall im Sinne einer progressiven paralytischen Demenz festzustellen; auch Größenideen, Euphorie usw. fehlten.

So blieb der Zustand im wesentlichen bis Dezember 1909; ja gerade in der letzten Zeit, wo epileptische Anfälle nur relativ selten sich einstellten, waren Phasen geistigen Wohlbefindens recht häufig zu konstatieren. Da stellte sich mit einem Male im Anschluß an einen ohne vorausgegangene besondere Schädlichkeiten eingetretenen schweren Krampfanfall ein erneuter heftiger Erregungszustand und weiterhin vom 15. XII. ab zunehmende Benommenheit und Teilnahmslosigkeit 
ein, die allmählich zu völliger Bewußtlosigkeit fortschritt; eine Schluckpneumonie gesellte sich hinzu und in tief komatösem Zustande erfolgte am 19. XII. 1909 früh 4 Uhr Exitus letalis unter den Zeichen zunehmender Herzschwäche.

Die am gleichen Tage früh $10^{1} / 2$ Uhr vorgenommene Sektion ergab in der Hauptsache: Körpergewicht $31 \mathrm{~kg}$, Körperlänge $152 \mathrm{~cm}$. Auf der Haut stellenweise oberflächliche, zum Teil strahlenförmig verlaufende Narben, insbesondere am linken Unterschenkel und unterhalb der beiden Kniescheiben. Schädeldach ziemlich dick und schwer, fast nur aus Compacta bestehend, GefäBfurchen an der Innenfläche tief und reich entwickelt, im übrigen keine wesentlichen Besonderheiten. Gehirn $1110 \mathrm{~g}$ schwer. Am Scheitel reichlich Pacchionische Wucherungen. Weiche Häute diffus milchig getrübt und allfällig verdickt, namentlich in den vorderen und mittleren Abschnitten des Großhirns, wo sie zugleich adhärent sind. Gehirn ödematös, Ventrikel mäßig erweitert, Ependym im 4. Ventrikel zart gekörnt, mäßiger Hydrocephalus internus. Beide Nn. optici um etwa die Hälfte geschrumpft, platt gedrückt. Basisgefäße leer, nicht obliteriert, aber stark sklerosiert. - All. gemeine Stauungserscheinungen an allen Organen. Herz schlaff, Muskulatur leicht verfettet, aufsteigende Aorta sklerosiert. Beiderseits Pleuritis adhaesiva. An beiden Lungenspitzen von alter Tuberkulose herrührende narbige Schrumpfungen und Einziehungen. In beiden Lungenunterlappen zahlreiche Aspirationsherde. Nieren mäßig atrophisch, an der Oberfläche fein granuliert. Auf der Leber mehrere oberflächliche, strahlig verlaufende, derbe, schwielige Narben. Rechts eine walnußgroße Ovarialcyste. Sonst makroskopisch keine bemerkenswerten Befunde weiter.

Die mikroskopische Untersuchung beschränkte sich auf einige Querschnitte aus den beiden Nn. optici und dem Rückenmark, sowie auf Stücke aus verschiedenen Gegenden der beiden Hirn- und Schläfenlappen, d. h. vornehmlich auf solche Bezirke, die auch makroskopisch Veränderungen darboten.

Die weichen Häute zeigten sich durch fibröses Gewebe verdickt, die Pia reichlich von Rundzellen durchsetzt. In den adventitiellen Scheiden der Blutgefäße fanden sich neben Lymphocyten vereinzelt auch Mast- und Plasmazellen. Im ganzen aber trat die zellige Infiltration gegenüber der diffusen Hyperplasie stark zurück. Längs der Pialscheiden der Gefäße griff die Rundzelleninfiltration teilweise auch auf die oberflächlichsten Schichten der Rindensubstanz über. Die Gefäßwände fanden sich zum Teil verdickt und gewuchert; vielfach machten sich fettige, resp. hyaline Entartungen der Intima geltend. Trotz stellenweise erheblicher Verengerung des Lumens war es zu einer völligen Obliteration nirgends gekommen. In der Umgebung der Gefäße war stellenweise reichliche Pigmentablagerung wahrzunehmen. Die Grenze zwischen Pia und Rindengewebe war wenig scharf; die gliöse Randschicht erschien deutlich vermehrt und gewuchert. Von den erwähnten Rundzelleninfiltrationen in der Umgebung der oberflächlichen Rindengefäße abgesehen, waren weitere Infiltrationserscheinungen in der Rindensubstanz kaum zu bemerken; ebensowenig fanden sich verkäste oder völlig dem Untergang verfallene, narbig geschrumpfte oder nekrotische Partien. Höchstens in der unmittelbaren Umgebung der Gefäße und überhaupt in der oberflächlichsten Rindenschicht schien es hier und dort zu einer Entartung, resp. zum Untergang der nervösen Elemente der Rinde gekommen zu sein; wenigstens fand sich hier das Gewebe meist auffällig arm an Ganglienzellen, während dagegen die Glia hier mehr oder minder deutlich gewuchert schien. Im übrigen war die Schichtung der Ganglienzellen erhalten geblieben; nirgends machten sich auffällige Störungen der Rindenarchitektonik geltend. Diese Veränderungen traten in den untersuchten Stücken aus der Großhirnrinde überall in annähernd gleicher Weise hervor; nirgends bemerkte man als sicher spezifisch-syphilitisch anzusprechende Veränderungen. 
Im Rückenmark und in den Nn. optici fanden sich überall die für einfache Atrophie und tabische Degeneration typischen Befunde.

Die familiäre Anamnese und das Vorleben der voranstehend geschilderten Kranken sind nur unvollständig bekannt geworden. Da ein Bruder geisteskrank gewesen sein soll, ist wohl erbliche Belastung anzunehmen. Die Erziehung der aus einem polnischen Bezirke Schlesiens stammenden Kranken scheint eine ziemlich mangelhafte gewesen zu sein; wenn sie aber auch Analphabetin war, so zeigte sie nach den vorliegenden Berichten doch Durchschnittsintelligenz. Nach ihrer an sich wohl glaubhaften, aber freilich nicht absolut sicher zu kontrollierenden Angabe hat sie bereits als Kind an ,Krämpfen“ gelitten, die dann, wie es in der Tat ja oft geschieht, spontan wieder verschwunden sind, um angeblich erst im 25. Lebensjahre von neuem hervorzutreten. $\mathrm{Ob}$ es sich dabei - die Glaubhaftigkeit der Kranken vorausgesetzt - um echte Epilepsie gehandelt hat, muß dahingestellt bleiben. Das Wiederhervortreten der Insulte im 25. Lebensjahre könnte als Folgewirkung einer allem Anscheine nach im 20. bis 21. Lebensjahre eingetretenen syphilitischen Infektion betrachtet werden; man könnte an einen stimulierenden Einfluß, an die ,Verstärkung einer hereditär-epileptischen Anlage durch Lues und das Wachrufen der latenten epileptischen Disposition durch die erworbene Syphilis" im Sinne der Ausführungen S. 525 denken. Allerdings fehlen auch darüber sichere Nachrichten, ob die Epilepsie vom 25. Lebensjahre an andauernd fortbestanden hat; seit der im 39. Lebensjahre erfolgten Unterbringung der Kranken wurden jedenfalls fortgesetzt Krampfanfälle von typisch epileptischem Gepräge beobachtet; denn die in der Häufigkeit und Schwere der Insulte hervorgetretenen Schwankungen, das zeitweise Sistieren derselben und der in der Art und Intensität der einzelnen Begleiterscheinungen sich bemerkbar machende Wechsel sprachen an sich in keiner Weise gegen gewöhnliche Epilepsie. Daß Syphilis vorgelegen hat, wird ärztlich ausdrücklich bezeugt und durch die bis zum 36. Lebensjahre aufgetretenen Ulcera cruris bewiesen, welche auf spezifische Kuren zur Abheilung gelangten und nur charakteristische residuäre Hautnarben zurückließen. Vielleicht lassen sich auch die in der Krankengeschichte erwähnten Irisdefekte, die beiderseits vorhanden gewesene Chorioiditis disseminata und die bei der Sektion konstatierten derben schwieligen Lebernarben auf abglaufene luetische Prozesse beziehen. Für Syphilis schienen ferner die zwischen dem 21. bis 35. Lebensjahre eingetretenen 3 Aborte und der bald nach der Geburt erfolgte Tod des letzten ausgetragenen Kindes zu sprechen. Schließlich deutete mit einer gewissen Wahrscheinlichkeit auch die in Frage stehende Erkrankung des Nervensystems auf eine luetische Ätiologie hin.

Daß es sich um ein schweres organisches Leiden im Zentralnerven- 
system handelte, konnte von vornherein einem Zweifel kaum unterliegen. Von den bereits erwähnten Feststellungen abgesehen, kamen für die Diagnose insbesondere noch die folgenden, im wesentlichen bereits bis zum 39. Lebensjahre zur Entwicklung gelangten Krankheitssymptome in Betracht: die schon im 37. Lebensjahre aufgetretenen, später oft wahnhaft umgedeuteten lancinierenden Schmerzen in den Beinen, die im 38. Lebensjahre zunächst auf dem rechten Auge einsetzende, allmählich auch auf das linke Auge übergreifende Erblindung infolge einfacher fortschreitender Sehnervenatrophie, die charakteristischen Pupillenstörungen, die total erloschene Erregbarkeit der Patellarreflexe, das Vorhandensein des Rombergschen Phänomens, die sukzessive hervorgetretenen eigentümlich Iokalisierten Sensibilitätsstörungen, die später noch sich geltend machenden Augen- und Klitoriskrisen, sowie die fortschreitende Ataxie der unteren Extremitäten. Das angeblich im 39. Lebensjahre vorhanden gewesene Beben und Flimmern im schlecht innervierten Mundfacialisgebiet und das Abweichen der vorgestreckten Zunge nach links konnte später nicht mehr festgestellt werden. Weiterhin waren differential-diagnostisch noch von Bedeutung die während der Dauer der Krankheit in unregelmäßigen Intervallen sich wiederholenden Krampfattacken, die daneben noch aufgetretenen psychischen Störungen und der ganze Verlauf des Leidens. Sprachstörungen, dauernde oder passagere Lähmungserscheinungen, spastische Paresen, Tremor von intentionellem Charakter, auf Herderkrankungen hindeutende Ausfallserscheinungen usw. fehlten und machten sich auch im Anschluß an Anfälle nie bemerkbar. Für die Annahme eines circumscripten Tumors, einer syphilitischen Erkrankung der Hirnbasis, einer multiplen Sklerose u. dgl. m. waren also ausreichende Anhaltspunkte nicht gegeben; die Anamnese und das klinische Gesamtbild schienen vielmehr auf diffuse Krankheitsprozesse im Zentralnervensystem hinzudeuten, und zwar mußte besonders in Betracht gezogen werden: diffuse Lues cerebrospinalis speziell der Konvexität und des Rückenmarkes und Tabes dorsalis mit funktionellen oder organisch bedingten Störungen der cerebralen Vorgänge. Die differentielle Abgrenzung dieser Krankheitsprozesse gegeneinander hatte aber nicht unerhebliche Schwierigkeiten zu überwinden.

Von vornherein stand fest, daß im Krankheitsbilde unverkennbar die Zeichen der Tabes dorsalis prävalierten. Sieht man ab von den erst später hinzugetretenen Sensibilitätsstörungen, der allmählich sich steigernden Ataxie der unteren Extremitäten, den im späteren Verlaufe wiederholt sich geltend machenden Augen- und Klitoriskrisen, sowie von den nur im 39. Lebensjahre festgestellten Anomalien der Innervation im Mundfacialisgebiet, so waren alle charakteristischen Symptome des Leidens bereits bis zum 39. Lebensjahre voll zur Aus- 
prägung gelangt. Im wesentlichen blieben sie auch stets stationär, resp. erfuhren nur allmählich eine dem typischen Verlaufe des Leidens entsprechende Ausgestaltung und Verschlimmerung. Die Sensibilitätsstörungen waren allerdings zum Teil etwas auffallend lokalisiert, auch schienen die im 39. Lebensjahre konstatierten Störungen der Innervation im Mundfacialisgebiet nicht ganz in das gewöhnliche Bild der Tabes zu passen; im übrigen aber war der zur Diagnose erforderliche Symptomenkomplex von Anfang an vorhanden; kaum ein charakteristisches Symptom wurde vermißt und auch in der Art und Gruppierung derselben und in ihrer zeitlichen Aufeinanderfolge schienen die Eigentümlichkeiten dieser Rückenmarkserkrankung voll ausgeprägt zur Geltung gelangt zu sein. Es fragte sich nur, ob alle überhaupt aufgetretenen Krankheitserscheinungen restlos aus der Annahme einer gewöhnlichen Tabes dorsalis mit hinzugetretenen funktionellen Störungen der cerebralen Vorgänge zu erklären waren oder ob neben den klinischen Symptomen der Tabes als etwas Neues noch auf spezifisch-luetische Prozesse oder auf degenerative Hirnrindenveränderungen zu beziehende Krankheitszeichen sich geltend machten.

Von den auf körperlichem Gebiete erhobenen Befunden waren, wie bemerkt, nur die im 39. Lebensjahre konstatierten Anomalien der Innervation im Mundfacialisgebiet und vielleicht auch die zum Teil etwas eigentümlich lokalisierten Sensibilitätsstörungen geeignet, Bedenken wachzurufen; diesen Feststellungen war aber ein maßgebender Wert für die Beurteilung des Krankheitsbildes um so weniger beizumessen, als sie einerseits völlig vereinzelt geblieben waren und bei späteren Untersuchungen nicht mehr erhoben wurden, andernteils ,,atypischerweise" sehr wohl auch einmal bei echter Tabes in der gleichen Form zur Entwicklung gelangt sein konnten. Weitere auf progressive Paralyse hinweisende Krankheitszeichen traten rein somatisch während der $6^{3} / 4$ jährigen Beobachtungsdauer nicht hervor. Aber auch für die Annahme einer diffusen Lues cerebrospinalis lieferten die somatischen Untersuchungsbefunde sichere Anhaltspunkte andauernd nicht dar. Wohl wiesen die Narben am Unterschenkel, die Irisdefekte und die Chorioiditis disseminata, von der Anamnese abgesehen, auf luetische Prozesse hin; aber diese waren als solche abgelaufen und für das vorliegende Nervenleiden differentialdiagnostisch daher nicht mehr recht verwendbar. Im übrigen fehlte dem Krankheitsbilde gerade das, was nach 0 p penheim, Nonne u. a. spezifische Affektionen im Bereiche des Zentralnervensystems besonders auszuzeichnen pflegt, das eigentümliche Oszillieren der Symptome, das plötzliche Umspringen, das fortwährende Kommen und Gehen derselben. Nie wurden z. B. Schwankungen in der Weite. und Lichtreaktion der Pupillen oder intermittierende aphasische Störungen oder andere durch ihre Flüchtigkeit ausgezeichnete Lähmungen 
oder sicher als Hirndruck anzusprechende Krankheitszeichen u.ä. m. wahrgenommen. Man blieb für die Diagnose daher fast ausschließlich auf die neben den somatischen Symptomen noch hervorgetretenen Störungen der cerebralen Vorgänge angewiesen und mußte sich fragen, ob speziell die Alterationen in der psychischen Sphäre und die daneben noch aufgetretenen epileptischen Insulte zur definitiven Klärung des Krankheitsbildes verwertbar erschienen.

Daß die Insulte nach Verlauf und Charakter durchaus denen der gewöhnlichen Epilepsie entsprachen, wurde bereits bemerkt; ihre wechselnde Schwere, ihre zeitweise statusartige Häufung, ihr gelegentliches völliges Sistieren etwa auf eingetretene Hirndruckschwankungen u. a. m. zu beziehen, lag kein genügender Anlaß vor; nie machten sich dabei corticale oder Herdsymptome bemerkbar; nie ging die Kranke aus den Attacken körperlich oder geistig auffallend defekter hervor, wenn auch eine gewisse Steigerung der psychischen Störungen unmittelbar vor oder nach den Anfällen unverkennbar war. Konnten so die Krämpfe zur Klärung der Sachlage an sich nichts beitragen, so fragte es sich doch, ob sie nicht in Verbindung mit den somatischen und psychischen Störungen auf ein spezielles Leiden im Zentralnervensystem hinwiesen.

In dieser Beziehung lag es zunächst nahe, an Tabesparalyse zu denken. Bekanntlich gehören Krampfattacken zu den häufigst beobachteten Verlaufseigentümlichkeiten der progressiven Paralyse, und wenn dieselben hier auch nur selten so ausgesprochen epileptisches Gepräge zeigen dürften wie in unserem Falle, so müssen sie doch jedenfalls nicht stets, wie es allerdings meist der Fall ist, mit corticalen Reizund Lähmungserscheinungen einhergehen, resp. apoplektiform verlaufen. Außer bei Paralyse kommen Krampfattacken gelegentlich aber aber auch bei diffuser Hirnlues und selbst bei einfacher Tabes dorsalis vor. Während sie bei progressiver Paralyse und bei diffuser Hirnlues wohl allgemein als integrierendes Krankheitssymptom betrachtet werden, sind die Meinungen über die Zugehörigkeit etwa auftretender Krampfparoxysmen zum Krankheitsbilde der gewöhnlichen Tabes noch geteilt. Erb und Oppenheim z. B. sehen sie mehr als Koeffekt der gleichen Ursache, nämlich der Syphilis, resp. als zufällige, wesentlich von Arteriosklerose abhängige Komplikation an. Indessen sind Veränderungen der Hirnsubstanz, welche mit diesen Störungen in $\mathrm{Zu}$ sammenhang gebracht werden könnten, bis jetzt nicht sicher konstatiert. Über das Vorkommen solcher Krampfattacken selbst haben Debove, Lecoq, Vulpian, Bernhardt u. a. einschlägige Beobachtungen publiziert. Auch Leyden erwähnt das gelegentliche Auftreten von Epilepsie im Gefolge langdauernder, mit anderen zerebralen Symptomen komplizierter Tabes und beobachtete in einem Falle sogar ,sehr zahlreiche schwere Krampfanfälle, danach Koma und Exitus letalis". 
Immerhin läßt die spärliche Zahl entsprechender Mitteilungen und die Geteiltheit der darüber geäußerten Meinungen erkennen, daß Störungen der erwähnten Art bei einer unkomplizierten Tabes im ganzen wohl nur selten zur Wahrnehmung gelangen, Grund genug, in differentialdiagnostischer Hinsicht Vorsicht zu üben. Auch gilt für diese Insulte bei Tabes sowohl als auch bei Hirnlues das gleiche, was oben für die bei Paralyse auftretenden Krampfattacken gesagt wurde: nach den vorliegenden Mitteilungen in der Literatur zeigen sie weitaus häufiger apoplektiformen oder sonst irgendwie modifizierten Verlauf als typisch epileptisches Gepräge; jedenfalls dürften so ausgesprochen epileptiform verlaufende Zustandsbilder, wie sie in unserem Falle zur Wahrnehmung gelangten, bei organischen Affektionen im Zentralnervensystem zu den größten Seltenheiten gehören; aber ihre Seltenheit kann an sich noch keinen Gegenbeweis für ihre Zugehörigkeit zu diesem oder jenem Krankheitsprozesse bilden.

Ähnliche Schwierigkeiten ergaben sich für die exakte Deutung der gleichzeitig beobachteten psychischen Alterationen. Waren sie rein funktionell bedingt oder waren sie Ausdruck einer Lues cerebrospinalis, resp. einer diffusen degenerativen Hirnrindenerkrankung? Seit C. Westphal wissen wir, daß sich der klinische Symptomenkomplex der Tabes nicht selten mit wirklicher Geisteskrankheit verbindet. Einmal können sich an eine progressive Paralyse Erscheinungen von Hinterstrangsentartung anschließen; dann kann der degenerative Prozeß im Rückenmark zu gleicher Zeit die Hirnrinde ergreifen und schließlich kann sich einer typischen Tabes im weiteren Verlaufe gelegentlich noch eine sog. aszendierende progressive Paralyse hinzugesellen. Andererseits aber wissen wir aus einschlägigen Mitteilungen von Cassirer, Me yer u. a. auch, daß zuweilen im Verlaufe der Tabes rein ,funktionelle" Psychosen zur Entwicklung kommen können. Speziell die chronische halluzinatorische Paranoia tritt nicht selten bei Tabikern auf, und Meyer, Kraepelin u. a. ${ }^{1}$ ) betrachten paranoide Krankheitszustände geradezu als die eigentlichen kennzeichnenden Tabespsychosen. Wie aber A. Westphal u. a. gezeigt haben, können mitunter im Verlaufe einer echten Hirnlues die allerverschiedensten Formen von Psychosen auftreten, ohne daß sie Ausdruck einer Paralyse zu sein brauchten. Für welche dieser Möglichkeiten schien die Wahrscheinlichkeit nun zu sprechen?

Nach der gegebenen Schilderung zeichneten sich die in unserem Falle beobachteten psychischen Störungen aus durch jähe Stimmungsschwankungen, massenhaft auftretende plastische Gesichts- und Gehörstäuschungen und daran anknüpfende Wahnideen und Erregungen.

1) Vgl. Kraepelin, Psychiatrie. 8. Aufl. 1909 ff. Ferner die am Schluß angeführte einschlägige Spezialliteratur. 
Gewisse Vorstellungsreihen kehrten wohl oft in ähnlicher Weise wieder und wurden dann nicht selten auch längere Zeit festgehalten; doch fand eine eigentliche Systematisierung nicht statt. Eine gewisse Verkümmerung in ethisch-moralischer Hinsicht war wohl zu bemerken, von einer eigentlichen fortschreitenden Demenz, von einer zunehmenden Urteils- und Gedächtnisschwäche dagegen konnte nicht gesprochen werden; ebensowenig fiel etwa ausgesprochen schwachsinnige Megalomanie und Euphorie u. dgl. m. an der Kranken auf. Bald schien ein charakteristisches paranoides Zustandsbild zu bestehen, bald glich die Alteration mehr einer akuten halluzinatorischen Verwirrtheit, gelegentlich wechselten auch delirante Zustände mit Zuständen von Benommenheit und Katalepsie ab. In Phasen leidlicher Ruhe vermochte die Kranke oft bis in die feinsten Details hinein sachgemäße Auskunft zu geben und zutreffende Urteile zu fällen, in Phasen gesteigerter seelischer Alteration dagegen fehlte ihr oft alle Besonnenheit und Krankheitseinsicht. Daß die in ihren Symptomen oft wechselnde Psychose periodisch, und zwar synchron mit den Anfällen exacerbierte, resp. nachließ, wurde oben bereits bemerkt; jedenfalls aber ließ sie ein einheitliches Gepräge vermissen. Das sprach nun an sich noch nicht ohne weiteres gegen funktionelle Bedingtheit; denn ähnliche oft wechselnde Krankheitszustände kommen zuweilen nicht nur im Verlaufe der gewöhnlichen Epilepsie, sondern auch sonst bei den verschiedensten Nervenkrankheiten ohne nachweisbare anatomische Schädigung der Hirnrinde zur Wahrnehmung. Immerhin war der proteusartige Wechsel der Symptome auffällig, das häufige Abwechseln von Benommenheits-, Erregtheits- oder Verwirrtheitszuständen mit Phasen leidlichen geistigen Wohlbefindens, die Verbindung mit Krampfattacken und der gleichzeitig bestehende somatische Symptomenkomplex. Wenn die letzteren auch keine absolut beweiskräftigen Hinweise auf organische Hirnrindenaffektionen zu enthalten schienen, so legten die psychischen Störungen doch immerhin den Verdacht auf solche nahe; denn ähnliche psychische Störungen können sowohl bei Tabesparalyse als auch bei syphilitischer Konvexitätsmeningitis auftreten. Daß es in unserem Falle zu einer tiefergehenden Demenz nicht gekommen ist, würde die Annahme eines spezifischen Hirnrindenprozesses eher noch zu stützen geeignet gewesen sein; aber auch bezüglich der Tabesparalyse hat insbesondere Binswanger nachdrücklichst auf gewisse für unseren Fall zutreffende Verlaufseigentümlichkeiten aufmerksam gemacht. Nicht nur das Gedächtnis, auch die geistige Regsamkeit überhaupt bleibt bei ihr nicht selten überraschend lange gut erhalten, die Charakterentartung überwiegt bei ihr meist die Verstandesschwäche, Sprachstörungen und andere motorische Anomalien fehlen häufig ganz, der Verlauf ist in der Regel ein sehr protrahierter, oft ist jahrelang kein Fortschreiten der psychischen 
Symptome wahrzunehmen usw. Allerdings pflegen Krampfparoxysmen bei diesen Formen meist nur selten aufzutreten; aber auf dieses Moment war wohl, wie wir oben sahen, allzu großes Gewicht in differentialdiagnostischer Hinsicht nicht zu legen.

Ziehen wir aus allen diesen Erwägungen das Fazit, so schien die Annahme einer Tabesparalyse, d. h. einer gleichzeitig mit der Tabes einsetzenden oder erst nach längerem Bestehen derselben hinzugetretenen Paralyse, am naheliegendsten, schon im Hinblick auf die bestehenden somatischen Störungen. Indessen war eine diffuse Lues cerebrospinalis nicht ganz von der Hand zu weisen, ebensowenig wie sich eine rein funktionelle Störung der cerebralen Vorgänge mit absoluter Sicherheit ausschließen ließ. Aus dem Mißerfolge der antiepileptischen und antiluetischen Kuren war ein bindender differentialdiagnostischer Schluß auf die Natur des vorliegenden Leidens nicht zu ziehen; einesteils gibt es ja genug Fälle typischer Lues des Zentralnervensystems, die sich refraktär gegen spezifische Kuren verhalten, andernteils aber sind auch rein funktionelle oder degenerative Hirnrindenaffektionen nicht immer in zweifelloser Weise durch Kuren irgendwelcher Art zu beeinflussen. Noch weitere Schwierigkeiten für die differentielle Abgrenzung der einzelnen hier in Betracht zu ziehenden Krankheitsbilder ergaben sich aber im Hinblick darauf, daß nicht allzu selten auch Mischformen verschiedener Krankheitsprozesse zur Entwicklung gelangen. So haben beispielsweise $O$ p penheim u. a. Fälle mitgeteilt, die zeigen, daß die spezifische Lues cerebrospinalis gelegentlich ein der Tabes dorsalis ähnliches, sich mit Hirnsymptomen kombinierendes Krankheitsbild hervorzurufen vermag, das daher wohl auch als Pseudotabes syphilitica bezeichnet worden ist. Ferner haben Dejerine, Sachs, HoffmannKuh, Dinkler u. a. Kombinationen der Tabes und Zambaco, Westphal, L. Meyer, Binswanger, Hübner, Sträussler, v. Rad, Heubner u. a. Kombinationen der Paralyse mit spezifischen syphilitischen Prozessen im Zentralnervensystem beobachtet." Auch das zuerst von Fournier und seinen Schülern gezeichnete Bild der syphilitischen Pseudoparalyse war in Betracht zu ziehen, wie denn wohl allgemein die Schwierigkeit der Differentialdiagnose zwischen allen diesen Krankheitsprozessen anerkannt wird ${ }^{1}$ ). So mußte die Diagnose des Krankheitsfalles intra vitam einigermaßen in suspenso gelassen werden.

Die Dauer der Krankheit betrug, wenn man das im 37. Lebensjahre der Kranken erfolgte Auftreten der lancinierenden Schmerzen als Be-

1) Vgl. hierzu namentlich Nonne, Syphilis u. Nervensystem, 2. Aufl., S. 307, $316,321,325,463,482$ usw.; O p pe nhei m, Lehrb. d. Nervenkrankheiten, 4. Aufl., S. 154, 324, 950ff.; S pielme yer, Die progr. Paralyse in Lewandows kys Handbuch d. Neurol., Bd. 3, S. 488ff.; ferner die in der Literaturübersicht am Schluß angeführten Spezialarbeiten. 
ginn betrachtet, über 8 Jahre; doch ist es nach der Anamnese nicht ausgeschlossen, daß dem Prozesse als einleitendes Stadium noch ein typisch epileptisches, im 25. Lebensjahre einsetzendes Zustandsbild vorausgegangen ist, wie es nach den Beobachtungen Binswangers u. a. ja gelegentlich geschieht. Der Tod der Kranken trat nach vollendetem 45. Lebensjahre im Anschluß an einen schweren Krampfanfall und an Erregungszustände mit konsekutivem Koma ein. Die Sektion ergab, von den durch den tödlich wirkenden Schlußzustand herbeigeführten Veränderungen der inneren Organe abgesehen, makroskopisch keine sicher auf Lues zu beziehenden Affektionen; immerhin seien als verdächtig erwähnt die auf der Leber vorhandenen oberflächlichen, strahlig verlaufenden, derben, schwieligen Narben, die diffuse milchige Trübung der auffällig verdickten und in den vorderen und mittleren Hirnpartien adhärenten weichen Häute, die Sklerose der Basisgefäße und der aufsteigenden Aorta, sowie der Hydrocephalus externus et internus, der allerdings nur mäßige Grade erreichte. Im übrigen fiel makroskopisch nur noch der dicke, kompakte Schädel mit seinen reich und tief entwickelten Gefäßfurchen, die zarte Granulierung des Ependyms im 4. Hirnventrikel und die graue Schrumpfung und Entartung der beiden Nn. optici auf. Mikroskopisch wurden zwar nur einzelne Stücke des Zentralnervensystems genauer untersucht; immerhin ließ sich doch soviel mit Sicherheit sagen, daß entschieden als gummös anzusprechende Veränderungen nicht vorlagen. Ob freilich ursprünglich eine spezifische diffuse Lues cerebrospinalis bestanden hat, war nicht sicher festzustellen; die Veränderungen an der Pia, an den Gefäßen und an den obersten Schichten der Hirnrinde konnten immerhin als inveterierte oder abgelaufene luetische Prozesse, resp. als Folgewirkungen solcher aufgefaßt werden. Eine in der typischen Weise lokalisierte Hirnrindenveränderung, wie sie der gewöhnlichen progressiven Paralyse eigen zu sein pflegt, lag jedenfalls nicht vor; doch waren wenigstens in den obersten Schichten der Hirnrinde typische degenerative Prozesse zur Entwicklung gelangt, so daß der Fall auch als „atypische Paralyse“ im Sinne der Autoren betrachtet werden konnte, umsomehr, als die in den Sehnerven und im Rückenmark konstatierten Veränderungen durchaus denen bei gewöhnlicher Tabes dorsalis entsprachen. Wir möchten es nach alledem für nicht unwahrscheinlich halten, daß ursprünglich eine diffuse Meningoencephalitis syphilitica an der Konvexität des Gehirns vorgelegen hat, die weiterhin $\mathrm{zu}$ einer diffusen degenerativen Erkrankung der oberflächlichen Hirnrindenschichten geführt und so Anlaß zu den beobachteten Störungen der zentralen Funktionen gegeben hat; auch dürfte es nicht ausgeschlossen erscheinen, daß den diffusen degenerativen atrophischen Prozessen im Rückenmark und in den Sehnerven, welche zur Entwicklung des typischen Symptomenkomplexes 
der Tabes dorsalis Anlaß gab, eine ähnliche Pathogenese zugrunde lag. -

Auch die beiden nächsten Fälle mögen als typische Beispiele für die Schwierigkeiten hier Platz finden, die sich in anamnestischer, ätiologischer und differentialdiagnostischer Hinsicht im Einzelfalle gelegentlich ergeben können.

Fall XII. Alwine Tb., geb. 18. IX. 1869, stammt aus kleinen, aber geordneten Verhältnissen, entwickelte sich kräftig und regelmäßig, ließ in der Schule mittlere Begabung erkennen. Die Epilepsie setzte im 9. Lebensjahre ein, angeblich sofort in ausgebildeter Form; einige Zeit vorher hat die Kranke ein Kopftrauma erlitten, das aber Spuren nicht zurückließ. Über ihren Lebenslauf ist näheres im übrigen nicht bekannt; insbesondere fehlen Mitteilungen darüber, ob die Kranke etwa einmal Syphilis akquiriert hat oder ob hereditäre Lues in Frage kommt, ob sie Aborte oder Fehlgeburten durchgemacht und in welcher Weise sich ihr epileptisches Leiden weiter entwickelt hat. Sichergestellt ist nur, daß die Kranke vom 9. Lebensjahre ab ununterbrochen in unregelmäßigen Intervallen von typischen epileptischen Insulten betroffen wurde, daß sexuelle Beziehungen wiederholt unterhalten worden sind, daß seit etwa 15-20 Jahren geistige Abschwächung erheblicheren Grades besteht, daß aber seit $4^{1} / 2-5$ Jahren der geistige Zustand abermals eine sichtliche Verschlimmerung erfahren hat. Die Anfälle selbst waren ihrem Charakter und Verlaufe nach stets gleich; sie traten mit Vorliebe nachts auf, in der Regel wöchentlich einmal, ab und zu aber auch in 3-4 hinter einander folgenden Nächten; besondere auslösende Momente sind nicht bekannt. Teils handelte es sich um universelle, beiderseits gleichstark ausgeprägte, mit Bewußtseinsverlust und Amnesie einhergehende tonisch-klonische Zuckungen, bei denen sie sich oft Zungenbisse zuzog, teils um rudimentäre Attacken. Nach Ablauf derselben erschien die Kranke bösartig, rücksichtslos, zornig gereizt; über ihr Verhalten in der Intervallärzeit wird nur summarisch gesagt, daß sie geistig erheblich abgeschwächt, aber körperlich rüstig und gesund sei; sie sorge und kümmere sich um nichts und habe nicht die geringste Lust zu einer geordneten Tätigkeit.

Am 16. VIII. 1909 hier untergebracht, bot sie im wesentlichen folgenden Zustand dar: Thre Körperlänge betrug $157 \mathrm{~cm}$, ihr Gewicht $52 \mathrm{~kg}$. Sie war regelmäßig, mittelkräftig entwickelt, Erscheinungen von Lues oder Residuen einer solchen waren nicht vorhanden. Die Haut an den Füßen und Unterschenkeln zeigte sich zeitweise stärker cyanotisch verfärbt, auch im Gesicht besteht deutliche Akrocyanose. Am Schädel fällt die fliehende Stirn auf, der Umfang beträgt $54 \mathrm{~cm}$, die Jochbogen springen stark vor, ebenso die Alveolarbogenfortsätze der Kiefer; letztere bedingen eine schräg nach vorn gerichtete Stellung des Gebisses, besonders der Schneidezähne; sonst sind besondere Deformitäten nicht wahrzunehmen. Die Augen liegen etwas tief in den Orbitalhöhlen. Die Augenlider werden nur wenig gehoben, doch besteht keine Ptosis. Die Pupillen sind beiderseits gleich, aber sehr eng (Miosis); die mit allen Kautelen vorgenommene Prüfung der Lichtreaktion ergibt prompte Reaktion auf Konvergenz und Akkommodation, aber beiderseits völlig erloschene Lichtreaktion; nur gelegentlich wurde eine ganz minimale Zuckung konstatiert. Die Gesichtszüge sind schlaff; der rechte Mundwinkel hängt etwas tiefer als der linke herab. Die Zunge wird auf Erfordern langsam vorgestreckt, ist auf der Oberfläche von tiefen Furchen durchzogen, weicht mit der Spitze etwas nach links ab und zittert deutlich. Die Tonsillen sind hypertrophisch. Am Stamm besteht ausgesprochener Angulus Ludovici. Die Reflexe der Kniescheibensehne sind sehr lebhaft, blitzartig ausfahrend, rechts stärker als links. Der linke Bauchdeckenreflex 
ist nicht auszulösen, rechts ist er deutlich vorhanden. Die Fußsohlenstich- und -strichreflexe sind beiderseits sehr lebhaft. Der Gang ist etwas schleppend und wenig elastisch, das Rombergsche Phänomen angedeutet. Beim Sprechen sind im Gesicht lebhafte fibrilläre Zuckungen wahrzunehmen. Beim Nachsprechen der bekannten Paradigmata, aber auch spontan macht sich erhebliches Silbenstolpern bemerkbar. Das Herz ist nach links bis zur Mammillarlinie verbreitert; die Herztöne an der Spitze sind etwas dumpf, der zweite Aortenton ist laut akzentuiert. Die rechte Arteria radialis fühlt sich etwas rigid an; die Pulswelle verläuft träge, der Puls ist im übrigen regelmäßig. Sonst bot die Untersuchung nichts auffälliges weiter dar. Auch in der Folgezeit blieb der körperliche Zustand im wesentlichen immer der gleiche; die körperlichen Reiz- und Lähmungserscheinungen erfuhren keine auffällige Verschlimmerung. Wiederholte Blutuntersuchungen ergaben stets positive Wasser mannsche Reaktion. Die ophthalmoskopische Untersuchung lieferte keine belangreichen Ergebnisse.

In geistiger Beziehung gibt sich in allen Äußerungen und Handlungen andauernd die fortgeschrittene Abschwächung zu erkennen. Stumpf, blöde für gewöhn. lich, gelegentlich aber auch sehr mißmutig und unwillig, wenn ihr etwas nicht nach Willen geschieht oder wenn sie den Zweck gewisser Maßnahmen (z. B. einer Untersuchung) nicht versteht, macht sie dann ihrem Verdrusse nicht selten in zerfahrener Weise durch Schimpfreden Luft. Eine gewisse summarische Orientierung ist noch vorhanden; doch sind ihre Äußerungen stets sehr läppisch und kindisch und vermag sie nur wenig zuverlässige Angaben über ihren Lebensgang und alle damit in Zusammenhang stehenden Fragen zu geben. Oft erscheint sie sehr trotzig und ablehnend; meist sind die Antworten, die sie auf Fragen gibt, sehr stereotyp und ausweichend. Ihre Kenntnisse sind selbst auf elementarsten Gebieten sehr dürftig und gering. Oft motivierte sie ihre Insuffizienz selbst mit den Worten: „Das kann ich mir alles nicht mehr merken; da bin ich zu schwach in meinem Schädel." Die Merkfähigkeit ist stark herabgesetzt; sie vermag daher längere Worte nicht nachzusprechen. Die Stimmung unterliegt häufigem jähen Wechsel: bald erscheint sie wehleidig, klagsam, weinerlich, bald - und solche Phasen überwiegen bei weitem enphorisch, sehr aufgeräumt, übermütig, zu Späßen und Witzchen geneigt, oft auch erotisch. Dazwischen schieben sich nicht selten Phasen, in denen sie ganz teilnahmlos und apathisch ist, oder sie wird plötzlich sehr erregt, laut und störend, belästigt und attackiert Mitkranke, braust heftig auf, beruhigt sich aber in der Regel, immer sehr bald wieder. Sinnestäuschungen und Wahnideen konnten nie nachgewiesen werden.

Die hier aufgetretenen Krampfparoxysmen unterschieden sich in nichts von den bei gewöhnlicher genuiner Epilepsie wahrzunehmenden Insulten; fast stets handelte es sich um vollausgeprägte Krampfanfälle; Anfälle von petit mal kamen bis jetzt höchstens zwei- oder dreimal zur Wahrnehmung. Das Bewußtsein war stets erloschen, hinterher bestand stets Amnesie. Nie machten sich cortikale oder Halbseitenerscheinungen $u$. dgl. m. geltend. Nach Ablauf derselben pflegt sich die Kranke immer sehr bald wieder zu erholen. Von Erscheinungen gesteigerter Gereiztheit und Empfindlichkeit abgesehen, zeigt sich der Zustand dann in psychischer Beziehung nicht wesentlich gegen sonst verändert. Die oben erwähnten Schwankungen im psychischen Verhalten sind nicht immer streng an Krampfparoxysmen gebunden, sondern machen sich in gleicher Weise oft auch in den intraparoxysmellen Intervallen geltend. Insgesamt gelangten in der hiesigen Anstalt in der Zeit vom 16. VIII. 1909 bis Ende April 1913119 Krampfanfälle zur Auslösung, 27 tagsüber, 92 nachts. Mehr als 3 Anfälle kamen an einem und demselben Tage bisher nicht vor. Die Zahl der Anfälle unterlag in den einzelnen Monaten großem Wechsel; die längste anfallsfreie $Z$ wischenzeit betrug einmal ohne voraus- 
gegangene, besondere Maßnahmen 3 Monate, meist nur höchstens $3-4$ Wochen; mehr als 10 Anfälle kamen im gleichen Monat bisher nicht vor.

Von einem schnellen fortschreitenden Verfall der geistigen Kräfte und Fähig. keiten war bis jetzt nichts zu bemerken. Die seit der Aufnahme zur Durchführung gelangte methodische Brommedikation hat einen bemerkenswerten Frfolg weder für die Epilepsie noch für das psychische Verhalten gehabt, ebensowenig deren zeitweilige Kombination mit Jodkali.

Fall XIII. Marta Sch., geb. 29. VII. 1866, soll erblich nicht belastet sein. Die Kranke entwickelte sich körperlich und geistig normal, machte schwerere Krankheiten nicht durch, wurde aber seit dem 12. Lebensjahre von typischen epileptischen Krampfanfällen heimgesucht, ohne daß anamnestisch eine Ursache dafür nachzuweisen wäre. Ob hereditäre oder akquirierte Syphilis in Frage kommt, ist nicht in Erfahrung zu bringen gewesen. Bis zu ihrer Verheiratung - am 17. VII. 1887 soll die Epilepsie jedenfalls nur verhältnismäßig leicht aufgetreten sein, seit etwa 1900 stellen sich die Krampfanfälle häufiger und heftiger ein als früher; einige Jahre später gesellten sich oft tagelang währende psychische Störungen hinzu, während vorher in den intraparoxysmellen Intervallen geistige Klarheit bestanden haben soll. Eine 1908 durchgeführte antiepileptische Kur von etwa 4 Monaten Dauer hatte keinen nennenswerten Erfolg. Úber etwa aufgetretene syphilitische Erscheinungen und spezifische Kuren ist nichts bekannt.

Ein ärztlicher Bericht aus dem Jahre 1910 besagt, daß die Kranke körperlich durchaus gesund erscheint. Auf ein organisches Gehirnleiden hindeutende Symptome wurden vermißt. Im übrigen heißt es: Bei Beginn eines Anfalles schreit die Kranke in der Regel laut auf, ihr Blick wird starr, dann verliert sie das Bewußt. sein, fällt um und hat $1-2$ Minuten lang allgemeine, beiderseits gleich stark ausgeprägte tonisch-klonische Krämpfe, bei denen sie sich oft kleine Verletzungen und Zungenbisse zuzieht, oft auch Urin und Kot unter sich läßt. Nach Ablauf des Anfalls erscheint die Kranke abgespannt und schläfrig; nach dem Erwachen hat sie nicht die geringste Erinnerung an das Vorgefallene. Mit Vorliebe treten die Anfälle nachts auf, teils vereinzelt, teils in Gruppen; unter einander zeigen sie größte Ähnlichkeit. Zwischen zwei Anfällen liegt nie eine über 3 Wochen währende Pause. In den anfallsfreien Zwischenzeiten erscheint die Kranke geistig abgeschwächt. An die Insulte schließt sich jetzt oft tagelang währendes Irresein an. Es kamen Zustände von Exaltation und Depression vor, letztere überwiegen in letzter Zeit. In solchen Phasen bestand nicht selten Taedium vitae mit Neigung zu Suicidversuchen, während die Exaltation sich oft bis zu Tobsuchtsanfällen steigerte, in denen sie gelegentlich gefährlich für ihre Umgebung wurde.

Am 28. VI. 1910 wurde die Kranke in der hiesigen Anstalt aufgenommen. Sie ist regelmäßig und sehr kräftig entwickelt, befindet sich in gutem Ernährungszustande, ist $167 \mathrm{~cm}$ lang, das Körpergewicht schwankte zwischen 59 bis $72 \mathrm{~kg}$. Störungen seitens der inneren Organe liegen nicht vor; auf Syphilis verdächtige Symptome gelangten nie zur Wahrnehmung; auch Residuen einer früheren Lues waren nicht aufzufinden. Doch fielen schon gleich bei der ersten Untersuchung eine Reihe von Störungen̂n auf körperlichem Gebiete auf, die auf ein organisches Gehirnleiden hinzuweisen schienen. Beim Sprechen traten Mitbewegungen im Gebiete der mimischen Muskulatur auf; beide Gesichtshälften erschienen etwas schlaff; in der Gesichtsmuskulatur bemerkte man gelegentlich fibrilläre Zuckungen. Auch die vorgestreckte Zunge, die Hände und die gespreizten Finger ließen leichte Tremorerscheinungen erkennen. Die Physiognomie war schlaff, ausdruckslos, deutlich dement. Der Gang war unsicher, die Haltung schlaff; spatische Erscheinungen bestanden nicht, auch keine ausgesprochene Ataxie; das Ro mbergsche Phänomen war angedeutet. Die Pupillen waren leicht different, reagierten aber damals noch 
prompt auf Lichteinfall und Akkommodation. Die Patellarreflexe waren etwas gesteigert, die Sensibilität, speziell die Schmerzempfindlichkeit allgemein etwas herabgesetzt. Die Sehrift war zitterig, unbeholfen; in den Worten traten, von orthographischen Unvollkommenheiten abgesehen, oft Auslassungen einzelner Buchstaben hervor. Die bekannten Paradigmata (Flanellappen usw.) wurden nur verstümmelt reproduziert; auch sonst erschien die Sprache vielfach fehlerhaft, stockend und unbeholfen. Eigentliche Herdsymptome waren nicht vorhanden.

Im Laufe der Zeit traten wesentliche neue Störungen nicht hinzu; einige nerväse Reiz- und Lähmungserscheinungen erfuhren freilich deutlichere Ausprägung. Namentlich in Zeiten gesteigerter Unruhe und Erregung treten z. B. die Sprachstörungen sehr auffällig hervor. Auch die Pupillenreaktion wurde oft sehr träge gefunden, bzw. ganz vermißt. Im ganzen aber trifft der bei der Aufnahme erhobene körperliche Status auch jetzt noch zu.

In geistiger Hinsicht zeigte sich das Befinden und Verhalten der Kranken fortgesetzt großem Wechsel unterworfen. Oft besteht Gereiztheit und Heftigkeit mit Neigung zu sinnlosen und verkehrten Hand]ungen. Die Orientierung über Zeit, Ort, Umgebung ist meist völlig gestört. In ihre Erlebnisse vermag sie keine rechte Ordnung mehr zu bringen; ihre Mitteilungen über persönliche, familiäre und in der Umgebung sich abspielende Ereignisse sind stets mehr oder weniger unklar, zerfahren und unzuverlässig. Die Stimmung schwankt zwischen leidlicher Ruhe und Besonnenheit, euphorischer Zufriedenheit, allgemeiner Exaltation und Erregtheit oder Depression mit Angstanfällen usw. hin und her. Zuweilen besteht völlige Verwirrtheit mit psychomotorischer Erregtheit, die sich gelegentlich unter dem Einflusse von Halluzinationen des Gesichts und Gehörs bis zu Tobsuchtsanfällen steigert. Oft sind die Außerungen durchsetzt von allerhand wechselnden Wahnideen, bald von vagen hypochondrischen Klagen und Befürchtungen, bald von Beeinträchtigungs- und Verfolgungsideen, bald auch von schwachsinnigen Größenideen. Alle Wahnvorstellungen haften immer nur kurze Zeit im Bewußtsein; eine Systematisierung ist nicht festzustellen. Intellektuell erscheint die Kranke auch in Phasen größerer Ruhe und Besonnenheit stets nur wenig rege; die Erinnerung für vergangene Erlebnisse ist stark beeinträchtigt, die Merkfähigkeit erheblich herabgesetzt, neue Eindrücke werden kaum noch aufgenommen und geistig verarbeitet. Ihre Kenntnisse sind dürftig und in der letzten Zeit offenbar stark zusammengeschrumpft. Gleichgültig, stumpf und teilnahmlos bringt sie die Zeit hin, ohne sich zu einer geordneten Tätigkeit heranziehen zu lassen und ohne sich ihrer Lage je bewußt zu werden. Zu den Krampfanfällen stehen die psychischen Alterationen in keiner deutlichen Beziehung; Steigerungen und Nachlässe kommen und gehen anscheinend regellos und unvermittelt. Anfangs gelangten noch häufiger Phasen leidlicher Ruhe und Besonnenheit zur Beobachtung als während der letzten Zeit; auch macht die Kranke seit etwa einem Jahr im ganzen einen noch schlafferen, gleichgültigeren, teilnahmloseren Eindruck als im Anfange; doch ist der Unterschied zwischen früher und jetzt kein allzu augenfälliger; insbesondere konnte nach den epileptischen Insulten kein hochgradiger Verfall der geistigen Kräfte und Fähigkeiten konstatiert werden.

Insgesamt gelangten in der hiesigen Anstalt seit dem 28. VI. 1910 bis Ende April 1913246 Krampfanfälle zur Wahrnehmung, 176 nachts, 70 bei Tage. 233mal handelte es sich um voll ausgeprägte große Attacken. 13 mal um Anfälle von petit mal. Die Zahl der in einem Monat aufgetretenen Paroxysmen schwankte zwischen 4-14, durchschnittlich kamen allmonatlich etwa 7 Insulte vor. An einem Tage traten bis jetzt nie mehr als 4 Anfälle auf, meist blieben sie vereinzelt; die anfallsfreie Zwischenzeit betrug im höchsten Falle 3 Wochen. Der Typus der Anfälle entsprach stets durchaus dem bei gewöhnlicher genuiner Epilepsie (initialer Schrei, 
allgemeine, beiderseits gleichstark ausgeprägte tonisch-klonische Krämpfe, Erlöschen des Bewußtseins, Enuresis, Zungenbisse, Amnesie usw.). Im Anschluß daran erschien die Kranke meist eine Zeitlang benommen, pflegte aber nach dem Erwachen gegen früher nicht auffällig verändert zu sein. Nie machten sich cortikale oder Halbseitenerscheinungen im Anfalle bemerkbar.

BrNa- und Jodkalikuren erwiesen sich bis jetzt völlig erfolglos. Die Wasser mannsche Blutreaktion und die Nonne-Apeltsche Phase I - Reaktion in der Cerebrospinalflüssigkeit fielen positiv aus.

Über erbliche Belastung oder Lues der Eltern war in diesen beiden Fällen Sicheres nicht zu ermitteln. Die Epilepsie gelangte bei Fall XII im 9. Lebensjahre zum Vorschein, angeblich nach einem Kopftrauma, das aber Spuren nicht zurückließ, während sie bei Fall XIII im 12. Lebensjahre hervortrat, ohne daß eine besondere Schädigung vorausgegangen zu sein scheint. $\mathrm{Ob}$ und wann im späteren Leben etwa eine Lues hinzugetreten ist, war gleichfalls nicht zu eruieren; Residuen oder Zeichen einer solchen sind jedenfalls nicht vorhanden; auch über Fehlgeburten u. dgl. m. verlautet nichts. Gleichwohl deutet der positive Ausfall der Wassermannschen Reaktion in beiden Fällen auf eine syphilitische Durchseuchung hin; auch spricht die schließliche Weiterentwicklung des epileptischen Leidens in beiden Fällen zum mindesten nicht gegen die Annahme eines luetischen Einschlages. Bei Fall XIII speziell findet dieser Verdacht noch darin weitere Stützen, daß die Kranke kinderlos geblieben ist und daß bei ihr im 34. Lebensjahre, d. h. ca. 13 Jahre nach der Verheiratung, ohne vorausgegangene besondere Schädigungen eine auffällige Häufung und Steigerung der Anfälle einzusetzen begann, wozu sich dann später noch allerhand psychische Störungen von anscheinend progressivem Charakter gesellten. Bei der Aufnahme in die Anstalt, die bei Fall XII im 40., bei Fall XIII im 44. Lebensjahre erfolgte, fanden sich die beiden Kranken bereits in hohem Grade geistig abgeschwächt, und wenn der Verfall der geistigen Kräfte und Fähigkeiten seitdem auch keine eklatanten Fortschritte weiter gemacht hat, so wird doch für beide Fälle eine seit einer Reihe von Jahren zu bemerkende fortschreitende Verschlimmerung des geistigen Gesamtzustandes bezeugt. Die in der hiesigen Anstalt wahrgenommenen Insulte entsprachen, wie die Beschreibung zeigt, stets durchaus denen der gewöhnlichen genuinen Epilepsie; vorzugsweise nachts auftretend, verliefen sie meist in Form großer, voll ausgeprägter Attacken, während kleine rudimentäre Attacken nur ganz vereinzelt zur Beobachtung gelangten. Nie machten sich corticale oder Herdsymptome im Anschluß daran bemerkbar. Die angewandten antiepileptischen und antiluetischen Heilmittel versagten und übten auf die weitere Ausgestaltung des Leidens überhaupt keinen bemerkenswerten Einfluß aus. Die proteusartig wechselnden Alterationen in der psychischen Sphäre, die im Verlaufe der Zeit namentlich bei Fall XIII 
zu einer tiefgreifenden Umwandlung der Persönlichkeit geführt haben, zeigen sich nicht immer streng an die Krampfparoxysmen gebunden, machen sich vielmehr auch in den Intervallärzeiten vielfach sehr ausgesprochen geltend, insbesondere bei Fall XIII. Hand in Hand damit gehen die auf körperlichem Gebiete hervortretenden nervösen Reizund Lähmungserscheinungen, die bemerkten Störungen der Innervation, der Motilität, der Sprache, der Schrift, der Sensibilität und der Reflexerregbarkeit.

In ihrer Gesamtheit sind alle diese Störungen geeignet, den Verdacht auf progressive Paralyse wachzurufen, zumal im Hinblick auf den positiven Ausfall der Wassermannschen Reaktion, auf die Krampfanfälle und die mit fortschreitender intellektueller Schwäche verbundenen psychischen Alterationen. Freilich hat die Demenz in der letzten Zeit keine auffälligen Fortschritte weiter gemacht. Aber in dieser Beziehung kommt es auch im Verlaufe der gewöhnlichen Paralyse gelegentlich zu mehr oder minder lang andauernden Stillständen. Daß die Insulte stets typisch epileptisches Gepräge erkennen lassen und schon seit der Jugend bestehen, spricht gleichfalls nicht unbedingt dagegen. Denn einmal können in allerdings ziemlich seltenen Fällen auch die paralytischen Insulte andauernd ganz nach dem Typus epileptischer Attacken verlaufen, und dann könnte es sich ja ursprünglich um echte genuine Epilepsie gehandelt haben, der sich nur später unter dem Einflusse einer luetischen Infektion eine fortschreitende diffuse degenerative Hirnrindenerkrankung, d. h. eben eine progressive Paralyse hinzugesellt hat. Immerhin bleibt zu bedenken, daß das Hinzutreten einer in der gewöhnlichen Weise verlaufenden progressiven Paralyse zu einer typischen, schon seit Dezennien bestehenden Epilepsie entschieden zu den größten Seltenheiten gehört ${ }^{1}$ ). Auch ist zu beachten, daß sich ähnliche Schädigungen in der psychischen Sphäre wie hier im Verlaufe der Jahre auch einer gewöhnlichen genuinen Epilepsie hinzugesellen können. Ferner können sich auch bei echter Epilepsie als Ausdruck anscheinend zentraler, wenn auch anatomisch noch nicht

1) Bei der Häufigkeit der Lues einerseits und der Epilepsie andererseits ist anzunehmen, daß nicht allzu selten wohl auch Epileptiker während ihres Verweilens in der Außenwelt eine Syphilis akquirieren. Wenn es nun zutrifft, was fast allgemein gelehrt wird und wofür sich die Beweise nach Noguchis Befunden in neuester Zeit noch zu mehren versprechen, daßß die Syphilis in der Ätiologie der progressiven Paralyse von ausschlaggebender Bedeutung ist, so müßten unseres Erachtens auch bei syphilitisch infizierten Epileptikern häufiger, als es tatsächlich der Fall ist, allmählich diffuse degenerative Hirnrindenerkrankungen zur Entwicklung gelangen können. Woran es liegen mag, daß tatsächlich nur äußerst selten der Ưbergang einer echten Epilepsie in progressive Paralyse zu beobachten ist, ist schwer zu sagen. Fast möchte es scheinen, als bilde eine bestehende Epilepsie bei etwa eintretender luetischer Durchseuchung einen gewissen Schutz gegenüber der späteren Etablierung einer typischen paralytischen Hirnrindenerkrankung. Tatsächlich 
genügend aufgeklärter Vorgänge nicht allzu selten allerhand chronisch fortbestehende Störungen der Sprache und der Innervation, Steigerungen der Reflexerregbarkeit $u$. dgl. m. einstellen, die in ihrer differentialdiagnostischen Bedeutung nicht überschätzt werden dürfen ${ }^{1}$ ). Schließlich läßt sich die Möglichkeit nicht ganz von der Hand weisen, daß ähnliche Störungen wie hier gelegentlich wohl auch ohne progressive organische Prozesse als einfache „,Stigmata der Lues des Zentralnervensystems" zustande kommen können. Wir wagen aus allen diesen Gründen nicht recht, diese Fälle ohne weiteres schon als progressive Paralyse anzusprechen, obschon sich nicht verhehlen läßt, daß psychischsomatische Störungen der erwähnten Art in dieser Häufung und Gruppierung bei gewöhnlicher Epilepsie nur selten zu finden sein dürften und da $B$ der positive Ausfall der Wassermannschen Reaktion und bei Fall XIII der gleichzeitig erhobene Globulinbefund in der Cerebrospinalflüssigkeit noch weiterhin zugunsten der Annahme einer diffusen degenerativen Rindenerkrankung oder zum mindesten einer paralyseähnlichen Affektion zu sprechen scheint. Für andersartige organische oder für spezifische luetische Prozesse im Zentralnervensystem liegen hinreichende Verdachtsmomente wohl in keinem der beiden Fälle vor.

Auch die folgenden drei Fälle wurden der Anstalt als ,Epileptiker“ überwiesen; nach der Art der aufgetretenen Krankheitserscheinungen, nach dem ganzen Verlaufe und nach den Ergebnissen der Autopsie kann es aber wohl kaum einem Zweifel unterliegen, daß es sich hier nicht um Epileptiker, sondern um Paralytiker gehandelt hat. Lediglich ihres allgemeinen Interesses und ihrer besonderen Eigentümlichkeiten wegen, die die differentielle Abgrenzung der Fälle insbesondere im Anfange schwierig gestalteten, mögen sie hier angereiht werden, zugleich als typische Beispiele sogenannter ,,postsyphilitischer" mit epileptischen Insulten einhergehender Erkrankungsformen.

Fall XIV. Gustav M., geb. 31. VII. 1846, muß als erblich belastet insofern gelten, als sein Vater Trinker war und ein Bruder durch Selbstmord endete. Er entwickelte sich körperlich und geistig regelmäßig, bot früher auffällige Störungen seitens des Nervensystems nicht dar, Jernte in der Schule gut, war nach seiner

scheinen solche Fälle auch meist in ,atypischer" Weise zu verlaufen, insofern epileptische und paralytische Symptome sich kombinieren und der Gesamtverlauf ein auffällig protrahierter und nicht so schnell in körperlichen und geistigen Verfall auslaufender ist. Ihre klinische Stellung und Zugehörigkeit zur echten Paralyse muß daher wohl vorläufig noch fraglich bleiben; vielleicht ist man nur berechtigt, von einer auf dem Boden der Epilepsie erwachsenden paralyse-ähnlichen Erkrankung zu sprechen, die sich etwa durch eine bestimmte Lokalisation und Ausbreitung der paralytischen Degeneration in der Hirnrinde gegenüber der gewöhnlihcen Paralyse auszeichnet. Hier würde für weitere klinisch-anatomische Untersuchungen gewiß noch ein dankbares Feld zu bebauen sein.

1) Vgl. hierzu z. B. R. So m mer, Diagnostik der Geisteskrankheiten. 1901, S. $142,274 \mathrm{ff}$. usw. 
Schulzeit zunächst Laufbursche, dann Bierausgeber, machte den Feldzug 1870-71 als Jäger mit und kehrte, bei St. Privat durch einen Schuß verwundet, als Invalide zurück. Als Soldat zog er sich eine Lues zu; ob er einer gründlichen Kur unterworfen worden ist, ist nicht sicher gestellt. Residuen der früheren Lues waren jedenfalls in späterer Zeit in keiner Weise mehr zu bemerken. 1871 heiratete er. Einige Kinder starben bald nach der Geburt, zwei Kinder blieben leben und sollen sich gesund entwickelt haben. Nach dem Tode der Frau — sie starb $1876 \mathrm{im}$ Anschluß an die letzte Entbindung - begann Pat. in stärkerem Maße zu trinken. Seit 1875 traten zuerst seltener, später häufiger, zuletzt etwa alle zwei Wochen vereinzelt, bald tags, bald nachts typische epileptische Krampfanfälle ohne andere cerebrale Begleitsymptome auf. Geistig erschien der Kranke, der wohl vorübergehend, aber nicht fortlaufend, ohne nennenswerten Erfolg mit Brompräparaten behandelt worden war, in den intraparoxysmellen Intervallen bis gegen Ende 1890 fast vollkommen gesund. Seit dieser Zeit machte sich schnell zunehmende geistige Abschwächung neben jähen Stimmungsschwankungen bemerkbar. Zeitweise traten auch allerhand unsinnige Größenideen hervor, daneben auch Sprach- und Schreibstörungen. Doch konnte er bis Weihnachten 1891 noch seiner Berufstätigkeit nachgehen; dann wurde er wegen ungenügender Leistungen entlassen und am 8. I. 1892 in der Irrenanstalt zu Dr. untergebracht. Hier zeigte er sich bereits hochgradig dement, machte über sich und seine Verhältnisse durchaus verworrene Angaben, äußerte allerhand schwachsinnige Größenideen, bezeichnete sich bald als Kaiser, bald als König, bald als Millionär, bald nur als Schlossergeselle. erwartete, da er sich nicht für krank hielt, alle möglichen militärischen Rangerhöhungen und Auszeichnungen u. ä. m., befand sich andauernd in heiter erregter Stimmung, erschien gelegentlich zu plötzlichen Gewalttaten geneigt. Tagsüber hielt er sich noch leidlich sauber und ordentlich, nachts war er oft unsauber. Nicht selten traten Anfälle auf, die in ibrem Verlaufe und Typus durchaus denen der genuinen Epilepsie entsprachen: universelle, beiderseits gleichstark ausgeprägte Zuckungen, die in der Regel bis zu $1 \frac{1}{2}$ Minuten anhielten, mit Bewußtseinsverlust einhergingen und nach einem kurzen Dämmerzustande keinerlei bemerkenswerte Störungen hinterließen. Mitunter traten dieselben in Gruppen bis zu 6 Anfällen an einem Tage auf. Doch ließ der körperliche Befund kaum noch einen Zweifel an der Diagnose: progressive Paralyse. Die Sprache war in charakteristischer Weise gestört, die Patellarreflexe zeigten sich gesteigert, die Zunge wurde zwar gerade, aber zitternd vorgestreckt, die linke Pupille erschien weiter als die rechte beide waren absolut lichtstarr, die Schmerzempfindung fand sich allgemein stark herabgesetzt usw. Bei der Überführung nach hier - am 23. VI. 1892 - erschien der Kranke geistig und körperlich schon völlig heruntergekommen und verfiel sichtlich mit jedem Tage mehr. Am 22. VIII. 1892 trat Exitus letalis ein.

Die Sektion ergab in der Hauptsache folgendes: Der Leichnam war $165 \mathrm{~cm}$ lang, $45 \mathrm{~kg}$ schwer. Das Schädeldach wird als dick und schwer bezeichnet. Die harte Hirnhaut war prall gespannt.; beim Einschneiden entleerte sich reichlich blutige Flüssigkeit; beim Zurückschlagen der Hirnhaut bemerkte man etwa in der Ausdehnung einer Birne ein $1 \mathrm{~cm}$ dickes Blutgerinnsel. Das ganze Gehirn war von einer dicken bindegewebigen Auflagerung umgeben, die Gefäße, besonders die der Basis, zeigten sich atheromatös entartet. Das Gehirn wog unzerschnitten $1280 \mathrm{~g}$, es flossen $140 \mathrm{cbcm}$ Subduralflüssigkeit und $100 \mathrm{cbcm}$ Hirnflüssigkeit ab. Das Gehirn erschien atrophisch, das Kleinhirn sehr blutreich, die Hirnhöhlen waren erweitert und reichlich mit Flüssigkeit gefüllt. Im übrigen fanden sich: das Herz erschlafft, die Coronararterien und die Aorta stark sklerosiert, rechts Pleuritis adhaesiva, beiderseits Lungenödem, beide Nieren etwas atrophisch, die Leber verfettet. Eine mikroskopische Untersuchung wurde nicht vorgenommen. 
Fall XV. Lina A., geb. 27. IV. 1861, soll erblich nicht belastet sein. Sic besuchte die Volksschule mit zufriedenstellendem Erfolge. Im Alter von 21 Jahren verheiratete sie sich. Über etwa zur Wirksamkeit gelangte besondere Schädlichkeiten ist nichts bekannt, auch von einer Lues verlautet nichts, ebensowenig über Aborte oder Fehlgeburten. Von fünf in der Ehe geborenen Kindern starben drei in zartestem Alter, zwei Töchter entwickelten sich angeblich normal und waren gesund; die eine davon wurde $2^{1 / 2}$ Jahre vor der Unterbringung der Kranken in der hiesigen Anstalt in Berlin ermordet, aus welchem Anlaß und unter welchen besonderen Umständen ist hierorts nicht bekannt geworden. Im Jahre 1886 machte die Kranke ein ,hitziges Nervenfieber" durch, im Jahre 1888 litt sie an Kopfrose. Nervöse Störungen sollen im übrigen früher nicht bestanden haben.

Im Jahre 1898 stellten sich zum ersten Male als epileptische bezeichnete Krampfanfälle auf; sie wurden von der Kranken stets als „Magenkrämpfe" bezeichnet. Sie stürzte in der Rgel plötzlich vornüber, lag mit starren Gliedern, zuerst blassem, dann blaurotem Gesicht und stieren Augen bewußtlos da. Nach einigen Minuten löste sich der Krampf und das Bewußtsein kehrte wieder. Hinterher bestand nur summarische Erinnerung an das Vorgefallene; die Kranke klagte dann meist über Kopfschmerz und Brausen im Kopfe. Die Anfälle traten alle paar Wochen oder alle paar Tage, selbst mehrmals am gleichen Tage auf, häufig auch nachts; oft fiel sie dabei aus dem Bett. Schon vor dem Ausbruch der Krämpfe war angeblich oft Mißlaunigkeit, Fahrigkeit und schroffe hitzige Handlungsweise zu bemerken.

Vor $2^{1 / 2}$ Jahren, nach Empfang der Nachricht von dem gewaltsamen Tode der verheirateten Tochter stellte sich ein besonders schwerer Anfall ein, der nicht nur eine Verschlimmerung des Krampfleidens, sondern auch eine krankhafte Störung der Geistestätigkeit zur Folge hatte. Die Kranke wurde immer reizbarer, ging gleich zu Tätlichkeiten über, ließ ihren Zorn am Geschirr und Hausrat aus usw. Die Arbeitsfähigkeit ließ immer mehr nach. Sie machte alles verkehrt, merkte sich nichts mehr, hatte keine Ausdauer, vagierte umher, entwickelte im Gegensatz zu früher große Klatschsucht, äußerte in der letzten Zeit allerhand schwachsinnige Größenideen, sprach von Reichtümern, vom gewonnenen großen Los, kaufte unsinnige Sachen zusammen usw., produzierte aber gelegentlich auch Kleinheitsideen, sprach von Hunger und Elend, äußerte ab und zu Selbstmordgedanken $u$. ä.m. Seit Anfang Juli 1908 wurde sie immer erregter; der Inhalt ihrer Äußerungen wurde immer verworrener. Oft sang und schrie sie stundenlang zusammenhanglose Sätze oder Wörter usw.

In diesem Zustande am 8. VIII. 1908 hier untergebracht, bot sie im wesentlichen folgendes Bild dar: Von mittelgroßer, regelmäßiger Statur, erschien sie im Verhältnis zu ihren Jahren frühzeitig gealtert. Am stärksten zeigte sich dieser senile Habitus am Kopfe ausgeprägt: Das Haar ist größtenteils stark meliert, zum Teil ganz weiß, bis auf die Partie über der Hinterhauptsschuppe, die schwarzbraun gefärbt ist. Das Gesicht ist runzelig; an den Hornhäuten ist eine Andeutung von Arcus senilis wahrzunehmen. Der Schädel hat mesocephale Form; die Stirn ist hoch. Die Pupillen sind entrundet, verengt, und zwar ist die linke nur stecknadelkopfgroß, während die rechte etwa doppelt so weit ist. Auf Lichteinfall und Konvergenz erfolgt keine Reaktion; beide Pupillen sind absolut lichtstarr. Die Sehschärfe ist für die Ferne nicht herabgesetzt; sonst besteht geringe Presbyopie. Die äußeren Augenmuskeln funktionieren in normaler Ausgiebigkeit. Die Gesichtsmuskulatur ist wenig, aber gleichmäßig innerviert. Es besteht leichte Muskelunruhe der vorgestreckten Zunge, die ein wenig nach rechts abweicht. Am Rumpfe ist das Fettpolster dürftig entwickelt, die Haut faltig und trocken. Lungen, Herz, Abdominalorgane o. B. Ein Ast der rechten Arteria mammaria verläuft geschlängelt nach 
der Mammilla zu, fühlt sich sehr rigid durch die Haut hindurch an, springt stark vor; links fehlt derselbe. Die Patellarsehnenreflexe sind beträchtlich gesteigert, die Fußsohlenreflexe ebenso. Das Babinskische Phänomen ist beiderseits angedeutet. Am ganzen Körper besteht eine beträchtliche Hypästhesie, an den Unterarmen und Unterschenkeln eine so hochgradige Analgesie, daß Pat. nicht eine Spur Reaktion auf ganz tiefe Nadelstiche zeigt. Im übrigen bestehen noch typische artikulatorische Sprachstörungen, ausgeprägtes Silbenstolpern bei Paradigmen wie: Flanellappen, dritte reitende Artilleriebrigade, Schlittschuhschlüssel u. a.

In psychischer Hinsicht zeigte die Kranke von Anfang an eine ausgesprochene schwachsinnige Euphorie: Sie schwätzte viel in konfuser, prahlerischer Weise, renommierte mit Reichtümern, bezeichnete sich zeitweise als Gräfin, äußerte hochfahrende, unsinnige Pläne. Sehr häufig aber schlug die euphorische Stimmung plötzlich ohne jede äußere Veranlassung in das Gegenteil um. Pat. war dann tief deprimiert, weinte viel, äußerte Kleinheitsideen. Stets und besonders stark trat die Depression hervor, wenn die Kranke nach dem Schicksale ihrer ermordeten Tochter befragt wurde oder wenn sie selbst darauf zu sprechen kam, was häufig der Fall war. Sie wurde dann ganz verzweifelt, jammerte laut und wußte sich nicht zu fassen. Auffallend war aber die fast momentane Beruhigung der Kranken, die dann eintrat, wenn sie durch ein Scherzwort oder durch einen Vorgang in ihrer Umgebung abgelenkt wurde. Uber ihre Person und über ihren Lebensgang zeigte sie sich noch leidlich gut orientiert, war jedoch gänzlich unfähig, in klarer, verständiger Weise eine übersichtliche Schilderung zu geben. Vom Inhalt gestellter Fragen schweiften ihre Aussagen beständig ab; oft gefiel sie sich in läppischen Witzeleien, z. B. als ihr gesagt wird, die Pupillen seien lichtstarr: ,sie habe keine Stare im Auge, die säßen auf dem Baume"; als eine Mitkranke krähende Laute ausstieß: ,jetzt werden wieder Eier fertig; die legt Eier"; auf die Frage: ,was ist ihr Mann ?" „Posamentierer. Der kann jetzt nichts machen, der macht den Advokaten; Liebesbriefe kann er nicht schreiben, nur Geschäftsbriefe" u. dgl. m. Die elementaren Kenntnisse sind ganz dürftig; sie kennt die Gebote nicht, nicht den Anfang der Bibel, nicht die Einteilung in Altes und Neues Testament, nennt als christliche Hauptfeste Kirmes und Weihnachten, kennt deren Bedeutung nicht, gibt die Tage des Jahres, der Monate falsch an, rechnet sehr mangelhaft, verstümmelt beim Lesen die Worte, läßt ganze Silben aus, setzt neue dafür ein usw. Die Merkfähigkeit ist erheblich beeinträchtigt; 6stellige Zahlen vermag sie nicht mehr fehlerlos nachzusprechen, setzt vielmehr beliebige andere Zahlen an verschiedenen Stellen ein, hält dabei alles für richtig, besitzt auch sonst nicht die geringste Krankheitseinsicht, bezeichnet sich vielmehr stets als „kerngesund“.

In der Folgezeit erschien die Stimmung andauernd sehr labil, bald depressiv, bald euphorisch, bald jäh in heftige Gereiztheit und Erregung umschlagend. Geistig wurde sie immer zerfahrener und urteilsschwächer, schließlich machte sich ein schnell zunehmender geistiger Verfall bemerkbar. Paralytische Insulte traten hier ins. gesamt 13 auf, $4 \mathrm{im}$ November 1908, 2 im Januar, 6 im September 1909, einer im Februar 1910. Die Insulte unterscheiden sich deutlich vom Typus der Anfälle bei gewöhnlicher Epilepsie. Meist brach die Kranke plötzlich kraftlos zusammen, zitterte am ganzen Körper, verzog krampfhaft den Mund; beim Versuche zu sprechen, kam immer nur ein Stammeln und Stottern zustande. Hinterher war der Gang schwankend, schleppend, taumelnd, wiederholt machten sich rechtsseitige Parese, Tremor linguae et labiorum, stärkere Benommenheit und Hinfälligkeit danach geltend. Anfang 1900 nahmen Ataxie, Sprachstörungen, allgemeine körperliche Hinfälligkeit schnell so zu, daß rom März ab dauernd Einbettung erforderlich wurde. Im Mai trat schwere psychische Benommenheit hinzu, die Kranke schluckte immer schlechter, es kam zu absoluter Anorexie, so daß Nährklysmen 
verabfolgt werden mußten. Am 12, V. 1910 früh verfiel sie schnell; unter Steigerung der'Temperatur auf $39,0^{\circ} \mathrm{C}$ und stertorösem Atmen trat schon nachmittags $21 / 2 \mathrm{Uhr}$ Exitus letalis ein.

Die am nächsten Tage früh $10^{1} / 2$ Uhr vorgenommene Sektion ergab in der Hauptsache folgendes: Leichnam marastisch, $165 \mathrm{~cm}$ lang, $41^{1 / 2} \mathrm{~kg}$ schwer. Schädeldach dick, Diploe nur stellenweise vorhanden, Nähte fast verknöchert, an der linken Seite sind die Äste der Arteria meningea ganz auffallend tief eingegraben. Die harte Hirnhaut ist mit dem Schädeldach verwachsen, im allgemeinen verdickt; über der ganzen linken Hemisphäre und im Bereiche der linken 2. Schädelgrube finden sich rötlichbraune, zum Teil auch grünliche Auflagerungen, die sich abziehen lassen; in der Gegend der linken Zentralwindungen bilden diese Auflagerungen, in denen die Gefäße der Pia abgedrückt sind, einen förmilichen abgegrenzten Tumor; nach Einreißen der innersten Haut entleert sich dickflüssiges bräunliches Blut (Pachymeningitis haemorrhagica inveterata). Weiche Häute sulzig getrübt und verdickt, Gefäße mäßig gefüllt; die subarachnoidealen Räume enthalten klare seröse Flüssigkeit in großer Menge (Leptomeningitis chronica; Hydrocephalus externus). Die Basalgefäße klaffen etwas, die Intima ist an einigen Teilungsstellen getrübt und verdickt. Die Windungen zeigen normale Anordnung, sind aber deutlich verschmälert; links im Bereiche der Zentralwindungen findet sich ein deutlicher Eindruck entsprechend den parchymeningitischen Auflagerungen. Die Rindensubstanz erscheint verschmälert, die Marksubstanz o. B. Die Ventrikel sind mäßig erweitert, das Ependym ist stellenweise gekörnt; der linke Plexus chorioideus lat. ist in eine sich kalkig anfühlende Masse verwandelt. Das unzerschnittene Gehirn wiegt $1135 \mathrm{~g}$. Die Hypophysis cerebri ist vergrößert, doch ergibt deren mikroskopische Untersuchung nichts auffälliges weiter. Im übrigen fanden sich noch: braune Atrophie des Herzmuskels; subepikardiales Fettgewebe, gallertig entartet. Ränder der Trikuspidal- und Mitralklappe zum Teil geschrumpft und knotig verdickt; Aortaklappen starr; Intima der aufsteigenden Aorta unregelmäßig verdickt und verhärtet, aber nirgends Geschwüre oder Verkalkungen zeigend. Pleuritis adhaesiva sinistra mäßigen Grades; Lungenunterlappen beiderseits hypostatisch, zum Teil pneumonisch infiltriert; Bronchien erweitert. Leber und Nieren fettig entartet. Auf der Oberfläche der Leber finden sich einige strahlige Narben. Cystitis chronica. Die mikroskopische Untersuchung einiger Teilstücke aus Stirn- und Schläfengegend der Großhirnrinde ergibt die typischen degenerativen Veränderungen bei progressiver Paralyse.

Fall XVI. Friedrich F., geb. 26. V. 1848. Von erblicher Belastung ist nichts bekannt. Der Kranke war von Haus aus körperlich gesund und geistig normal veranlagt. 1868-187I diente er als Soldat. Uber eine etwa erfolgte syphilitische Infektion ist nichts bekannt. 1877 heiratete er; von vier in der Ehe geborenen Kindern blieb nur eines am Leben; die übrigen starben in zartem Alter. Potator soll der Kranke nicht gewesen sein, wenn er auch regelmäßig alkoholische Getränke in mäßiger Menge zu sich nahm; 1895 soll er einmal im Anschluß an einen Rausch ein kurz dauerndes Delirium durchgemacht haben. Im Herbst 1897 fiel ihm ein Mauerziegel aus einer Höhe von $6 \mathrm{~m}$ auf den Kopf; er trug eine blutende Wunde davon, stürzte in sich zusammen und war darnach kurze Zeit bewußtlos bez. benommen. Am Tage nach dem Unfall nahm er die Arbeit wieder auf, bot bis Mitte 1898 auch keine auffälligen Störungen weiter dar. Um diese Zeit traten ohne vorausgegangene besondere Schädigung nächtliche Aufregungszustände auf, die zeitweise mit Wahnvorstellungen, Schlaflosigkeit, Kopfschmerzen, Schwindel und krampfartigen Zuckungen in der ganzen rechten Seite einhergingen. Später wurden die Zuckungen allgemein und zeigten sich auf beiden Seiten gleich stark ausgeprägt. Schon seit längerer Zeit ärztlich behandelt, wurde er schließlich am 20. VII. 1899 
der Irrenanstalt zu Dr. überwiesen. Dort gelangten wiederholt typische epileptische Insulte zur Auslösung. Den Anfällen gingen tagelang Parästhesien an den Beinen und Händen voraus. Im Anfall pflegte der Kranke laut aufzuschreien, dann bestanden eine Zeitlang klonische Zuckungen, die sich gleichmäßig über alle Muskeln erstreckten. Zungenbisse und Bettnässen wurden nicht beobachtet. Hinterher bestand für die Zeit des Anfalls völlige Amnesie. Meist traten die Anfälle nachts auf. Nach Gemütserregungen sollen sie häufiger gewesen sein, im übrigen kehrten sie in ganz unregelmäßigen Intervallen wieder, bald vereinzelt, bald in Gruppen, nicht selten in Pausen von 8 Tagen bis zu 6 Monaten. Nach den Anfällen bestanden meist Dämmerzustände, in denen der Kranke sich völlig verworren zeigte, halluzinierte, häufig auch in tobsüchtige Erregung mit Neigung zu Gewalttätigkeiten geriet. Ihre Dauer betrug in der Regel nur einige Tage. In der anfallsfreien Zeit zeigte sich der Kranke leicht erregbar. Seine Intelligenz war etwas herabgesetzt; er neigte dazu, sich in weitschweifigen, endlosen Erzählungen über seine Lebensschicksale zu ergehen. Im übrigen erschien er klar, geordnet und besonnen, körperlich rüstig und gesund, frei von kortikalen Reiz- und Lähmungserscheinungen usw. Es wurde „traumatische Epilepsie" angenommen.

Am 22. VIII. 1900 wurde er in die hiesige Anstalt überführt. Er ersehien körperlich durchaus gesund unid rüstig, nervöse Reiz- und Lähmungserscheinungen konnten auch hier in der ersten Zeit nicht festgestellt werden. Als Residuum des früheren Kopftraumas fand sich auf der Höhe des Scheitels eine verschiebliche Hautnarbe; am Schädel selbst konnte eine Verdickung nicht nachgewiesen werden. 1901 wird bemerkt: Bei Druck gegen beide Schädelgegenden klagt der Kranke über unangenehme Empfindungen, als ob etwas am Schädel zittere oder etwas im Kopfe liefe. Dieselbe Empfindung wird durch schwaches Heben ausgelöst. Beim Beugen wird über Zittern im Kopf und Flimmern vor den Augen geklagt. Das Kopfhaar ist ergraut. Die Pupillen sind ziemlich eng, zeitweise ungleich, reagieren träge auf Lichteinfall. Die Zunge zittert beim Vorstrecken stark; am linken Rande bemerkt man eine von einem Anfalle herrührende Narbe. Die Sprache ist etwas zitternd, die Patellarreflexe gelangen beiderseits nur schwach zur Auslösung. Bis 1909 blieben sich diese Symptome im ganzen stets gleich; um diese Zeit machten sich stärkere ataktische Gehstörungen neben artikulatorisçhen Sprachstörungen und absoluter Lichtstarre der Pupillen geltend. Auffälligere Schreibstörungen traten nie hervor. Auch sonst konnten andere wesentliche Reiz- und Lähmungserscheinungen nie festgestellt werden. Die Arteria radialis fühlte sich beiderseits hart an, die Arteria temporalis erschien geschlängelt. Der Urin war frei von Zucker und Eiweiß. Im übrigen wird in körperlicher Beziehung nur noch Emphysem mit Bronchitis erwähnt.

Geistig erschien der Kranke im Anfange klar und besonnen; über seine persönlichen Verhältnisse und die Entwicklung seiner Krankheit gab er in zusammen. hängender, geordneter Weise Auskunft. Er besa B Krankheitseinsicht und zeigte sich auch in der Folgezeit zeitweise wenigstens stets ganz besonnen und geordnet, wie überhaupt eine auffällig schnell fortschreitende und tief gehende Beeinträchtigung in der intellektuellen Sphäre bis ziemlich zuletzt ausblieb. Immerhin trat etwa seit 1905 immer deutlicher Gedächtnis- und Urteilsschwäche, verbunden mit Schwerfälligkeit des Denkens, sowie schlaffes, gleichgültiges Wesen an ihm hervor. Auch stellten sich Phasen leidlichen geistigen Wohlbefindens im Verlaufe der letzten Jahre immer seltener ein; mehr und mehr machten sich Erscheinungen schwerer geistiger Störung geltend; insbesondere an Anfälle schlossen sich oft länger dauernde Dämmerzustände, oft auch tagelang anhaltende Beängstigungen und Erregungen mit Unruhe an; oft aber ließen die in der psychischen Sphäre auftretenden schweren Alterationen auch jeden Zusammenhang mit epileptischen Insulten ver- 
missen, obschon freilich eine gewisse Periodizität im Verlaufe bis zuletzt unverkennbar blieb. Die Stimmung unterlag jähem Wechsel: bald erschien er verstimmt, gereizt, heftig, bald beängstigt, bald verschlossen, zurückhaltend, bald wieder sehr mitteilsam und gesprächig, oft auch ohne jede äußere Veranlassung sehr heiter, aufgeräumt, euphorisch. Als die Ursache dieser meist ganz unvermittelt ineinander umschlagenden Stimmungsschwankungen waren massenhaft auftretende Sinnestäuschungen und darauf sich aufbauende Wahnideen zu betrachten. Eine Systematisierung der letzteren fand nicht statt; sie wechselten vielmehr mit den Sinnestäuschungen. Der Kranke bezeichnete sie zwar mitunter ,als rätselhaft und unerklärlich", nahm sie aber im übrigen ohne alle Kritik als feststehende Tatsachen an und zog stets entsprechende Schlüsse daraus; er wurde in freundlichem oder feindlichem Sinne von außen her beeinflußt; in der Hauptsache handelte es sich dabei um Verfọlgungs- und Größenideen. Wiederholt beschwerte er sich über seine „Stimmen" oder forderte als Entschädigung für ihm widerfahrene Beleidigungen 100000 Mark. Besonders gern erzählte er stets von seinen ,Träumen" und seiner ,traumatischen Epilepsie" und deduzierte: alles, was ihm oft so „träumerisch" vorkomme, müsse unbedingt zutreffen, da er doch an "traumatischer Epilepsie“ leide! Nicht selten erklärte er: ihm gehöre die ganze Anstalt, er besitze 5 MiHionen u. dgl. m.

Paroxysmen von typisch epileptischem Gepräge gelangten hier insgesamt 257 zur Wahrnehmung; 46 mal handelte es sich um universelle, beiderseits gleichstark ausgeprägte Krampfanfälle mit BewuBtseinsverlust und Amnesie, 211 mal um rudimentäre Attacken, Schwindel und Ohnmachtsanwandlungen usw. Apoplektiforme Insulte traten nicht auf; auch fehlten stets corticale und andere cerebrale Begleiterscheinungen; ebensowenig machten sich darnach Paresen, aphasische Störungen u. dgl. m. geltend. 188 Paroxysmen traten bei Tage, 69 nachts auf. Oft blieb der Kranke 2 bis 3 Monate völlig frei von Paroxysmen, in manchen Jahren gelangten nur wenige zur Auslösung, so z. B. 1903 und 1906, im ganzen aber verteilten sie sich ziemlich gleichmäßig über die ganze Dauer der Beobachtung. Durch BrNaGaben - der Kranke erhielt täglich bis zu 4,0 $\mathrm{BrNa}$ - waren sie nicht deutlich zu beeinflussen. Mehr als 3 bis 4 Insulte gelangten wohl nie an einem Tage zur Auslösung; die höchste Zahl der in einem Monat registrierten Anfälle betrug 15.

Mit Beginn des Jahres 1910 machte sich ein auffällig schneller Rückgang seiner körperlichen Kräfte bemerkbar, während der Zustand in geistiger Hinsicht keine wesentliche Veränderung weiter erfuhr. Der Kranke wurde allmählich immer kachektischer; während er früher stets gegen $70 \mathrm{~kg}$ gewogen hatte, ging sein Gewicht im Verlaufe eines halben Jahres auf etwa $49 \mathrm{~kg}$ zurück. Die Ursache bildete ein Magenkrebs. Der Puls wurde allmählich ganz irregulär, die Symptome des Emphysems und der Bronchitis steigerten sich, Ödeme an den unteren Gliedmaßen gesellten sich hinzu, die Verdauung lag schließlich ganz darnieder. Endlich erfolgte am 29. VII. 1910 früh $4^{1} / 2$ Uhr Exitus letalis.

Die Sektion ergab in der Hauptsache folgendes: Körperlänge $174 \mathrm{~cm}$, Gewicht $42 \mathrm{~kg}$, allgemeiner Marasmus. Schädeldach mesocephal, schwer und dick, Diploe stark sklerosiert. Harte Hirnhaut verdickt und getrübt, läßt die Piagefäße nur wenig durchschimmern. Weiche Häute allenthalben, am stärksten über dem Stirnlappen, über den Zentral- und Schläfenwindungen milchig getrübt und sulzig ödematös; Liquor beträchtlich vermehrt. Basisgefäße teilweise etwas atheromatös entartet. Windungen deutlich atrophisch, am stärksten im Bereiche der Stirnlappen. Gehirn 1270 g schwer, stark durchfeuchtet. Ventrikel mäßig erweitert, Ependym in den Seitenventrikeln und in den Recessus des 4. Ventrikels fein gekörnt. Im übrigen bietet das Gehirn makroskopiseh auffälligere Befunde nicht dar. Sonst fanden sich noch: Pleuritis adhaesiva sinistra; Lungen in den lufthaltigen Bezirken emphyse- 
matös gebläht, Unterlappen links im Zustande der grauen Hepatisation, Unter. lappen rechts nicht pneumonisch infiltriert, nur stark hyperämisch. Pleura beiderseits bedeckt mit kleinen, miliaren, bis linsengroßen, derben, markigweißen Knötchen, die deutlich den Verästelungen der Lymphgefäße folgen (Lymphangitis carcinomatosa). Herz vergrößert, schlaff, Muskel fettig entartet. Coronargefäße stellenweise leicht sklerosiert, die Aortaklappen zeigen stellenweise knotige, kalkig inkrustierte Verdickungen. Netz ganz atrophisch. Nieren beiderseits verkleinert, Oberfläche fein granuliert, vereinzelt bestehen tiefe narbige Einziehungen in der Rinde, die im ganzen geschrumpft erscheint. Nebennieren klein, brüchig, atrophisch. Leber verfettet, mäßig verkleinert. Der Magen fühlt sich im Bereiche der kleinen Kurvatur sehr derb, verdickt an; beim Einschneiden zeigt sich die Magenschleimhaut hier in großer Ausdehnung tumorartig gewuchert und zum Teil schon geschw ürig zerfallen; der Tumor hat ein weißes bis markigweißes Aussehen und durchsetzt stellenweise die Magenwand ganz; der Geschwürsgrund ist schmutzig, schmierig belegt, der übrige Tumor zottig und wallartig erhaben. Mehrere Mesenterialdrüsen sind beträchtlich vergrößert, markig weiß, zum Teil erweicht und nekrotisch zerfallen. -Die mikroskopische Untersuchung einiger Schnitte aus dem Bereiche beider Stirn- und Schläfenlappen, sowie beider Zentralwindungen ergibt sehr starke Randgliose und reichliche Plasmazelleninfiltrationen neben allen sonst noch für progressive Paralyse charakteristischen Befunden. Das Rückenmark wurde nicht untersucht.

Dicse drei Fälle mußten schon des späten Auftretens der „Epilepsie“ wegen suspekt erscheinen; trat diese doch bei Fall XIV erst im 29. bis 30., bei Fall XV im 38., bei Fall XVI im 50. bis 51. Lebensjahre hervor. Erbliche Belastung konnte nur bei Fall XIV nachgewiesen werden, die körperliche und geistige Entwicklung selbst soll in allen drei Fällen regelmäßig erfolgt sein. Bei Fall XIV scheinen dem Ausbruche der epileptischen Insulte auffälligere Störungen von seiten des Nervensystems nicht vorausgegangen zu sein, bei Fall XV dagegen machten sich schon einige Zeit vorher allerhand unmotivierte Stimmungsschwankungen bemerkbar, und bei Fall XVI soll bereits im 47. Lebensjahre im Anschluß an einen Alkoholrausch ein kurzes Delirium zur Auslösung gelangt sein. Eine luetische Infektion war nur für Fall XIV sicher nachgewiesen; Residuen syphilitischer Prozesse fanden sich in keinem der drei Fälle; doch fällt in der Anamnese aller drei Fälle die Polymortalität der Nachkommenschaft auf, wennschon in jedem dieser Fälle ein bis zwei Kinder am Leben geblieben sind und sich in normaler Weise entwickelt haben sollen. Als weitere schädigende Momente kommen für Fall XIV und XVI vielleicht noch Mißbrauch alkoholischer Getränke, für letzteren Fall außerdem ein im 50. Lebensjahre erlittenes Kopftrauma in Frage, während für Fall XV ein besonderer schädigender Einfluß nicht zur Wirksamkeit gelangt zu sein scheint. An das Kopftrauma schlossen sich bei Fall XVI ca. $3 / 4$ Jahre später psychische Erregungszustände mit Zuckungen in der rechten Seite an, die allmählich in allgemeine Krämpfe übergingen.

Daß es sich um wirkliche Epilepsie handelte, wurde bei Fall XIV 
bis etwa zum 44. und bei Fall XV bis etwa zum 45. Lebensjahre in keiner Weise in Zweifel gezogen; erst um diese Zeit begannen sich hier deutlich die Zeichen der progressiven Paralyse dem Krankheitsbilde hinzuzugesellen. Fall XVI wurde zunächst als ,traumatische Epilepsie“ betrachtet; doch mußte hier schon vom 53.-54. Lebensjahre ab eine Reihe nervöser Reiz- und Lähmungserscheinungen Bedenken gegen die gestellte Diagnose wachrufen. Ob bei Fall XIV dem zunehmenden Alkoholmißbrauch ein maßgebender Einfluß auf die verhängnisvolle Weiterentwicklung des Leidens beizumessen ist, bleibe dahingestellt; bei Fall XV soll die Verschlimmerung des Krampfleidens und des psychischen Gesamtzustandes erst im unmittelbaren Anschluß an eine heftige emotive Erregung eingetreten sein, die die Nachricht von der Ermordung der einen Tochter zur Auslösung brachte; bei Fall XVI ist über neu hinzugetretene schädigende Momente nichts bekannt geworden. Während sich bei Fall XVI die Epilepsie von Anfang an durch psychische Störungen kompliziert zeigte, blieb sie bei Fall XIV ca. 14-15, bei Fall XV ca. 7-8 Jahre monosymptomatisch; auch auffälligere Störungen in der psychischen und speziell in der intellektuellen Sphäre sollen in diesen Fällen bis dahin nicht hervorgetreten sein. Bei Fall XVI blieb die Intelligenz trotz der bestehenden psychischen Störung ebenfalls 6-7 Jahre lang leidlich gut erhalten; doch hatten sich hier schon ca. $3^{1} / 2$ Jahre nach dem Auftreten der ersten Krankheitserscheinungen deutlich somatische Zeichen der progressiven Paralyse im Krankheitsbilde geltend gemacht. Jedenfalls konnte nach den im späteren Verlaufe des Leidens erhobenen Untersuchungsbefunden auf körperlichem und geistigem Gebiete wohl in keinem der drei Fälle die Diagnose progressive Paralyse mehr in Zweifel gezogen werden. Bezüglich der Krampfattacken scheinen bei Fall XIV bis zuletzt keine auffälligen Abweichungen vom Typus der gewöhnlichen epileptischen Insulte hervorgetreten zu sein; bei Fall XV nahmen die Paroxysmen allmählich einen mehr apoplektiformen Typus an, bei Fall XVI unterlagen sie nach Zahl und Heftigkeit fortgesetzt großem Wechsel; meist handelte es sich hier um rudimentäre Attacken, oft traten sie auch für mehr oder minder lange Zeit auffällig im Krankheitsbilde zurück. Die Fälle XIV und XV gingen in körperlich und geistig ganz heruntergekommenem Zustande in der gewöhnlichen Weise der Paralytiker zugrunde, Fall XIV nach vollendetem 46. Lebensjahre, ca. 21/4 Jahre nach dem Hervortreten des paralytischen Symptomenkomplexes, Fall XV im 50. Lebensjahre, ca. $4 \frac{1}{2}$ Jahre nach erfolgtem Utbergang der Epilepsie in progressive Paralyse. Bei Fall XVI gelangte im 62. Lebensjahre ein Magencarcinom zur Entwicklung, dem der Kranke etwa 7 Monate später erlag. Aus den bei der Sektion der Fälle erhobenen Befunden seien hervorgehoben: als allen drei Fällen gemeinsam die 
Verdickung des Schädeldaches, die ausgedehnte Arteriosklerose, die chronische Leptomeningitis, der Hydrocephalus externus et internus, die namentlich in den vorderen Abschnitten des Gehirns hervortretende Atrophie; in Fall XIV und XV ergab sich noch ausgedehnte Pachymeningitis haemorrhagica interna resp. Hämatom der Dura mater.

Ist es nach unseren heutigen Kenntnissen über die Wandelbarkeit, die Polymorphie und die Unbestimmtheit der makroskopischen Gehirnbefunde bei Psychosen aller Art auch kaum möglich, auf Grund der makroskopischen Feststellungen allein mit Sicherheit die Diagnose der progressiven Paralyse zu stellen, so dürfte doch nach dem Ergebnisse der klinischen Ermittelungen und nach dem ganzen Charakter und Verlaufe der insbesondere in der letzten Zeit hervorgetretenen Krankheitserscheinungen die Diagnose in unseren Fällen als gesichert betrachtet werden können. Die lange Dauer der Krankheit und ihr Beginn mit Epilepsie vermochte sie nicht zu erschüttern. Bekanntlich kann durch Remissionen und Stillstände die Gesamtdauer der progressiven Paralyse, die nach neueren Zusammenstellungen, vom Auftreten evidenter Symptome ab gerechnet, im. Mittel nur ca. 26 Monate beträgt, gelegentlich auf ein Jahrzehnt und selbst auf mehrere Dezennien verlängert werden. So hat Tuczek in einem Falle von Paralyse eine Remission von 22 Jahren beobachtet; ebenso haben Lustig, Jahrmärker, Schäfer, Wickel und Ga upp über Fälle berichtet, deren Gesamtdauer bis zu 20 und mehr Jahren betrug, und wenn auch manche dieser Fälle bezüglich der Diagnose zu Bedenken Anlaß geben, so läßt sich das Vorkommen so langandauernder Paralysen doch namentlich angesichts eines von Alzheimer anatomisch untersuchten einwandfreien Falles kaum noch bezweifeln, in dem die Gesamtdauer 32 Jahre betrug und durch das Auftreten einer interkurrenten Krankheit sogar noch eine vorzeitige Abkürzung erfahren zu haben scheint'1). Unsere letztgeschilderten drei Kranken dürften, wie sich aus den beigebrachten Einzelheiten ergibt, denjenigen Fällen beizuzählen sein, bei welchen der progressiven Paralyse jahrelang als Vorstadium eine echte Epilepsie vorausgeht ${ }^{2}$ ). Setzt man den Beginn der Erkrankung des Zentral-

1) Vgl. W. Spielmeyer, Die progr. Paralyse in Lewandowskys Handb. d. Neurol. Bd. 3, S. $502 \mathrm{ff}$. Lustig, Zur Kasuistik der Paralyse. Allg. Zeitschr. f. Psych. 1900, Bd. 57, S. 509. Jahrmärker, Beitr. z. Dem. paralytica b. weibl. Gesehlecht. Ebenda Bd. 58, S. $1 \mathrm{ff}$. Schäf er, Zur Kasuistik der progr. Paralyse. Ebenda 1903. Bd. 60, S. 571ff. Wickel, Zur Frage der stationärën Paralyse. Zentralbl. f. Nervenheilkde. u. Psych. 1904, S. 561. R. Gaupp-Alzheimer, Die stationäre Paralyse. Ebenda 1907, S. $696 \mathrm{ff}$.

$\left.{ }^{2}\right)$ Vgl, oben S. 521, ferner auch die Fälle VI und XI. Bei den Fällen XII und XIII dagegen handelt es sich unseres Erachtens ursprünglich wohl um echte genuine Epilepsie, die sich nur unter dem Einflusse einer syphilitischen Durchseuchung allmählich in deletärer Weise weiter entwickelt hat, hier dürfte die progresives Paralyse gewissermaßen als der Epilepsie aufgepfropft zu betrachten sein. 
nervensystems in die Zeit des Auftretens der Epilepsie, so betrug die Gesamtdauer der Krankheit bei Fall XIV ca. 17, bei Fall XV und XVI je ca. 12 Jahre. Deutliche Zeichen von Paralyse traten bei Fall XIV erst etwa 15, bei Fall XV etwa $7-8$, bei Fall XVI etwa $3 \frac{1}{2}$ Jahre nach dem Auftreten der Epilepsie hervor. Der völlige körperliche und geistige Verfall vollzog sich dann bei den Fällen XIV und XV ziemlich schnell, nämlich im ersten Falle in ca. $2^{1 / 4}$, im letzten Falle in ca. $4 \frac{1}{2}$ Jahren. Fall XVI bot von Anfang an Störungen in der psychischen Sphäre dar, eine progressive Demenz machte sich aber erst ca. 7 Jahre darnach, resp. 31/2 Jahre nach dem Hervortreten der auf Paralyse hindeutenden nervösen Reiz- und Lähmungserscheinungen bemerkbar; der Fall unterschied sich indessen auch dadurch von den übrigen, daß die geistige Abschwächung hier überhaupt nur sehr langsame Fortschritte machte; wäre nicht durch das Magencarcinom dem Leben ein vorzeitiges Ziel gesetzt worden, so hätte der Krankheitsfall mutmaßlich wohl noch länger fortgedauert. Eine mikroskopische Untersuchung des Zentralnervensystems wurde bei Fall XIV nicht vorgenommen, bei den Fällen XV und XVI beschränkte sie sich auf einige Teilstücke aus dem Bereiche beider Stirn- und Schläfenlappen, sowie beider Zentralwindungen; sie vermochte die gestellte Diagnose für diese beiden Fälle nur zu bestätigen.

Stellen wir zum Schluß die beigebrachten Fälle nach ihren hauptsächlichsten Ergebnissen nochmals kurz zusammen, so handelte es sich bei den Fällen I-III, VI-IX, XI-XIII und XV um weibliche, bei den Fällen IV, V, X, XIV und XVI um männliche Kranke. Ätiologisch kam für die Fälle I-VI mehr oder minder ausschließlich eine hereditäre, für die Fälle VII-XVI eine akquirierte Lues in Frage. Sicher erwiesen war die Lues anamnestisch bei den Fällen I, II, IV, V, VII-XI und bei Fall XIV. Residuen der Syphilis oder manifeste Erscheinungen derselben machten sich bei Fall III und bei den Fällen VIII-XI geltend; sicher als luetisch anzusprechende Affektionen fehlten bei den Fällen I, II, IV, VI, VII, sowie XII-XVI. Doch scheint bei Fall IV die im 16. Lebensjahre aufgetretene Apoplexie durch eine spezifische Gefäßaffektion im Bereiche der linken Fossa Sylvii verursacht worden zu sein. Ob bei Fall V die durch Operation entfernten adenoiden Wucherungen in der Nase als spezifisch anzusehen waren, muß dahingestellt bleiben. Im übrigen wiesen jedoch bei den Fällen I-III und bei Fall V noch allerhand Stigmata auf hereditäre Lues hin, wie wohl auch sonst in allen Fällen noch eine Reihe anamnestischer Verdachtsmomente auf Lues hinzudeuten schienen. Der Wassermannschen Reaktion konnten nur die Fälle I, III, V, VII-IX, XII und XIII unterworfen werden; sie lieferte in allen diesen Fällen positive Ergebnisse. 
Erbliche Belastung war für die Fälle I, III, IV-VII, XI und XIV mit mehr oder minder großer Wahrscheinlichkeit anzunehmen. Von sonstigen schädigenden Einflüssen werden noch geltend gemacht resp. waren für den Ausbruch der Epilepsie oder für die deletäre Ausgestaltung des Krankheitsbildes immerhin in Betracht zu ziehen: Traumen bei den Fällen VI, VIII, XII und XVI, individueller Alkoholmißbrauch bei den Fällen XIV und XVI, eine heftige emotive Erregung bei Fall XV. Zum Teil freilich lagen diese Schädigungen so weit zurück (z. B. bei den Fällen VI und VIII), daß ihnen nur bedingt ein Wert beizumessen war. Alle sonst etwa noch zur Wirksamkeit gelangten Schädlichkeiten (z. B. Infektionskrankheiten aller Art) dürften nach Lage der Dinge ohne wesentlichen Belang für die schließlich zur Entwicklung gelangte Erkrankung im Zentralnervensystem gewesen sein.

Der Ausbruch der Epilepsie erfolgte bei Fall III im 6., bei Fall XII im 9., bei Fall V im 10., bei Fall XIII im 12., bei den Fällen I, II, IV, VI und $\mathrm{X}$ zur Zeit der Pubertätsentwicklung, bei Fall VIII im 22., bei Fall VII im 23., bei Fall XI angeblich im 25., bei Fall XIV im 29. -30., bei Fall IX im 36., bei Fall XV im 38. und bei Fall XVI im 50.-51. Lebensjahre. Bei den Fällen I und VII sollen schon während der ersten Zahnung, bei Fall XI in der Kindheit Krämpfe aufgetreten sein, die aber spontan wieder verschwanden, um erst später von neuem zum Vorschein zu kommen. Unter den Fällen mit akquirierter Lues wiesen bereits vor der Infektion Epilepsie die Fälle X, XII und XIII auf, während bei den Fällen VII-IX und XIV - XVI die Epilepsie erst nach der Infektion zutage trat. Auch bei Fall XI scheint erst die luetische Infektion die Epilepsie von neuem hervorgerufen zu haben; doch ist in diesem Falle die Anamnese ziemlich lückenhaft und unzuverlässig. Utber das zwischen der Infektion und dem Ausbruch der Epilepsie resp. der deletären Weiterentwicklung des Krankheitsbildes liegende Intervall sind wir in den Fällen XII-XVI nur schlecht orientiert; bei Fall VII lagen wohl etwa 3, bei Fall VIII und X je etwa 4, bei Fall XI etwa $4 \frac{1}{2}$, bei Fall IX etwa 11, bei Fall XIII mutmaßlich etwa 13 Jahre dazwischen. Als auffällige Störungen gingen den Krampfattacken mehr oder minder lange Zeit voraus bei Fall V Schreckhaftigkeit, bei den Fällen VI und XV unmotivierte Stimmungsschwankungen, bei Fall I Ohnmachtsanwandlungen, bei Fall XVI ein akutes Alkoholdelirium, bei den Fällen II und IV „Schlaganfälle“; doch ist nur bei Fall IV eine Apoplexie sichergestellt. Trotz mannigfacher Abweichungen im einzelnen entsprachen die Krämpfe in allen Fällen denen der gewöhnlichen Epilepsie; nur bei Fall XV nahmen dieselben im späteren Verlaufe einen mehr apoplektiformen Typus an. Einfache epileptische Neurosen lagen nach den klinisch hervorgetretenen Krankheitserscheinungen bei den Fällen I-III und VII-IX vor. Fall $\mathrm{X}$ zeigte sich 
durch eine funktionelle Psychose kompliziert, während sich in allen anderen Fällen auf organische Affektionen im Zentralnervensystem hindeutende Krankheitserscheinungen bemerkbar machten.

Will man die Lues in der Anamnese nicht etwa grundsätzlich nur als koinzidierendes, zufälliges Moment gelten lassen, so dürften, den obigen Ausführungen entsprechend, die Fälle I-III und VII-X als ,parasyphilitisch“ bedingte Epilepsieformen zu betrachten sein, während in den übrigen Fällen materielle Veränderungen im Zentralnervensystem vorlagen. Von „Verstärkung einer epileptischen Anlage durch Lues und Wachrufen der latenten epileptischen Disposition durch die erworbene Syphilis" könnte höchstens bei Fall VII und allenfalls noch bei Fall XI für das dem späteren Prozesse vorausgegangene epileptische Vorstadium gesprochen werden. Für keinen der Fälle VII-X traf die Behauptung Fourniers zu, daß die ,parasyphilitische“ Form der Epilepsie mit der Sekundärperiode der Syphilis zugleich entstehe und wieder verschwinde; kam es in den Fällen VIII und IX, wie übrigens auch in den Fällen III, X und XI doch während des Bestehens der Epilepsie noch zur Entwicklung syphilitischer Erscheinungen am Körper, allerdings tertiärer Art. Durch kombinierte antiepileptische und antiluetische Kuren konnte nur bei Fall IX Heilung des epileptischen Leidens herbeigeführt werden; in allen übrigen Fällen war eine zweifellose Beeinflussung der krankhaften Störungen im Zentralnervensystem durch die angewandten Heilverfahren nicht zu erzielen. Angesichts des erzielten therapeutischen Erfolgs war für Fall IX die Möglichkeit nicht ganz von der Hand zu weisen, daß es sich hier nicht um eine rein funktionelle Störung der cerebralen Vorgänge, sondern um die ersten Anfänge neoplastischer Prozesse, resp. um räumlich nur wenig ausgedehnte und einer Rückbildung noch zugängliche spezifische Gehirnveränderungen im Sinne Binswangers gehandelt hat. Im übrigen waren die Fälle I-III wohl als ,dyskrasische“ Formen der hereditär-luetischen Epilepsie zu betrachten, während für die Fälle VII und VIII toxische molekulare Schädigungen der Nervensubstanz durch das syphilitische Virus am meisten wahrscheinlich erschienen. Daß etwa die als Keratitis interstitialis lokalisierte Syphilis erst in späteren Lebensjahren das Zentralnervensystem durch ihre Toxine geschädigt haben könnte, war im Hinblick auf Fall III nicht wahrscheinlich; denn hier war die Epilepsie ja schon lange vorher zum Vorschein gelangt und das Auftreten der spezifischen Affektion selbst wirkte in keiner Weise verändernd auf den Verlauf der Epilepsie ein.

Bei Fall XI scheint die syphilitische Infektion, wie bemerkt, zu nächst zu einer „Verstärkung der epileptischen Anlage und zum Wachrufen der latenten epileptischen Disposition" geführt zu haben; weiterhin aber scheint sie hier wie bei den Fällen X, XII und XIII zur Ent- 
wicklung einer funktionellen Psychose, resp. zu organischen degenerativen Veränderungen im Zentralnervensystem AnIaß gegeben zu haben. Immerhin ist hervorzuheben, da $\beta$ bei Fall $\mathrm{X}$ die Akquirierung der Lues zunächst keinen steigernden Einfluß auf die Häufigkeit und Schwere der Krampfanfälle selbst ausgeübt hat; erst später - nach dem Auftreten tertiär-luetischer Affektionen - trat hier die Psychose, resp. bei Fall XI die Tabes dorsalis hinzu. Während aber Fall X trotz des Vorhandenseins der Psychose mit großer Wahrscheinlichkeit noch als „,parasyphilitische" Epilepsieform zu betrachten war, waren die Fälle XI bis XVI ebenso wie die Fälle IV-VI mindestens in ihren Endstadien als auf materiellen Gehirnveränderungen beruhende Epilepsieformen anzusprechen. Bei Fall IV war die im 16. Lebensjahre aufgetretene Apoplexie, an die sich alsbald epileptische Attacken anschlossen, allem Anscheine nach wohl durch eine spezifische GefäBaffektion im Bereiche der linken Fossa Sylvii bedingt, während bei Fall XI vielleicht ursprünglich eine diffuse Meningo-encephalitis syphilitica an der Konvexität des Gehirns vorgelegen hat, die weiterhin zu einer diffusen degenerativen Erkrankung der oberflächlichen Hirnrindenschichten geführt und so Anlaß zu den beobachteten Störungen der cerebralen Funktionen gegeben hat; eine ähnliche Pathogenese lag hier vielleicht auch den im Rückenmark und in den Sehnerven eingetretenen diffusen degenerativ-atrophischen Prozessen zugrunde, die den typischen Symptomenkomplex der Tabes dorsalis hervorgerufen hatten.

Die Fälle V, XII und XIII sind mit großer Wahrscheinlichkeit, die Fälle VI, XIV, XV und XVI mit Sicherheit als ,,postsyphilitische“" Erkrankungsformen, nämlich als progressive Paralysen aufzufassen. Alle diese Fälle zeigen ,,atypischen", sehr protrahierten Verlauf und sind durch die epileptischen Insulte besonders bemerkenswert. In den Fällen VI, XI, XIV, XV und XVI sind die aufgetretenen epileptischen Attacken wohl als Vorstadien der späteren organischen Gehirnveränderungen aufzufassen, in den Fällen XII und XIII dagegen dürfte es sich um die unter dem Einflusse einer syphilitischen Durchseuchung erfolgte deletäre Weiterentwicklung einer gewöhnlichen genuinen Epilepsie zur progressiven Paralyse handeln. Bei den bereits ad exitum gelangten Fällen betrug die Gesamtdauer der Krankheit, vom Auftreten der epileptischen Insulte an gerechnet, in Fall VI ca. 13, in Fall XI mutmaßlich ca. 20, in Fall XIV ca. 17, in den Fällen XV und XVI je ca. 12 Jahre. Fall VI scheint von Anfang an einen zwar langsamen, aber stetigen progressiven Verlauf genommen zu haben, speziell auch in bezug auf die Abschwächung der intellektuellen Kräfte und Fähigkeiten; Fall XVI war von Anfang an durch das Hinzutreten einer Psychose kompliziert, nervöse Reiz- und Lähmungserscheinungen machten sich hier bereits $3^{1} / 2$ Jahre später geltend, erst 7 Jahre nach 
dem Auftreten der Krampfanfälle aber traten Anzeichen fortschreitender Demenz hervor; doch schritt selbst dann noch der geistige Verfall nur langsam weiter fort. In den Fällen XIV und XV blieb die Epilepsie etwa 15 bzw. 7-8 Jahre lang monosymptomatisch; dann aber trat in beiden Fällen schneller körperlicher und geistiger Verfall ein, bei Fall XIV in ca. $2^{1} / 4$, bei Fall XV in ca. $4^{1} / 2$ Jahren.

Autopsiebefunde liegen bei den Fällen II, IV, VI, X, XI, XIV, $\mathrm{XV}$ und XVI vor; mikroskopische Untersuchungen von Teilstücken aus dem Zentralnervensystem wurden bei den Fällen VI, XI, XV und XVI vorgenommen. Wegen der festgestellten Einzelheiten sei auf die Krankengeschichten selbst und die daran anknüpfenden epikritischen Bemerkungen verwiesen.

\section{Literaturverzeichnis.}

Allen, Two cases illustrating certain relations of syphilis and epilepsy. The Cleveland med. Journ. II.

Altha us, Med. times and gaz. London 1874, 1876 und anderwärts.

Alzhei mer, Die Frühformen der allgemeinen progressiven Paralyse. Allgem. Zeitschr. f. Psych. 1896. Bd. 52. Histolog. Studien zur Differentialdiag. nose der progress. Paralyse. Jena 1904. Utber atypische Paralyse. Zentralbl. f. Nervenhlkde. 1902. Die Gruppierung der Epilepsie. Ref. in Allgem. Zeitschr. f. Psych. 1907, Bd. 64.

Aschaffenburg, Utber Epilepsie und epileptische Zustände im Kindesalter. Arch. f. Kinderheilk. Bd. 46.

Astruc, De morbis venereis. Lib. IV, cap. 9. Paris 1740.

Baginsky, Die Pathologie der Parasyphilis im Kindesalter. Arch. f. Kinderheilk. 52.

B. Bell, Treatise on gonorrhoea virulenta and the venereal diseases. Edinburgh 1793. Traité de la gonorrhoe virulente. T. II p. 672.

Bernhard tartber apoplektiforme (und epileptiforme) Anfälle in frühen Stadien oder im Verlaufe der Tabes. Arch. f. Psych. 1883. Bd. 14.

Binswanger, Die Epilepsie. Nothnagels Handb. Bd. 12. 1899. 2. Aufl. 1913. Zur Pathogenese und differentiellen Diagnose der progressiven Paralyse. Virchows Archiv Bd. 154. Hirnsyphilis und Dementia paralytica. Festschr. f. L. Meyer 1891. Die allgemeine Paralyse der Irren. Deutsche Klinik 1901. Zur allgemeinen Pathologie und pathologischen Anatomie der Taboparalyse. Monatsschr. f. Psych. u. Neurol. 10. Die klinische Stellung der sogen. genuinen Epilepsie. Ref. Ztschr. f. d. ges. Neur. u. Psych. 1912, Bd. 6.

Biro, Ubb. Epilepsie. Dtsch. Zeitschr. f. Nervenheilk. 1903. Nr. 23.

Boerhave, Praelectiones academicae de morbis nervorum. 1762.

Bratz und Lüth, Hereditäre Lues und Epilepsie. Archiv f. Psych. 1900. Bd. 23. Bravais, Thèse de Paris. 1827.

J. Bresler, Erbsyphilis und Nervensystem. Leipzig 1904.

Broadbent, Syphilitic affections of the nervous system, cerebral disease in infantile Syphilis. Lancet 1874.

Bulle n, Journ. of mental Sc. April 1890.

Buzzard, Clinical aspects of syphilitic nervous affections. London 1874. 
R. Cassirer, Tabes und Psychose. Berlin 1903.

- und StrauB, Tabes dorsalis incipiens und Syphilis. Monatsschr. f. Psych. u. Neurol. 9.

Charcot, Klinische Vorträge, 2 Abtlg., Teil 4.

Chavet, Influence de la syphilis sur les maladies du système nerveux central, th. 1880 .

A. Cramer, Die Epilepsie. Bruns-Cramer-Ziehens Handb. d. Nervenkrankheiten im Kindesalter. Berlin 1912.

Debove, De l'hémiplégie des ataxiques. Progr. médic. 1881.

Derville, Influence de la syphilis sur les maladies du cerveau. Journ. des scienc. méd. de Lille. 1888.

O. Dornblüth, Neurosen infolge von Syphilis. Münch. med. Wochenschr. 1897.

Echeverria, Journ. of mental Sc. 1880.

W. Erb, Tabes dorsalis. Deutsche Klinik, Bd. 6, 1. Abtlg. 1906, S. $807 \mathrm{ff}$.

Erlenmeyer, Die luetischen Psychosen. 1877. Über die durch kongenitale Syphilis bedingten Hirnerkrankungen. Zentralbl. f. Nervenheilkunde. 1891.

- Klinische Beiträge zur Lehre von der kongenitalen Syphilis und über ihren Zusammenhang mit einigen Gehirn- und Nervenkrankheiten. Zeitschr, f. klin. Medizin 21.

Feinberg, Zur Kasuistik der Epilepsia luetica. Neurol. Centralbl. 1902, S. 792.

Féré, Die Epilepsie. Deutsch von Ebers. Leipzig 1896.

Fischl, Kortikale Epilepsie kongenital-syphilitischen Ursprungs. Zeitschr. f. Heilk. 11, 1890.

A. Fournier, De l'épilepsie syph. tertiaire. Paris 1876. Epilepsie et syphilis. Gaz. des hôp. 61. La syphilis du cerveau. Paris 1879. La syphilis héréditaire tardive. Paris 1886. Annales de Dermatol. et Syph. 1889. Epilepsie parasyphilitique. Rev. neur. 1893.

- E., Les affections parasyphilitiques. Paris 1894.

J. Frank, Praxeos medicinae universae praecepta. 1821.

- Die Nervenkrankheiten. Leipzig 1843.

Gajkiewicz, Syphilis du système nerveux. Paris 1892. Fälle von Hirnsyphilis. Ref. in Neurol. Centralbl. 1895.

Gamel, Essai sur les tumeurs gommeuses du cerveau. Th. de Montpellier 1875.

Gowers, Epilepsie. 2. Aufl. Deutsch von Weiß. 1902.

Gros et Lancereaux, Des affections nerveuses syphilitiques. Paris 1861.

Guénot, Epilepsie syphilitique secondaire. Gaz. des hôp. 1909.

Thierry de Héry, La méthode curative de la maladie vénérienne etc. Paris 1552.

O. Haßmann und H. Zingerle, Beiträge zur Kenntnis der Verlaufsformen der progressiven Paralyse. Neurol. Centralbl. 1913. Nr. 1.

Heubner, Syphilis des Gehirns und des übrigen Nervensystems. Ziemssens Handb. Bd. 1l. Ửber die Hirnerkrankungen der Syphilitischen. Archiv f. Heilkde. 1870. Syphilis im Kindesalter. Gerhardts Handb. d. Kinderkrankh. 1896. Endarteriitis syphilitica etc. bei einem $2 \frac{1}{2}$ jähr. Kinde. CharitéAnnalen 1902.

Fr. Hoff $\operatorname{mann}$, Medicina rationalis systematica. Medicina consultatoria. Hal. $1718-1740$.

Ulr. v. Hutten, De guajaci medicina et morbo gallico lib. unus. 1519.

Jackson, Lancet $1868 \mathrm{ff}$. Med. tim. and gaz. 1872ff. Journ. of mental Sc. 20 u. anderwärts.

Jolly, Über Gehirnsyphilis. 66. Versammlung deutsch. Naturf. u. Ärzte. Wien 1894. Syphilis und Geisteskrankheiten. Berliner klin. Wochenschr. 1901, Nr. 1. 
Kahane, Die syphilitischen Erkrankungen des Nervensystems. Nothnagels Handb. Bd. 13.

Klein, Kasuistische Beiträge zur Differentialdiagnose zwischen Dementia paralytica und Pseudoparalysis (Fournier). Monatsschr. f. Psych. u. Neurol. 1899, Bd. 5 u. 6.

Kowalewsky, Syphilitische Epilepsie. Berliner klin. Wochenschr. 1894. Die funktionellen Nervenkran.heiten und die Syphilis. Archiv f. Psych. Bd. 26. Geistesstörungen bei Syphilis. Allgem. Zeitschr. f. Psych. 1894. Bd. 50.

Korotnew, Parasyphilitische Epilepsie. Korsakoffsches Journ. 1910.

Krause, tber syphilitische Psychosen. Neurol. Centralbl. 1899.

Lecoq, Etude sur les accidents apoplectiformes qui peuvent compliquer le début, le cours, la fin de l'ataxie locomotice. Revue de Méd. 1882.

Leyden, Tabes dorsalis. Eulenburgs Realencykl. 3. Aufl.

Al. Luisinus, De morbo gallico omnia quae extant apud omnes medicos cuiuscunque nationis etc. 1566 .

Mallet, Contribution à l'étude de l'épilepsie syphilitique. Th. de Paris. 1889.

N. Massa, De morbo gallico etc. Cap. VII. 1532. Epistolae medicinal. et physiolog. 1542.

O. Masson, Epilepsie et syphilis. Gaz. des hôp. 61 .

G. Meyer, Beitrag zur Kenntnis der nicht paralytischen Psychosen bei Tabes dorsalis. Monatschr. f. Psych. u. Neurol. 13.

Morgagni, De sedibus et causis morbor. Epist. IX, art. 23, lib. I.

Näcke, Ein Fall von atypischer Peraralyse mit echt epileptischen Krämpfen usw. Archiv f. Psych. 1912, Bd. 49.

Nissl, Zur Histopathologie der paralytischen Rindenerkrankungen. Jena 1904.

Nonne, Syphilis und Nervensystem. Berlin 1902. 2. Aufl. 1909.

Nonne-Apelt, Utber fraktionierte Eiweißausfällung aus der Spinalflüssig= keit usw. Archiv f. Psych. 1908. Bd. 43. Utber Lymphocytose und Globulinuntersuchungen der Spinalflüssigkeit bei organischen Nervenkrankheiten. Neurol. Centralbl. 1908.

Oppenheim, Lehrbuch der Nervenkrankheiten. 4. Aufl. Berlin 1905. Die syphilitischen Erkrankungen des Gehirns. Nothnagels Handb. 2. Aufl. 1903. Zur Lehre der kongenitalen Hirn-Rückenmarkssyphilis. Archiv f. Psych. 1889, Bd. 20.

Paracelsus, Von der frantzösischen Krankheit. Drey Bücher. 1530.

A mbr. Paré, cuvres. B. 16. Paris $1575 \mathrm{ff}$.

Parizot, Syphilis et Epilepsie. Gaz. des hôp. 1888.

Pellizzari, Della sifilide epilettiforme. Lo sperimentale. 1879. 44.

Plenck, Sammlung von Beobachtungen etc. Wien 1770.

Ponyton, Some unusual sequence of convulsive seizures in childhood. The Lancet II, 1908.

Ranke, Utber Gewebsveränderungen im Gehirne luetischer Neugeborener. Neurol. Centralbl. 1907. Uber Gehirnveränderungen bei der angeborenen Syphilis. Zeitschr, f. d. Erforschg. d. jugendl. Schwachsinns. Bd. 2.

Redlich, Die klinische Stellung der sogen. genuinen Epilepsie. Ref. in Zeitschr. f. d. ges. Neurol. u. Psych. 1912. Bd. 6.

Reynoldt, Syphilitic diseases of spinal. cord. Brit. med. Journ. 1889.

Rondoni, Beitrag zum Studium der Entwicklungskrankheiten des Gehirns. Archiv f. Psych. Bd. 40.

Ru mpf, Die syphilitischen Erkrankungen des Nervensystems. 1887.

Sanchez, Examen historique sur l'apparition de la maladie vénérienne en Europe etc. 1774. 
Sauvages, Pathologia methodica etc. Nosologia methodica etc. 1760.

Schuster, Uber syphilitische Epilepsie. Vierteljahrschr. f. Dermatol, u. Syphilis. 1876.

Schustow, Epilepsie durch Syphilis. Russk. med. 1884.

Soltmann, Epilepsie. Gerhardts Handb. d. Kinderkrankh. 1880.

van Swieten, Commentaria in H. Boerhave Aphorismos etc.

Tissot, Traité des nerfs et de leurs maladies. 1781.

Todd, Clinic. lectures on paralysis ete, 1854.

Veit, Neurol. Centralbl. 1905.

H. Vogt, Die klinische Gruppierung der Epilepsie. Ref. in Allgem. Zeitschr. f. Psych. 1907. Bd. 64. Epilepsie und Schwachsinnszustände im Kindes alter. Archiv f. Kinderheilk. 1908. 48.

J. Voisi n, L'Epilepsie. Paris 1897.

Vulpian, Observation de tabes avec phénomènes épileptiformes pendant les premières périodes de l'affection. Rev. de Méd. 1882.

A. Westphal, Zur Lehre von der kongenitalen Hirn- und Rückenmarkssyphilis. Archiv f. Psych. Bd. 20. Zur Differentialdiagnose der Dementia paralytica. Med. Klin. 1905, Nr. 27, 1907, Nr. 4, 5.

- C., Utber Erkrankungen des Rückenmarks bei der allgemeinen progressiven Paralyse der Irren. Virchows Archiv, Bd. 39.

o. Woltär, Drei Fälle von Epilepsie auf luetischer Basis. Prager med. Wochenschr. 1909.

Yvaren, Des métamorphoses de la syphilis. Paris 1854. Des lésions cérébrales liées à la syphilis. Gaz. méd. 1858.

Zambaco, Des affections nerveuses syphilitiques. Paris 1862. 